\title{
Experiments and Evaluation of Chaotic Behavior of Dripping Water in Fracture Models
}

Jil T. Geller, Sharon E. Borglin, and Boris A. Faybishenko

Earth Sciences Division, E. O. Lawrence Berkeley National Laboratory

June 2001

This work was supported by the Environmental Management Science Program of the U.S.

Department of Energy under Contract no. DE-AC03-76SF00098 


\section{Table of Contents}

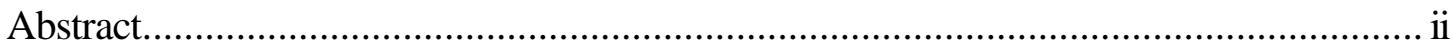

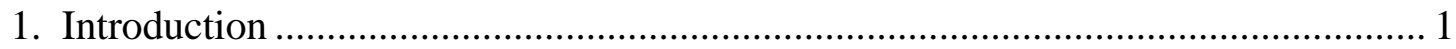

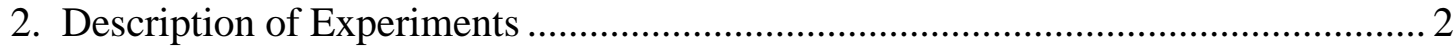

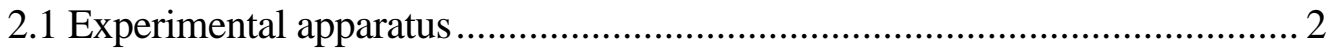

2.2 Water supply and boundary conditions .............................................. 2

2.3 Pressure measurements.......................................................................... 3

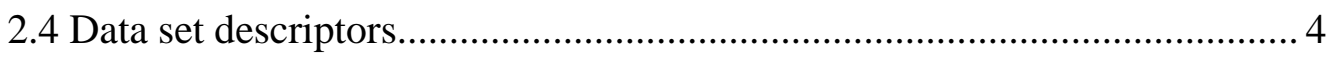

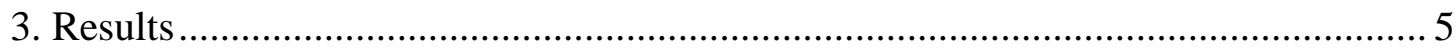

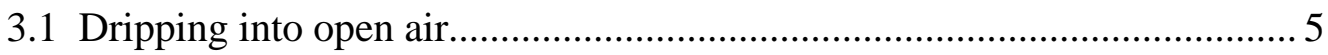

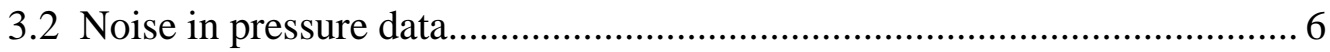

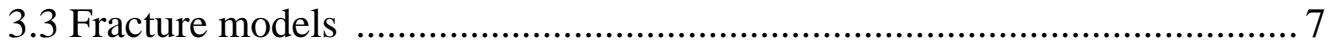

3.3.1 Smooth parallel glass plates ..................................................... 7

3.3.2 Variable aperture fracture models ............................................. 7

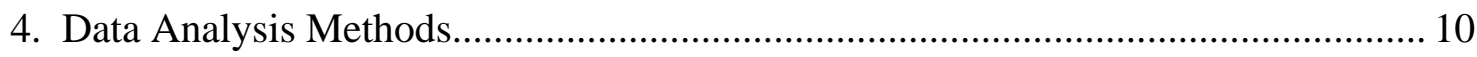

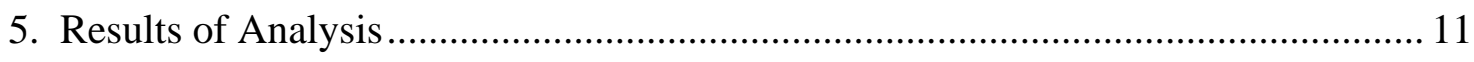

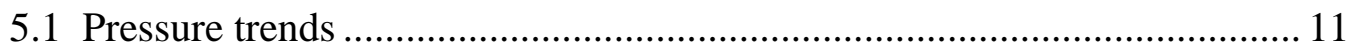

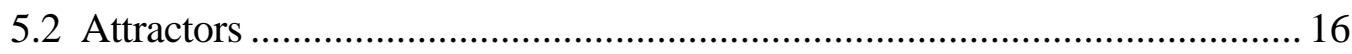

5.3 Effect of removing low-frequency pressure oscillations (filtering).............. 16

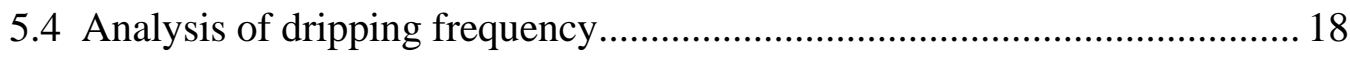

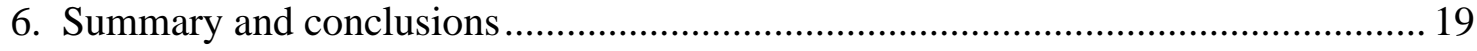

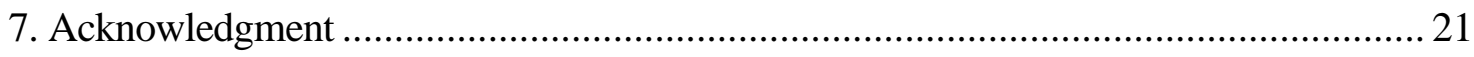

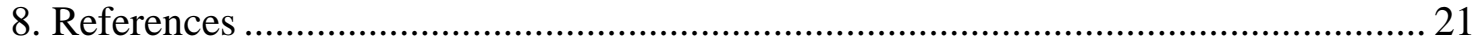

Appendix I. Settings for Cspw program ............................................................... 25

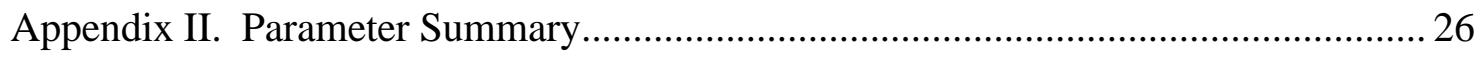

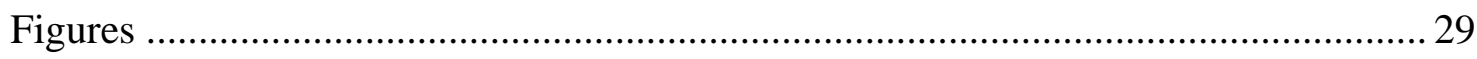




\title{
Experiments and evaluation of chaotic behavior of dripping water in fracture models \\ by Jil T. Geller, Sharon E. Borglin and Boris A. Faybishenko
}

\begin{abstract}
Laboratory experiments of water seepage in smooth and rough-walled, inclined fracture models were performed and the monitoring data analyzed for evidence of chaos. One fracture model consisted of smooth, parallel glass plates separated by $0.36 \mathrm{~mm}$. The second model was made with textured glass plates. The fracture model was inclined $60^{\circ}$ from the horizontal. Water was delivered to the fracture model through a capillary tube in contact with the top fracture edge at constant flow rates. Three types of capillary tubes were used: (1) a stainless steel blunt needle of $0.18 \mathrm{~mm}$ ID for flow rates of 0.25 to $4 \mathrm{~mL} / \mathrm{hr}$, (2) a nylon tube of $0.8 \mathrm{~mm}$ ID for flow rates of 0.25 to $10 \mathrm{~mL} / \mathrm{hr}$, and (3) a glass tube of 0.75 $\mathrm{mm}$ ID for flow rates of 0.5 to $20 \mathrm{~mL} / \mathrm{hr}$. Liquid pressure was monitored upstream of the capillary tube. Visual observations showed that water seeped through the fracture models in discrete channels that underwent cycles of snapping and reforming. Observations also showed that liquid segments, or drips, detached at different points along the water channel. The measured liquid pressure responded to the growth and detachment of drips. Separate experiments were carried out to measure pressure time-trends for dripping into open air to compare these data with those obtained in fracture models. Analysis of the pressure timetrends included determination of the time lag from the minimum of the average mutual information function, the local and global embedding dimensions, Lyapunov exponents and the Lyapunov dimension, the Hurst exponent and the entropy as a function of the embedding dimension for each data set. Most of the water pressure data contain oscillations exhibiting chaotic behavior, with local embedding dimensions ranging from 3 to 10, and global embedding dimensions one to two units higher. The higher dimensionality of some of the data sets indicates either the presence of high-dimensional chaos or a significant random component. It was determined that the flow rate, which affects seepage behavior and is reflected in the pressure measurements, is inversely correlated with the Hurst exponent. This supports the hypothesis that at higher flow rates, the random component of seepage behavior (as represented by liquid pressure) increases. However, there was no simple, consistent correlation between the trends for the other diagnostic parameters of chaos and flow rate. Three-dimensional plots of selected data sets in pseudo-phase space exhibit definite structures with some scattering of data points on the attractor. All the analyses confirm that the pressure time trends that describe flow behavior are mostly characterized by low-dimensional, deterministic chaotic dynamics with some random component.
\end{abstract}




\section{Introduction}

Where fractures intersect rock openings such as caves and tunnels, water that seeps through the fractures may drip into the openings. This water dripping can be the only directly observable manifestation of water seepage through fractured rock. Characterization of dripping water may be used to help describe water seepage in fractures, or to predict contaminant transport, if the relationship to seepage within the fracture can be determined. Podgorney et al. (2000) measured dripping frequency from an in situ fracture subjected to ponded infiltration at the Hells Half Acre site adjacent to the Idaho National Environmental and Engineering Laboratory. Time variations in flow and drip frequency were affected by different types of instabilities and chaos (Podgorney et al., 2000; Faybishenko et al., 2001). The limitation of studying dripping phenomena at the field scale is that the flow mechanisms within the fractures which generate water dripping cannot be identified or quantified. Or and Ghezzehei (2000) modeled dripping rates, drop sizes and chemical composition of water droplets dripping from unsaturated fractures as a function of environmental conditions. In their model, drops emanated from an idealized representation of flow within the fracture as partially liquid-filled grooves and adjacent film flow. A consideration of the complex nature of nonlinear processes affecting unsaturated flow within the fracture was outside the scope of their study.

Observations of water seepage in bench-scale experiments using fracture replicas and fractured cores have shown the pervasiveness of highly localized and extremely nonuniform flow paths in the plane of the fracture (Nicholl et al., 1994; Persoff and Pruess, 1995; Su et al., 1999; Geller et al., 2000). Liquid flow in channels within the plane of the fractures is intermittent as the channels undergo cycles of draining and filling, and small connecting threads snap and reform. This unsteady behavior occurs even in the presence of constant pressure or constant flow rate boundary conditions (Persoff and Pruess, 1995; Su et al., 1999; Geller et al., 2000). While deterministic numerical models with stochasticallydistributed soil properties can describe the spatial volume-averaged features of liquid flow (Pruess and Tsang, 1990; Pruess, 1998), they do not capture the time-dependent behavior of intermittent flow, which can significantly affect predictions of solute travel-time and solutesolid interaction in the presence of preferential flow. Furthermore, actual flow and transport behavior within fractures remains unknown.

In order to predict flow behavior, one needs to know whether the system can be characterized using deterministic or random models, or their combinations. A stochastic analysis predicts the probability of a system state around a mean. The chaos framework provides unique predictive tools for analyzing the deterministic behavior of a system exhibiting random-looking data. If a system is chaotic, then the accuracy of the prediction of future behavior decreases with time. None-the-less, exact behavior can be predicted over short time periods, while behavior bounds can be determined for the long term. The chaotic nature of water dripping from a faucet into open air has been established in the classic work by Shaw (1984). However, in the case of seepage in fractures, different forces and mechanisms may control dripping, including capillarity, liquid viscosity, fracture surface 
roughness and wettability, fracture aperture distribution, and the magnitude and geometry of the surface area controlling fracture-matrix interactions.

The need to understand and predict the unsteady behavior of flowing liquid channels motivated the current study. Dripping water behavior between parallel plates is used as an idealized representation of some of the flow behavior characteristics of water seepage through fractured rock. These fracture models with impermeable walls are used to investigate the role of fracture capillarity, flow rate, and aperture distribution on dripping behavior in the absence of fracture-matrix interaction. The goal of this study was to carry out a series of laboratory liquid flow experiments in fracture models under constant boundary conditions and assess the presence of chaos in this flow. This report documents the results of our investigations and includes a description of the experiments, the data obtained, and analyses of various parameters that are diagnostic of the chaotic and random components of the measured liquid pressure at the fracture model inlet.

\section{Description of Experiments}

2.1. Experimental apparatus. Figure 1 is a schematic of the experimental apparatus used with two types of fracture models- smooth and rough ("shower-door" textured) glass plates of sub-millimeter separation, representing constant aperture and variable aperture models, respectively. Two plates, $19.5 \mathrm{~cm}$ x $21.5 \mathrm{~cm}$ x $8 \mathrm{~mm}$ thick, were held together with a pair of flanges. This assembly was inclined $60^{\circ}$ from horizontal. The glass plates were cleaned with Liquinox soap and rinsed with methanol and distilled water. Rough plates were baked-out at $500^{\circ} \mathrm{F}$ to remove organics, then soaked in $10 \% \mathrm{HNO}_{3}$ to remove inorganic deposits before washing. The transparent fracture model was mounted over a light table which was occasionally illuminated to video-tape the liquid distribution within the fracture. The effects of room temperature fluctuations were minimized by housing the fracture models in a thermally insulated box. All tubing up to the point source (described in the next paragraph) was 1/8" O.D. stainless steel. Equipment specifications are listed in Table 1.

2.2. Water supply and boundary conditions. A constant flow rate of water was delivered to the fracture model through a point source using three different types of capillary tubes: (1) a metal needle inserted between the plates, (2) a nylon tube touching the inlet edge of the plates, and (3) a glass tube touching the inlet edge of the plates. The first experiments with the glass capillary tube were conducted with untreated inlet edges. In subsequent experiments, the inlet edges were ground to improve contact between the tube and plates. To determine pressure fluctuations due to other factors besides flow behavior in the fracture, experiments were also conducted with the point source flowing into open air (infinite aperture) and submerged in water. The small inside diameters of the capillary tubes used as point sources prevented air entry into the open end of the tube. The sides of the glass plates of the fracture model were either sealed to air-flow with tape, or held waterwetted sponges to minimize moisture loss from the fracture to the outside air, while allowing pressure equilibration between the air in the fracture and the ambient atmosphere. At the fracture-model outlet, water dripped freely to the atmosphere. 
2.3. Pressure measurements. Pressure was measured at 1.1 -second time intervals upgradient of the point source with a differential pressure transducer connected to the computer data acquisition system. The transducer had one end open to atmosphere, so the measured pressure response to the formation and release of drips from the point source is relative to atmospheric pressure. The height of the pressure transducer was adjusted so that the range of pressure fluctuations fell within the $14 \mathrm{~cm} \mathrm{H}_{2} \mathrm{O}$ full scale of the transducer. The sensitivity of the pressure measurements is $0.25 \%$ of full scale, or $0.035 \mathrm{~cm} \mathrm{H}_{2} \mathrm{O}$. The magnitude of pressure fluctuations measured in the experiments was 0.3 to $12 \mathrm{~cm} \mathrm{H}_{2} \mathrm{O}$, which is significantly greater than the transducer sensitivity.

Table 1. Equipment specification and tasks

\begin{tabular}{|l|l|l|}
\hline Equipment & Task & Specification \\
\hline $\begin{array}{l}\text { Smooth glass } \\
\text { plates }\end{array}$ & $\begin{array}{l}\text { Create constant aperture } \\
\text { fracture model }\end{array}$ & Separated by 0.36 mm shims \\
\hline $\begin{array}{l}\text { Rough glass } \\
\text { plates }\end{array}$ & $\begin{array}{l}\text { Create variable aperture } \\
\text { fracture model }\end{array}$ & $\begin{array}{l}\text { Separated by 0.36 mm shims, or placed } \\
\text { together }\end{array}$ \\
\hline Syringe pump & $\begin{array}{l}\text { Provide constant flow } \\
\text { rate delivery }\end{array}$ & $\begin{array}{l}\text { Model 33, Harvard Apparatus, South Natick, } \\
\text { MA }\end{array}$ \\
\hline $\begin{array}{l}\text { Syringes for } \\
\text { pump }\end{array}$ & Dispense water in pump & $\begin{array}{l}\text { Monoject 140 mL plastic syringe, Harvard } \\
\text { Apparatus, South Natick, MA }\end{array}$ \\
\hline $\begin{array}{l}\text { Differential } \\
\text { pressure } \\
\text { transducer }\end{array}$ & $\begin{array}{l}\text { Measure pressure } \\
\text { upgradient of point } \\
\text { source }\end{array}$ & $\begin{array}{l}\text { DP15-20, Validyne Engineering Corp., } \\
\text { Northridge, CA }\end{array}$ \\
\hline Blunt needle & $\begin{array}{l}\text { Establish point source } \\
\text { water supply }\end{array}$ & $\begin{array}{l}\text { Stainless steel, 28 gauge, 51 mm long, 0.18 } \\
\text { mm ID, 0.36 mm OD, blunt-ended (p/n } \\
\text { 91028, Hamilton Co., Reno, NV) }\end{array}$ \\
\hline Glass tube & $\begin{array}{l}\text { Establish point source } \\
\text { water supply }\end{array}$ & $\begin{array}{l}\text { 6" x 1/4" OD x 0.75mm ID glass injector } \\
\text { liner, \#5818A, Alltech Associates, Deerfield, } \\
\text { IL }\end{array}$ \\
\hline Plastic tube & $\begin{array}{l}\text { Establish point source } \\
\text { water supply }\end{array}$ & Nylon 1/8" OD, 0.8 mm ID \\
\hline Thermister & $\begin{array}{l}\text { Measure temperature } \\
\text { near fracture model }\end{array}$ & Model 4404, YSI Inc., Yellow Springs, OH \\
\hline $\begin{array}{l}\text { Sensor } \\
\text { interface card }\end{array}$ & $\begin{array}{l}\text { Acquire pressure and } \\
\text { temperature data to 486 } \\
\text { PC }\end{array}$ & $\begin{array}{l}\text { UPC 601-U, Validyne Engineering Corp., } \\
\text { Northridge, CA }\end{array}$ \\
\hline Video camera & $\begin{array}{l}\text { Visually monitor flow } \\
\text { behavior in fracture } \\
\text { model }\end{array}$ & $\begin{array}{l}\text { JVC KY-F55BU with lens JVC TY-10x6 } \\
\text { MDPU }\end{array}$ \\
\hline $\begin{array}{l}\text { Time-coded } \\
\text { video recorder } \\
\text { synchronization with } \\
\text { pressure measurements }\end{array}$ & $\begin{array}{l}\text { Digitize images from } \\
\text { video tape }\end{array}$ & $\begin{array}{l}\text { Truevision, TARGA 16/32 +F with Diaquest } \\
\text { software controller }\end{array}$ \\
\hline Frame grabber & Sony SVHS no. SVO-5800 \\
\hline
\end{tabular}


2.4. Data set descriptors. Data set names were assigned to indicate the flow rate (first three integers), inlet condition or plate type, point source, and initial moisture conditions, according to the following scheme:

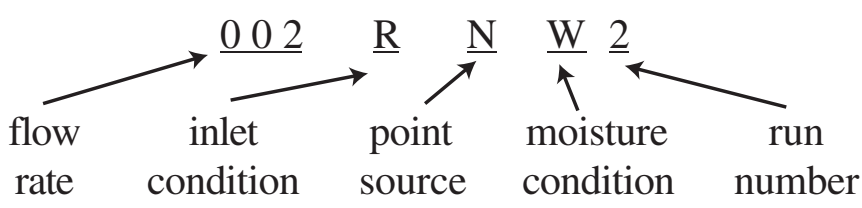

Data set descriptors are summarized in Table 2. The different inlet conditions and flow rates used in the experiments are listed in Table 3.

Table 2. Data set descriptors

\begin{tabular}{|c|c|}
\hline Descriptor & Parameters and Conditions \\
\hline \multicolumn{2}{|r|}{ Flow rate $(\mathrm{mL} / \mathrm{hr})$} \\
\hline 001 & 0.1 \\
\hline 002 & 0.25 \\
\hline 005 & 0.5 \\
\hline 010 & 1 \\
\hline 020 & 2 \\
\hline 050 & 5 \\
\hline 100 & 10 \\
\hline \multicolumn{2}{|r|}{ Inlet Condition } \\
\hline $\mathrm{B}$ & Baseline (point source submerged in water) \\
\hline $\mathrm{O}$ & Open drips (point source dripping into open air) \\
\hline $\mathrm{S}$ & Smooth glass plates separated by $0.36 \mathrm{~mm}$ shims \\
\hline $\mathrm{R}$ & $\begin{array}{l}\text { Rough glass plates separated by } 0.36 \mathrm{~mm} \text { shims(glass } \\
\text { plate edges are as cut.) }\end{array}$ \\
\hline $\mathrm{RG}$ & $\begin{array}{l}\text { Rough glass plates with Ground edges separated by } \\
0.36 \mathrm{~mm} \text { shims (the plate edges contacting the point } \\
\text { source are ground to improve contact) }\end{array}$ \\
\hline RGTGNS & $\begin{array}{l}\text { Rough glass plates with Glass Tube and Ground } \\
\text { edges and No Shims (the plate edges contacting the } \\
\text { point source are ground to improve contact) }\end{array}$ \\
\hline \multicolumn{2}{|r|}{ Point Source } \\
\hline $\mathrm{N}$ & Needle \\
\hline $\mathrm{T}$ & Tube (nylon) \\
\hline GT & Glass Tube \\
\hline \multicolumn{2}{|r|}{ Initial moisture condition of fracture model } \\
\hline $\mathrm{D}$ & Initially Dry plates \\
\hline $\mathrm{W}$ & Wetted plates (from previous runs) \\
\hline $\mathrm{H}$ & Humid plates (wetted sponges on plate edges) \\
\hline
\end{tabular}


Table 3. Inlet conditions and flow rates for experiments

\begin{tabular}{|l|l|}
\hline $\begin{array}{l}\text { Point source/ } \\
\text { Inside } \\
\text { diameter }\end{array}$ & Plates, descriptors, and flow rates $(\mathbf{m L} / \mathbf{h r})$ \\
\hline $\begin{array}{l}\text { Blunt needle/ } 0.18 \\
\mathrm{~mm}\end{array}$ & $\begin{array}{l}\text { Dripping into open air, ON, and } 0.25,0.5,2 \\
\text { Inserted between smooth plates, SN, and } 0.25,0.5,1,1.5,2,3,4 \\
\text { Inserted between rough plates, RN, and } 0.25,0.5,2,4\end{array}$ \\
\hline $\begin{array}{l}\text { Plastic tube/0.8 } \\
\mathrm{mm}\end{array}$ & $\begin{array}{l}\text { Dripping into open air, OT, and 5 } \\
\text { Contacting inlet edges of smooth plates, ST, and } 0.1,0.25,0.5,1,2,5,6,8,10 \\
\text { Contacting inlet edges of rough plates, RT, and 0.1. 1, 10 }\end{array}$ \\
\hline $\begin{array}{l}\text { Glass tube, tube } \\
\text { end ground flat/0.75 } \\
\text { mm }\end{array}$ & $\begin{array}{l}\text { Dripping into open air, OTG, and 5 } \\
\text { Contacting inlet edges of rough plates, RTGH, and } 0.5,5 \\
\text { Contacting inlet edges of rough plates, ground inlet edges, RGTG, and } 0.5,5,10, \\
20 \\
\text { Contacting inlet edges of rough plates, ground inlet edges, no shims, RGTGNS, } \\
\text { and } 0.5,5,10\end{array}$ \\
\hline
\end{tabular}

\section{Results}

\subsection{Dripping Into Open Air}

The pressure response was measured to the formation of drips from the point source hanging in the open air. Examples of these data are shown in Figure 2. Comparison of the pressure trend with visual observation of drop formation showed that pressure decreases with drop formation at the tip of the needle. This is because the drop is formed below the elevation of the pressure transducer tap and behaves like a hanging water column. The time at which the drop detaches from the column coincides with an increase in pressure. Note that the absolute value of the pressure depends upon the height of the pressure transducer relative to the source opening; pressures can be negative if the transducer is high enough above the point source. Based upon visual inspection, the occurrence of drip detachment appears quasi-periodic, while the magnitude of the pressure excursions vary. The variation in pressure excursions indicates that the amount of water accumulating at each drip event varies. Some of this variation may also be due to pump performance; the specified accuracy of the syringe pump is $\pm 1 \%$ and reproducibility is $\pm 0.1 \%$ of the indicated flow rate.

A comparison of Figures $2 \mathrm{a}$ and $\mathrm{b}$ for the needle point source for flow rates of 0.25 and 0.5 $\mathrm{mL} / \mathrm{hr}$, respectively, shows that dripping frequency increases and the variation in pressure excursions is greater at the higher flow rates. Similar behavior occurred for the dripping faucet (Shaw, 1984). Figures $2 \mathrm{c}$ and $d$ show that for the same flow rate, dripping frequency is lower for the glass capillary tube compared to the plastic. This occurs because the neck of the drop has the same diameter as the outside tube diameter, and therefore the volume per drop of liquid is greater for the glass tube (1/4" O.D.) compared to the plastic tube (1/8" $\mathrm{OD}$.) The overall pressure change for dripping from the needle is much greater than that of the tubes because of the much smaller inside diameter of the needle $(0.18 \mathrm{~mm})$ relative to the tubes ( 0.8 and $0.75 \mathrm{~mm}$.) Pressure losses through the needle, calculated according to 
Hagen-Poiseuille's formula (e.g. Bird et al., 1960), are 1.4 and $2.8 \mathrm{~cm}$ for 0.25 and 0.5 $\mathrm{mL} / \mathrm{hr}$, respectively, which is less than the pressure changes shown in Figures $2 \mathrm{a}$ and $\mathrm{b}$. The pressure change of approximately $0.3 \mathrm{~cm}$ for the tubes (Figures $2 \mathrm{~b}$ and $\mathrm{c}$ ) is close to the vertical dimension of the drip before detachment. Pressure loss through the glass tube due to flow is an order of magnitude less $(0.03 \mathrm{~cm}$, calculated according to Hagen-Poiseuille.)

Another difference in pressure time-trends between the needle and tube is seen in the rate of pressure change upon drip detachment and formation. In the needle, the rate of pressure increase upon detachment is slower than the rate of pressure decrease upon formation. The larger pressure change for the needle (an order of magnitude greater than the drip length) and relative rates of pressure change indicate that pressure builds in the needle before drip formation, and is quickly relieved once the drip forms. In the tubes, pressure increases sharply upon drip detachment, then decreases more slowly with drip formation. This is a result of both the small resistance to flow in the tubes, and their larger wall thickness relative to the needle. The drop emanating from the tube initially grows horizontally along the tube wall cross-section, causing little pressure change, before it grows vertically with corresponding pressure decreases.

\subsection{Noise in Pressure Data}

Various experimental artifacts can cause noise in the pressure response, such as the presence of air bubbles in the tubing, leaks in the tubing connections, vibrations and nonideal pump performance. To assess the magnitude of these noise-inducing effects, we measured baseline pressure fluctuations for flow through the different point sources submerged in water. Under these conditions, the pressure head at the outlet of the point source was constant, and any measured pressure fluctuations were therefore caused by factors other than drip formation.

Baseline data for the nylon and glass tubes at $5 \mathrm{~mL} / \mathrm{hr}$ in Figures $3 \mathrm{a}$ and $\mathrm{b}$, respectively, show minimal pressure oscillations, although some drift occurs for the glass tube due to the water level rise in the container in which the tube was submerged. The baseline data for the blunt needle are shown in Figures 2c, d and e for flow rates of $0.25 \mathrm{~mL} / \mathrm{hr}, 2$ and $3 \mathrm{~mL} / \mathrm{hr}$, respectively. The much smaller inside diameter of the needle compared to the tubes caused two types of noise to appear in the data. The pressure in Figure $2 \mathrm{c}$ fluctuates about 0.1 to $0.5 \mathrm{~cm}$ over several seconds, however the baseline over the 2000 secpmds is flat. At 2 and 3 $\mathrm{mL} / \mathrm{hr}$, a lower frequency pressure fluctuation appears, having periods greater than 500 seconds. At these higher flow rates, the magnitude of the higher frequency pressure fluctuations decreased. We attributed the high frequency noise to vibrations of the water meniscus on the outside wall of the needle submerged in water; this noise did not appear in the pressure data for needles dripping in open air (Figure 2a and b.) Data obtained from experiments with blunt needles in open air and inserted into fractures for flow rates of 2 $\mathrm{mL} / \mathrm{hr}$ and greater did have low frequency oscillations in addition to the drip-induced fluctuations, therefore these data sets were filtered to remove the low-frequency trend. Filtering was accomplished by transforming the time-trend data set to frequency domain by means of Fast Fourier Transform, multiplying the data by a filter function and then transforming it back to time domain. The filter function used was 
$\left[1+\mathrm{e}^{-8} / \text { frequency }^{4}\right]^{-1}$. In Figure 4 , the raw and filtered data are compared for dripping from an open needle at $2 \mathrm{~mL} / \mathrm{hr}$.

\subsection{Fracture models}

3.3.1. Smooth parallel glass plates. Figure 5 presents an example of how the measured pressure responded to drips formed under a flow rate of $0.5 \mathrm{~mL} / \mathrm{hr}$ through the needle installed in a fracture model of smooth parallel glass plates of $0.36 \mathrm{~mm}$ aperture. Figure $5 \mathrm{a}$ is a section of the raw pressure data. Figure $5 \mathrm{~b}$ is an expansion of the boxed section shown in a, and Figure $5 \mathrm{c}$ shows the frames from the video tape, which was synchronized with the pressure record. The drop begins to grow around the needle until enough mass has accumulated for the drop to move downward (at this time the pressure decreases), forming a neck at the end of the needle (pressure slightly increases). Then, a thread of water connecting the drop to the needle forms and grows (pressure continues to decrease), which eventually snaps (pressure significantly increases). Compared to the open drips, the pressure pattern for dripping in the fracture model contains additional fluctuations during a cycle of drip formation, some of which are caused by necking and thread-formation promoted by the fracture-model surfaces.

3.3.2. Variable aperture fracture models. The aperture distribution measured by light attenuation through the variable aperture fracture model is shown in Figure 6 (see Su et al. (1999) for description of measurement methods). For the measurement, the rough sides of two "shower-door" glass plates were placed directly against each other, the sides were sealed with silicone caulk and the apertures were filled with dyed water. The spatial resolution of these measurements is $0.28 \mathrm{~mm}$, and the depth resolution is $2.9 \%$ of the aperture value. The largest apertures are $0.19 \mathrm{~mm}$, and they occur near the point of contact between the capillary tube and fracture model. In the experiments conducted with the 0.36 $\mathrm{mm}$ shims holding the plates apart, all aperture values in Figure 6 increase by approximately $0.36 \mathrm{~mm}$.

Figure 7 shows the pressure time-trend synchronized with images of the liquid distribution in the variable aperture fracture, which exhibited more complex behavior compared to the constant aperture fracture model. Here, the point source was a plastic tube contacting the inlet edge of the model. During this data record, water flowed only through the liquid segments on the right side of the model; liquid segments in the center and left side of the model were immobile. Frames $\mathrm{A}$ through $\mathrm{C}$ show a cycle of drip formation and detachment occurring approximately $5.5 \mathrm{~cm}$ down from the inlet edge, corresponding to pressure excursions of 1 to $4 \mathrm{~mm}$. In frames D through F, drip formation occurs approximately 3 $\mathrm{cm}$ down from the inlet edge, and corresponds to pressure excursions of $4.5 \mathrm{~cm}$. The mass of water in this drip and its length are visibly greater than for the drip in frames A through C. Both drip size and proximity to the model inlet appear to control the magnitude of the resulting pressure excursion.

While video-taped images of flow in the fracture indicated correspondence between the dripping behavior and the pressure trend, inspection of the pressure trends indicated that the time-series pattern was not unique for a given fracture model and inlet condition. These 
observations led to the hypothesis that dripping behavior was also controlled by factors other than the inlet condition, such as initial surface properties of the glass plates. The data sets were examined and five characteristic shapes of pressure time-series plots were identified (shown in Figure 8) and assigned a type number of one through five. The data sets were then grouped according to pressure-trend type, as listed in Table 4. 
Table 4. Data sets sorted according to pressure trend "type"

\begin{tabular}{|c|c|c|c|}
\hline Tyре & Description & \multicolumn{2}{|l|}{ Data sets } \\
\hline \multirow[t]{7}{*}{1} & \multirow[t]{7}{*}{$\begin{array}{l}\text { "Sawtooth" signature, indicates dripping } \\
\text { without strings forming }\end{array}$} & ST & $\begin{array}{l}\text { 001STH1, 005STW3, 100STW1, } \\
\text { 050STD1, 060STD1 }\end{array}$ \\
\hline & & $\mathrm{SN}$ & 002SNW1 \\
\hline & & RT & $*$ \\
\hline & & $\mathrm{RN}$ & 002RNW1 \\
\hline & & RTG & $*$ \\
\hline & & RGTGNS & (005)RGTGNS2, 050RGTGNS 1 \\
\hline & & RGTG & 005RGTG1, 100RGTG1 \\
\hline \multirow[t]{7}{*}{2} & \multirow[t]{7}{*}{ Irregular short and long breaks } & ST & $*$ \\
\hline & & $\mathrm{SN}$ & $\begin{array}{l}\text { 030SNW2f, } 030 \text { SNW 3f, } 040 \\
\text { SNW 4f }\end{array}$ \\
\hline & & RT & 010RTH1 \\
\hline & & $\mathrm{RN}$ & 020RNW1f \\
\hline & & RTG & $*$ \\
\hline & & RGTGNS & $*$ \\
\hline & & RGTG & $*$ \\
\hline \multirow[t]{6}{*}{3} & \multirow[t]{6}{*}{ Some type 1 and some type 4} & ST & 002STH1, 010STW2, 010STD1 \\
\hline & & SN & $*$ \\
\hline & & RT & 001RTH1 \\
\hline & & $\mathrm{RN}$ & $*$ \\
\hline & & RGTGNS & (005)RGTGNS3 \\
\hline & & RGTG & $*$ \\
\hline \multirow[t]{7}{*}{4} & \multirow[t]{7}{*}{ Sawtooth with lag due to string formation } & ST & $\begin{array}{l}\text { 001STH1, 010STH1, 020STD2, } \\
\text { 020STH1, 050STD1 }\end{array}$ \\
\hline & & $\mathrm{SN}$ & $\begin{array}{l}002 \text { SNW 2, } 005 \text { SNW 1, } 010 \\
\text { SNW 1, 020 SNW } 2\end{array}$ \\
\hline & & RT & $*$ \\
\hline & & $\mathrm{RN}$ & $*$ \\
\hline & & RTG & (005)RTGH1, 050RTGH1, \\
\hline & & RGTGNS & 050RGTGNS2, 100RGTGNS1 \\
\hline & & RGTG & $*$ \\
\hline \multirow[t]{7}{*}{5} & \multirow[t]{7}{*}{ Sections of types 1,2 and 4} & ST & 005STH1, 020STW2, 080STD1, \\
\hline & & SN & $*$ \\
\hline & & $\mathrm{RT}$ & 100RTH1, 100RTH2 \\
\hline & & RN & $*$ \\
\hline & & RTG & $*$ \\
\hline & & RGTGNS & (005)RGTGNS1 \\
\hline & & RGTG & $*$ \\
\hline
\end{tabular}




\section{Data Analysis Methods}

This section provides a brief overview of the data analysis methods employed and descriptions of the various parameters that are generated. Further details can be found in Faybishenko (2000). The data analysis of pressure fluctuations measured during experiments was conducted using the method of reconstruction of the phase space. Phase space is a multi-dimensional space in which the coordinate axes are the state variables of the system under consideration. Under some chaotic conditions, phase-space trajectories occupy a particular region of the space, known as the "attractor." The attractor is a geometrical structure that exhibits the range of system behavior. For deterministic chaotic systems, attractor geometry represents the bounds of system behavior and can be described with simple mathematical models. The number of dimensions required to unfold the attractor indicates a minimum number of state variables required to describe the system behavior. Even if we don't know the equations describing a system, we can predict the system behavior by considering the movement along the attractor trajectories, given that enough data points of the appropriate state variables have been measured. Data can also be plotted in "pseudo" phase space where the coordinate axes are successive measurements of a single variable or parameter, separated by a certain time delay (Moon, 1987).

To plot the attractor in a pseudo-phase space, the time delay $(\Delta \tau)$ between axes is determined from the first minimum of the average mutual information (AMI) function resulting from a non-linear correlation between data points (Abarbanel, 1996). The local and global embedding dimensions (LED and GED, respectively) indicate the number of dimensions required to unfold the attractor. The analysis used to determine GED produces a plot of false nearest neighbors (FNN) as a function of the embedding dimension. When FNN reaches zero (or close to zero), the attractor has been unfolded, in such a way that the attractor trajectories do not intersect. LED evaluates how the points move in relation to each other as the attractor unfolds. An embedding dimension less than five indicates a lowdimensional deterministic-chaotic system, while higher values indicate a high-dimensional deterministic system or an increase in the random (or noisy) component of the system; data noise was not separated out in this study.

The Lyapunov exponent is a measure of the rates at which nearby trajectories in phase space diverge. It determines the average rate of convergence or divergence of two neighboring trajectories on the attractor. The number of Lyapunov exponents is equal to LED. Exponents can be positive, negative, or zero. Positive exponents indicate divergence of the attractor trajectories, negative exponents indicate convergence, and a zero exponent indicates that the trajectories neither diverge nor converge, but that their separation stays constant (or increases at a rate that is less than exponential). The magnitude of the positive Lyapunov exponent(s) indicates the magnitude of the rate of divergence of neighboring trajectories. If the sum of Lyapunov exponents is negative, then the attractor is converges (i.e. a welldefined attractor exists.) The presence of at least one positive exponent is another criterion of a chaotic system. If these criteria are met, then a Lyapunov dimension (LYP), which is a dimension of the attractor, exists and can be calculated from the Lyapunov exponents. For periodic orbits, all Lyapunov exponents are negative. 
The data analysis of the time trends of the measured pressures was performed using the Contemporary Signal Processing for Windows (Cspw) version 1.2 (Applied Nonlinear Sciences, LLC/ Randle Inc.) and the Chaos Data Analyzer (CDA), the Professional Version (Physics Academic Software, Raleigh, North Carolina). Numerical settings for the Cspw program are tabulated in Appendix I.

The Cspw program was used to calculate $\Delta \tau$, using the program's default parameters. The value of $\Delta \tau$ is used as the time delay parameter for plotting the attractor and in calculating LED, GED and Lyapunov exponents.

In calculating Lyapunov exponents, the Cspw program fits a 2- or 3-order polynomial to a section of data and determines how subsequent data behave on the attractor. Initial attempts were made to calculate the Lyapunov exponents with a 3-order polynomial. If the program could not generate a Lyapunov exponent, then the order was decreased to 2 . The program produces a plot showing each Lyapunov exponent and reports their sum and the Lyapunov dimension (LYP). The program does not generate a value for LYP if the Lyapunov exponents do not meet the criteria for chaos, i.e. at least one exponent is positive and the sum of the exponents is negative.

The CDA program was used to determine entropy values for some of the data sets. The entropy is a measure of the disorder of the data in the phase-space. This parameter is calculated as a function of the embedding dimension, up to 9. If the entropy does not saturate or reach a steady value as the dimension increases, then the data set requires a higher embedding dimension or has a significant random component. That is, the attractor can be fully unfolded in the dimension at which entropy reaches a steady value. The entropy is calculated as the sum of the positive Lyapunov exponents, and its reciprocal is roughly the time over which meaningful prediction is possible.

The CDA program was also used to calculate the Hurst Exponent. The Hurst exponent is a measure of the divergence of the data. A value greater than 0.5 indicates a significant deterministic component to the data set. A value less than 0.5 indicates a larger random component. A low value of the Hurst exponent indicates that the data are either random or exhibit high-dimensional chaotic behavior.

\section{Results of Analysis}

5.1. Pressure trends. Time trends of pressure were first inspected for baseline shifts due to extraneous factors, as noted in Section 3.2. Data sections without these anomalies were analyzed. Inspection of ambient temperature and barometric pressure fluctuations indicated that these environmental parameters did not affect the fracture inlet pressure. Both filtered and raw data for the needle point source using flow rates of $2 \mathrm{~mL} / \mathrm{hr}$ and greater were analyzed. The number of data points available for analysis varied from approximately 5,000 to 25,000 points. 
The higher the embedding dimension, the larger the number of data points that are required to analyze the data set. There are no set criteria for determining the number of data points required to produce the parameters determined in this report. However, the following equation provides an estimate of the required number of data points $(n)$ to obtain the results of the correlation dimension with the accuracy of $5 \%$ for a given embedding dimension, (ED) (Tsonis, 1992):

$$
n=10^{(2+0.4 E D)} \text {. }
$$

While fewer points can be used for the calculation of the parameters in this report, data sets meeting the criteria of Equation (1) definitely have enough points. In the data summary in Appendix II, $n$ from Eqn. (1) is calculated for both the global and local embedding dimensions. Due to the low dimensionality of most of the data sets (less than 6), the data sets are generally large enough for deterministic chaotic analysis.

The summary of the analysis for each of the data sets is tabulated in Appendix II. The following comparison of parameters from different data sets excludes those having significant baseline shifts (attributed to trapped air bubbles), anomalous pressure spikes (attributed to sticking of the pump's syringe barrel) and low frequency baseline oscillations (where only filtered files are used for the needle point sources with flow rates of $2 \mathrm{~mL} / \mathrm{hr}$ and greater.) The names of these data sets are marked with an asterisk in Appendix II.

Table 5 summarizes the range of analytical parameters for data sets obtained in this study with those for archetypical data sets: random (obtained from the CDA package), periodic (the sine function) and the Lorenz equations (obtained from the Cspw package.) The values of the diagnostic parameters may give different indications of the chaotic or random component of the data. Comparison of results for different data sets is affected by the variability in the amount of noise in a given data set. Different lengths in data sets can affect the amount of noise appearing in the analysis results. The presence of noise can be seen in the FNN function. For instance, a plot of FNN versus embedding dimension, which is used to determine GED, may decrease to zero or near zero at a given dimension and then increase as the dimension increases. This behavior usually indicates the presence of noise or that there are insufficient data points to determine the dimension. For these types of files, depending on the magnitude of the increase of FNN with dimension, it may still be possible to obtain a (low-dimensional) value of LED and a value of LYP. If the sum of the Lyapunov exponents is positive, the attractor trajectories diverge and therefore cannot be predicted, because the system is too noisy or high-dimensional.

The data in Table 5 show that for the random data set, the Hurst exponent is much less than 0.5; values for LED, GED and LYP were not calculated. The periodic sine function has an embedding dimension of 2, and a LYP of unity. The value of the Hurst exponent for the deterministic chaos time series of the Lorenz equation is slightly greater than 0.5 . In the data sets obtained in this study, the local embedding dimensions ranged from 3 to 10, with global embedding dimensions equal to, or several units higher than, the local values. There were two exceptions (noted in Table 5) where the calculated embedding dimensions were greater than 12. One of these exceptions occurred for the open drip data set of $2 \mathrm{~mL} / \mathrm{hr}$ 
through a needle, and one for the glass tube to rough glass plates at $20 \mathrm{~mL} / \mathrm{hr}$. LYP could not be calculated for either of these two data sets, but was computed for all of the other data sets. Most of the data sets have Hurst exponents that are more than one to two orders of magnitude greater than that of the random data set, which indicates that the observed data are not random. Figures 9 and 10 summarize the magnitude of these parameters as a function of inlet flow rate and the types of fracture models.

Table 5. Comparison of parameters for archetypical data sets with measured data for dripping water experiments

\begin{tabular}{|c|c|c|c|c|c|c|}
\hline Data set & $\begin{array}{l}\text { No. } \\
\text { data } \\
\text { sets }\end{array}$ & $\begin{array}{l}\text { Flow rate } \\
\text { range } \\
(\mathrm{mL} / \mathrm{hr})\end{array}$ & LED & GED & LYP & HURST \\
\hline Random & 1 & N/A & N/A & N/A & N/A & 0.0026 \\
\hline $\begin{array}{l}\text { Periodic (Sine } \\
\text { function) }\end{array}$ & 1 & N/A & 2 & 2 & 1.00 & 0.72 \\
\hline $\begin{array}{l}\text { Chaos (Lorenz } \\
\text { equations) }\end{array}$ & 1 & N/A & 3 & 3 & 2.07 & 0.54 \\
\hline Open drips ${ }^{(1),(2)}$ & 8 & $0.25-5$ & $3-6$ & $4-7$ & $2.1-4.1$ & $0.24-0.41$ \\
\hline $\mathrm{SN}$ & 8 & $0.25-4$ & $3-5$ & $4-7$ & $2.3-4.7$ & $0.24-0.63$ \\
\hline ST & 21 & $0.25-10$ & $3-10$ & $5-10$ & $2.2-9.9$ & $0.11-0.70$ \\
\hline $\mathrm{RN}$ & 4 & $0.25-4$ & $3-4$ & $5-6$ & $2.9-4.0$ & $0.24-0.86$ \\
\hline RT & 5 & $0.1-10$ & $4-7$ & $5-7$ & $2.3-6.6$ & $0.15-0.38$ \\
\hline $\operatorname{RGTG}^{(1)}$ & 7 & $0.5-20$ & $3-4$ & $5-8$ & $3.0-4.0$ & $0.13-0.45$ \\
\hline RGTGNS & 5 & $0.5-10$ & 4 & $4-6$ & $3.3-4.0$ & $0.29-0.70$ \\
\hline \multicolumn{7}{|c|}{$\begin{array}{l}\text { (1) One data set of this type had LED,GED>12, and no value of LYP could be calculated } \\
\text { (discussed in text.) } \\
\text { (2) One data set of this type had a Hurst exponent equal to }-0.05 \text { (discussed in text.) }\end{array}$} \\
\hline
\end{tabular}

Plots of entropy as a function of embedding dimension are shown in Figures 11 and 12 for needle, plastic tube and glass tube point sources. A constant entropy value after a given dimension, or saturation, indicates that the data set has a significant chaotic component. In thirteen out of the twenty-nine data sets analyzed, entropy does not saturate; this is indicative of the presence of a random component in the phase-space of those data sets. However, whether or not the entropy saturates does not correlate with the magnitude of the other diagnostic parameters (embedding dimensions, LYP or Hurst exponent) for a given data set (see Appendix II.)

We initially hypothesized that flow rate would be an important variable controlling the chaotic nature of the system, and would affect the magnitude of the parameters. One possible manifestation of this hypothesis is that as flow rate increases, the system becomes more random. A positive correlation between the flow rate, and the embedding and Lyapunov dimensions, and a negative correlation between the flow rate and Hurst exponent are consistent with an increasing random component as flow rate increases. The fact that the high-dimensional data sets noted in Table 5 for which LYP could not be calculated were for relatively high flow rates also supports this hypothesis. 
Tables 6 and 7 show correlations between the parameters and flow rate, as a function of inlet conditions and pressure trend type, respectively. Table 8 shows correlations between the parameters themselves for all of the data sets. The values in Tables 6-8 are the correlation coefficients $\left(R^{2}\right)$ derived from linear regression. Significant correlations $\left(R^{2}>|0.5|\right)$ are indicated in bold typeface. The greatest number of significant correlations occurs for the Hurst exponent and flow rate. All the correlations between Hurst exponent and flow rate are significant and negative, which is consistent with the hypothesis described in the previous paragraph. Some of the data sets show positive significant correlations between flow rate and LED (RN and GTG data sets) and GED (RN data sets), which also supports the flow rate hypothesis. Contrary to the flow rate hypothesis, however, are the results that flow rate and GED are negatively correlated for the RN data sets and the only significant correlations between flow rate and LYP is negative (inlet condition RT.) Table 8 shows that GED and LED are significantly and positively correlated, as are LED and LYP. All of the correlation coefficients with the Hurst exponent in Table 8 are negative, however they are all less than -0.5 (i.e. insignificant.)

Correlation coefficients between flow rate and parameters according to pressure trend type in Table 7 are significant and negative with the Hurst exponent for Types 1 and 5 of pressure trends, and insignificant for the other types of pressure trends. Coefficients for the LYP are significant and negative for pressure trend Types 2, 3 and 5. Correlations with LED and GED are insignificant for all pressure trend types.

The regression analysis suggests that the Hurst exponent (which is calculated in a time domain) is a robust parameter in evaluating the flow behavior, however the response of the other parameters is not always consistent. This inconsistency may arise from the different lengths of the time-series data sets. Because the relatively small inside diameter of the capillary tube for the RN and SN systems, the flow rate range was smaller than that for the other systems. The inlet condition for the ST data sets was more difficult to reproduce experimentally, compared to the other data sets, due to the nature of the contact between the plastic tube and the plate edges. Correlation according to pressure trend type may have been affected by the different number of data sets of each type. More generally, the optimum number of data sets required for correlation analysis was not determined. Finally, the assignment of pressure trend type to the data sets was subjective, based upon the visual examination of the pressure time-series. 
Table 6. Correlation coefficient $\left(\mathrm{R}^{2}\right)$ for the relationship between chaos parameters and flow rate for all experiments, depending on the types of inlet conditions and fracture models. Cases where $\left|\mathrm{R}^{2}\right|>0.5$ are shown in bold.

\begin{tabular}{|l|l|l|l|l|l|l|}
\hline $\begin{array}{l}\text { Inlet Condition } \\
\text { and fracture } \\
\text { model }\end{array}$ & $\begin{array}{l}\text { No. of } \\
\text { data } \\
\text { sets }\end{array}$ & $\begin{array}{l}\text { Range } \\
\text { of flow } \\
\text { rates } \\
\text { (mL/hr) }\end{array}$ & LED & GED & LYP & Hurst \\
\hline All Experiments & 49 & $0.1-20$ & 0.477 & 0.473 & -0.064 & $-\mathbf{0 . 5 5 3}$ \\
\hline SN & 8 & $0.25-4$ & -0.147 & 0.046 & -0.010 & $\mathbf{- 0 . 6 8 0}$ \\
\hline ST & 21 & $0.25-10$ & 0.162 & -0.066 & 0.125 & $\mathbf{- 0 . 5 2 8}$ \\
\hline RN & 4 & $0.25-4$ & $\mathbf{0 . 5 5 6}$ & $\mathbf{- 0 . 8 2 0}$ & -0.132 & $\mathbf{- 0 . 8 0 5}$ \\
\hline RT & 5 & $0.1-10$ & $\mathbf{- 0 . 6 3 1}$ & -0.048 & $-\mathbf{0 . 7 2 8}$ & $\mathbf{- 0 . 7 6 7}$ \\
\hline RGTG & 7 & $0.5-20$ & $\mathbf{0 . 7 8 3}$ & 0.102 & -0.406 & $\mathbf{- 0 . 7 9 7}$ \\
\hline RGTGNS & 5 & $0.5-10$ & $(1)$ & -0.098 & 0.072 & $\mathbf{- 0 . 5 3 0}$ \\
\hline (1) Parameter constant for all flow rates & & \\
\hline
\end{tabular}

Table 7. Correlation coefficient $\left(\mathrm{R}^{2}\right)$ for the relationship between chaos parameters and flow rate according to pressure trend types. Cases where $\left|\mathrm{R}^{2}\right|>0.5$ are shown in bold.

\begin{tabular}{|l|l|l|r|r|r|r|}
\hline Type & \# data sets & $\begin{array}{l}\text { Flow rate } \\
\text { range }(\mathbf{m L} / \mathbf{h r})\end{array}$ & \multicolumn{1}{l|}{ LED } & \multicolumn{1}{l|}{ GED } & \multicolumn{1}{l|}{ LYP } & \multicolumn{1}{l|}{ Hurst } \\
\hline 1 & 13 & $0.25-10$ & 0.383 & 0.172 & 0.439 & $\mathbf{- 0 . 7 3 9}$ \\
\hline 2 & 6 & $1-4$ & -0.270 & -0.269 & $\mathbf{- 0 . 5 0 4}$ & -0.181 \\
\hline 3 & 6 & $0.25-1$ & -0.130 & -0.167 & $\mathbf{- 0 . 5 1 0}$ & -0.230 \\
\hline 4 & 13 & $0.1-10$ & 0.058 & 0.015 & 0.120 & -0.256 \\
\hline 5 & 11 & $0.5-20$ & -0.336 & 0.261 & $\mathbf{- 0 . 5 1 4}$ & $\mathbf{- 0 . 7 4 8}$ \\
\hline
\end{tabular}

Table 8. Correlation coefficient $\left(R^{2}\right)$ between chaos parameters. Cases where $\left|R^{2}\right|>0.5$ are shown in bold.

\begin{tabular}{|l|l|l|l|}
\hline Parameter & GED & LYP & Hurst \\
\hline LED & $\mathbf{0 . 7 7 6}$ & $\mathbf{0 . 9 5 7}$ & -0.397 \\
\hline GED & 1 & 0.432 & -0.360 \\
\hline LYP & 0.432 & 1 & -0.311 \\
\hline
\end{tabular}




\subsection{Attractors}

Plots of attractors for selected data sets and sections of the time-trends are shown in Figures 13 - 17. The attractors are plotted in three dimensional pseudo phase space, with the number of data points skipped between each axis equal to $\Delta \tau$ (determined from the minimum of the AMI function.) The values of LED range from three to six, and the GED values are one to several units greater. Consequently, the three-dimensional plot does not completely unfold the attractor, but it does provide an illustrative basis for identifying a geometrical structure of the attractor. These structures are indicative of the presence of deterministic chaos and allow a comparison of different types of time-series data.

Attractors for the archetypical data sets are shown in Figure 13. The attractor for the random data set has no structure and points are evenly distributed throughout the phase space. Periodic data, such as the sine function, is an open structure in the shape of an oval; the noise scatters data around the oval while maintaining an open structure. The attractor for the Lorenz equations has a distinct, structure, with twisting and in-filling of points within the structure's boundaries.

Figure 14 shows attractors for experiments with needle point sources in the rough and smooth glass plates. The first two examples at $0.25 \mathrm{~mL} / \mathrm{hr}$ in rough plates and $0.25 \mathrm{~mL} / \mathrm{hr}$ in smooth plates have open structures with some twisting and excursions; the attractor for the rough plates is somewhat more filled. The pressure fluctuations range from 2 to over 10 $\mathrm{cm}$; the larger fluctuations are indicative of long drip and thread formation before detachment. The last example of $1 \mathrm{~mL} / \mathrm{hr}$ in smooth plates also has an open structure with long pressure excursions due to long drip and thread formation before detachment. Figure 15 shows attractors for the plastic tube point sources in smooth plates, with flow rates ranging from 0.5 to $6 \mathrm{~mL} / \mathrm{hr}$. The magnitude of the pressure excursions increases at the higher flow rate. Attractors for the glass tube point sources are shown in Figures 16-17. All of these attractors (except RGTGNS1 in Fig. 17a) have defined, open structures that are angular and bent with twisting. The structure for RGTGNS1 (flow rate of $0.5 \mathrm{~mL} / \mathrm{hr}$ ) is elongated, without bending or opening.

\subsection{Effect of removing low-frequency pressure oscillations (filtering)}

The analyses of raw and filtered data sets (according to procedure described in Section 3.1) are compared in Table 9 and Figures 18 through 20. Filtering of the low frequency trends was done for data sets obtained with a needle point source at flow rates of $2 \mathrm{~mL} / \mathrm{hr}$ and greater. 
Table 9. Comparison of analysis for raw and filtered data sets.

\begin{tabular}{|l|r|r|r|r|r|r|}
\hline data set $^{(1)}$ & \multicolumn{1}{|c|}{$\Delta \tau$} & LED & GED & LYP & Hurst & Figure \\
\hline \hline 020ON1 & 12 & 3 & 5 & 2.131 & 0.452 & $20 \mathrm{a}$ \\
\hline 020ON1f & 9 & $>12$ & $>12$ & $(2$ & 0.324 & $20 \mathrm{~b}, \mathrm{c}$ \\
\hline \hline 020RNW1 & 10 & 4 & 6 & 3.048 & 0.413 & $19 \mathrm{a}$ \\
\hline 020RNW1f & 9 & 4 & 4 & 3.925 & 0.237 & $19 \mathrm{~b}, \mathrm{c}$ \\
\hline \hline 020SNW1 & 12 & 5 & 5 & 4.462 & 0.455 & $18 \mathrm{a}$ \\
\hline 020SNW1f & 10 & 5 & 5 & 4.130 & 0.437 & $18 \mathrm{~b}, \mathrm{c}$ \\
\hline \hline 030SNW3 & 14 & 6 & 8 & 5.980 & 0.266 & $19 \mathrm{~d}$ \\
\hline 030SNW3f & 6 & 4 & 6 & 3.866 & 0.241 & 19e,f \\
\hline \hline 040RNW1 & 8 & 4 & 4 & 3.402 & 0.409 & \\
\hline 040RNW1f & 5 & 4 & 4 & 3.132 & 0.287 & \\
\hline \hline 040SNW1 & 12 & 5 & 6 & 4.899 & 0.274 & 20d \\
\hline 040SNW1f & 11 & 6 & 6 & 5.967 & 0.230 & 20e,f \\
\hline \hline
\end{tabular}

(1) " $\mathrm{f}$ " indicates a filtered data set

(2) High dimensional, LYP could not be calculated for this data set

Filtering out of low-frequency trends caused by factors other than drip formation (described in Section 3.1) affected some of the parameters in some of the data sets. Due to filtering, the affected parameters either decreased or did not change, with only a few exceptions. This result indicates that the long period oscillations that were filtered out contributed to the highdimensional nature of the data set. The reduction in embedding and Lyapunov dimensions suggests a decrease in either the random component or amount of deterministic chaos in the data set. The long period variations also contributed to the magnitude of the Hurst exponent because larger exponents reflect long-time correlations. Figures 18 through 20 show the attractors for the raw and filtered data of selected experiments. In all cases, filtering condensed the attractor. Figure 18 shows the attractors for raw and filtered data from 020SNW1, where there was little change in parameters as well as the shape of the attractors as a result of filtering. This attractor's form is very similar to those shown by Nicholl et al. (1994) of time intervals between drips for the dripping faucet experiments by Shaw (1984) and of Nicholl et al.'s analysis of eruption interval data from Old Faithful geyser in Yellowstone National Park.

Figure 19 shows two experiments where parameters decreased as a result of filtering: 020RNW1 and 030SNW3. Filtering significantly changed the shape of the attractor for 020RNW1 (Figure 19c), and for 030SNW3 produced a more obvious structure (Figure 19(f).) Figure 20 shows the attractors for two experiments where the dimensions increased as a result of filtering. The 3-D plot of the attractor for $020 \mathrm{ON} 1 \mathrm{f}$ would not be expected to have a structure due to the high dimensionality of the data set. However, the attractor for 
040SNW1f, with smaller dimensions compared to 020ON1f, appears to have some structure.

\subsection{Analysis of dripping frequency}

A FORTRAN routine was written to find the times of drip-snapping events and record the time interval between snaps, based on the observation that drop detachment coincides with a sharp increase in pressure. Table 10 lists the files for which this was performed.

Table 10. Data sets analyzed for time intervals between drip snapping events

\begin{tabular}{|l|l|r|l|}
\hline Data set & $\begin{array}{l}\text { Time interval } \\
\text { filename }\end{array}$ & $\begin{array}{l}\# \\
\text { snapping } \\
\text { events }\end{array}$ & Analysis results \\
\hline 002ON1 & ch10997.snp & 1210 & $\Delta \tau=5$, HURST $=0.1642748,(1)$ \\
\hline 002RNW1 & ch82597.snaps & 229 & \\
\hline 002SNW2 & ch92597.snap & 317 & \\
\hline 005RNW1 & ch73097.s01 & 636 & \\
\hline 005RNW2 & ch72997.s01 & 556 & \\
\hline 005RNW3 & ch73197.s03 & 474 & \\
\hline 020SNW1 & ch92697.snp & 519 & \\
\hline 020RNW1 & ch42098a4.snaps & 1080 & $\Delta \tau=1$, HURST $=0.013211(1)$ \\
\hline 030SNW3 & ch02298.s16 & 201 & \\
\hline 040SNW2 & ch02498.s03 & 317 & \\
\hline (1) significant random component \\
\hline
\end{tabular}

Using the criterion given by Eqn. (1), the drip-time interval data sets are only large enough to analyze for GED < 3. Because the data sets 002ON1 and 020RNW1 have the largest number of points, they are analyzed as examples. Figure 21 shows the time intervals between drip events for the data sets. The open needle drips appear to have a cyclic behavior, while the needle in the rough plates shows a dominant value, with deviations. The analysis of the drip time data sets indicated a significant random component, with large embedding dimensions; LYP was not generated and the Hurst exponents are low. The three-dimensional pseudo phase-space attractors are plotted in Figure 22 using the time between drip events (in minutes), with values of each axis incremented by $\Delta \tau$. The attractors do have some structure, which indicates that the data sets have a component of highdimensional chaos. The attractor for $002 \mathrm{ON} 1$ has similar structure to the attractor for the dripping faucet and Old Faithful shown in Nicholl et al. (1994) and noted in the previous section. 


\section{Summary and conclusions}

This report presents laboratory measurements of water dripping from capillary tubes that were either open to the atmosphere or inserted in glass fracture models. Experimental variables included flow rate, material and diameter of capillary tube, the type of the contact between the tube and the fracture, and fracture surface texture (smooth or rough.) Flow through the fracture models occurred as dripping water in channels. Drops detached at different locations along the water channel. Drop growth and detachment created pressure fluctuations that were transmitted upgradient to the pressure sensor. Pressure fluctuations occurred in response to down-gradient flow behavior, despite the constant flow rate supplied into the capillary tube.

Analysis of the pressure time series data for these experiments indicates the presence of deterministic-chaotic processes with a certain random component. The analysis included determination of the time lag from the minimum of the average mutual information distribution, the local and global embedding dimensions, the Lyapunov exponents and dimension, the Hurst exponent and the entropy of the data set as a function of the embedding dimension. The local embedding dimensions ranged mostly from 3 to 7 , indicating the presence of low-dimensional chaos. Global embedding dimensions were one to several units higher than the local dimensions. The magnitude of the Hurst exponents also confirmed the presence of a significant deterministic component. The contribution of a random component increased as the Hurst exponent decreased and global dimension, local dimension, and Lyapunov dimension increased. In the experiments with the smallest capillary tubes, the pressure time-trend data had low frequency pressure fluctuations that were unrelated to dripping phenomena. Filtering to remove low frequency pressure fluctuations resulted in condensing the attractors relative to the raw data, and in most cases a decrease in the magnitude of the parameters resulting from the data analysis.

Visual observation and pressure monitoring of liquid flow within the fracture models showed that the experimental variables affected the spatial and temporal liquid distributions in the fracture. However, liquid distributions were not always reproducible for the same inlet conditions. Subtle differences in inlet conditions that could not be controlled or exactly replicated appear have a significant effect on flow behavior. Linear regression between the chaos parameters and flow rate was performed to see if the effect of the experimental variables can be seen in the magnitude of the chaos parameters. The linear correlation coefficients between the magnitude of the Hurst exponent and flow rate suggest that the seepage behavior becomes more random as flow rate increases. However, there was no simple, consistent correlation between the trends of the other diagnostic parameters and experimental variables. In three-dimensional pseudo-phase space, some of the pressure time-trend data sets have definite structure, even when the local embedding dimension is greater than three. Attractors for different data sets that were obtained over a wide range of experimental conditions have some common features. These features include an open, angular structure with bends and twists. 
The phenomena of dripping water in fracture models reported here differ from those observed from a single faucet investigated by Shaw (1984). Shaw (1984) showed that the dripping from a faucet could be described by a simple logistic equation for which a pseudophase portrait of the time interval between drips is a map with a small noise component. Drip formation processes within the fracture are affected by liquid viscosity and surface tension, and fluid phase changes in the fracture; these attributes introduce more complex chaotic processes compared to the dripping faucet. Interestingly, the shape of the twodimensional attractor for the dripping faucet data is similar to attractors for some of the pressure time-trends and drip interval times measured in this report.

The data and analysis in this report show that deterministic-chaotic processes are present in unsteady channel flow in fractures. The pressure time-series data were useful for analysis because they responded to the fluctuations in liquid distribution. However, noise and/or random processes are present in the data and need to be addressed in subsequent analysis. Another issue to be considered is the relationship between the length of the data set and presence of noise.

The application of the chaos framework for short-term predictions of unsaturated flow and transport requires the development of appropriate models, and determining the time-scale for which they are valid. Another essential component is to determine what type of data should be measured for analysis in this framework, and how to apply laboratory results to the field scale. While we can make high resolution measurements of liquid distribution in the laboratory, this cannot be achieved in the field. Even if we determine that unsaturated flow is inherently chaotic at the laboratory scale, we must consider the effect of averaging and environmental noise that inevitably occur at the field scale. Averaging and noise may make chaotic processes appear random. Environmental factors that may be the important drivers of flow and transport must be appropriately measured and accounted for. Progress in this area will also require the development of improved sensors for laboratory and in-situ measurements of fluid pressure in fractures that are robust indicators of fluid flow behavior. 


\section{Acknowledgment}

Funding of this work was provided by the Environmental Management Science Program of DOE, under Contract no. DE-AC03-76SF00098. The authors greatly appreciate Tim Kneafsey and Christine Doughty of the Earth Sciences Division of LBNL for their careful review of this manuscript and helpful suggestions for improvement.

\section{References:}

Abarbanel, H. D. I., Analysis of Observed Chaotic Data, Springer, New York, 1996.

Bird, R. B., W. E. Stewart and E. N. Lightfoot, Transport Phenomena, John Wiley \& Sons, Inc., New York, p. 46, 1960.

Faybishenko, B., Chaotic Dynamics in Flow through Unsaturatd Fractured Media, LBNL Report 46958, Lawrence Berkeley National Laboratory, Berkeley, California, October, 2000.

Faybishenko, B., P. A. Witherspoon, C. Doughty, J. T. Geller, T. Wood and R. Podgorney, Multi-scale investigations of liquid flow in a fractured basalt vadose zone, in Flow and Transport in Fractured Rocks, American Geophysical Union Monograph, T. J. Nicholson and D. D. Evans, eds., 2001.

Geller, J. T., H-Y. Holman, G. Su, M. S. Conrad, K. Pruess and J. C. Hunter-Cevera, Flow dynamics and potential for biodegradation of organic contaminants in fractured rock vadose zone, J. of Contam. Hydrol., Vol. 43, No. 1, 63-90, 2000.

Moon, F. C., Chaotic vibrations : an introduction to chaotic dynamics for applied scientists and engineers, New York, Wiley, 1987.

Nicholl, M. J., R. J. Glass, and S. H. Wheatcraft, Gravity-driven infiltration instability in initially dry nonhorizontal fractures, Water Resour. Res., Vol. 30, No. 9, pp. 2533-2546, 1994.

Nicholl, M. J., S. W. Wheatcraft and S. W. Tyler, Is Old Faithful a strange attractor?, Journal of Geophysical Research, Vol. 99, No. B3, pp. 4495-4503, 1994.

Or, D. and T. A. Ghezzehei, Dripping into subterranean cavities from unsaturated fractures under evaporative conditions, Water Resour. Res., Vol. 36, No. 2, pp. 381-393.

Persoff, P. and Pruess, K., Two-phase flow visualization and relative permeability measurement in natural rough-walled rock fractures. Water Resour. Res., Vol. 31, No. 5, 1173-1186, 1995.

Podgorney, R., T. Wood, B. Faybishenko, and T. Stoops, Spatial and temporal instabilities in water flow through variably saturated fractured basalt on a one-meter scale, in Dynamics of Fluids in Fractured Rock, edited by B. Faybishenko, P. A. Witherspoon and S. M. Benson, AGU Geophysical Monograph 122, 2000.

Pruess, K., On water seepage and fast preferential flow in heterogeneous, unsaturated rock fractures, J. of Contam. Hydrol., Vol. 30, 333-362, 1998.

Pruess, K. and Y. W. Tsang, On two-phase relative permeability and capillary pressure of rough-walled rock fractures, Water Resour. Res., Vol. 26, No. 9, 1915-1926, 1990. 
Shaw, R., The dripping faucet as a model of chaotic system, Aerial Press, Santa Cruz, Calif., 1984.

Su, G., Geller, J. T., Pruess, K. and Wen, F., Experimental studies of water seepage and intermittent flow in unsaturated, rough-walled fractures. Water Resour. Res., Vol. 35, No. 4, 1019-1037, 1999.

Tsonis, A. A., Chaos: from theory to applications, New York, Plenum Press, 1992. 
Appendix I.

Table I.1: Settings for Global Embedding Dimension Calculations (Cspw program)

\begin{tabular}{|l|l|}
\hline Field in Window & Setting or Range of Settings \\
\hline Number of samples to process & Entire file (default) \\
\hline Number of samples to skip & 0 (default) \\
\hline Minimum Dimension & 1 (default) \\
\hline Maximum Dimension & 15 (default) \\
\hline Time lag & $\begin{array}{l}\text { Use time delay from AMI. May be varied } \\
\text { by } 50 \%\end{array}$ \\
\hline Decorrelation Time & Ten times AMI (default) \\
\hline Maximum Neighbors & 400 (default) \\
\hline Group Factor & 20 (default) \\
\hline Tolerance 1 & 17.1 (default) \\
\hline Tolerance 2 & 1.8 (default) \\
\hline Verbose output during computation & Checked \\
\hline Hold Output Screen & Unchecked \\
\hline
\end{tabular}

Table I.2: Settings for Local Embedding Dimension Calculations (Cspw program)

\begin{tabular}{|l|l|}
\hline Field in Window & Setting or Range of Settings \\
\hline Number of samples to process & Entire file (default) \\
\hline Number of samples to skip & 0 (default) \\
\hline Global Dimension & 15 \\
\hline Maximum Dimension & 15 (default) \\
\hline Decorrelation Time & Use default value (ten times AMI) \\
\hline Time lag & $\begin{array}{l}\text { Use time delay from AMI. May be varied } \\
\text { by 50\% }\end{array}$ \\
\hline "Bad" predict time & Ten times AMI (default) \\
\hline Number of Neighbors & $10 \%$ of sample size \\
\hline Group Factor & 20 (default) \\
\hline Size Criterion (Beta) & $0.1-0.3$ (increase if plot looks noisy) \\
\hline Evaluate Backwards & Unchecked \\
\hline Verbose output during computation & Checked \\
\hline Hold Output Screen & Unchecked \\
\hline
\end{tabular}




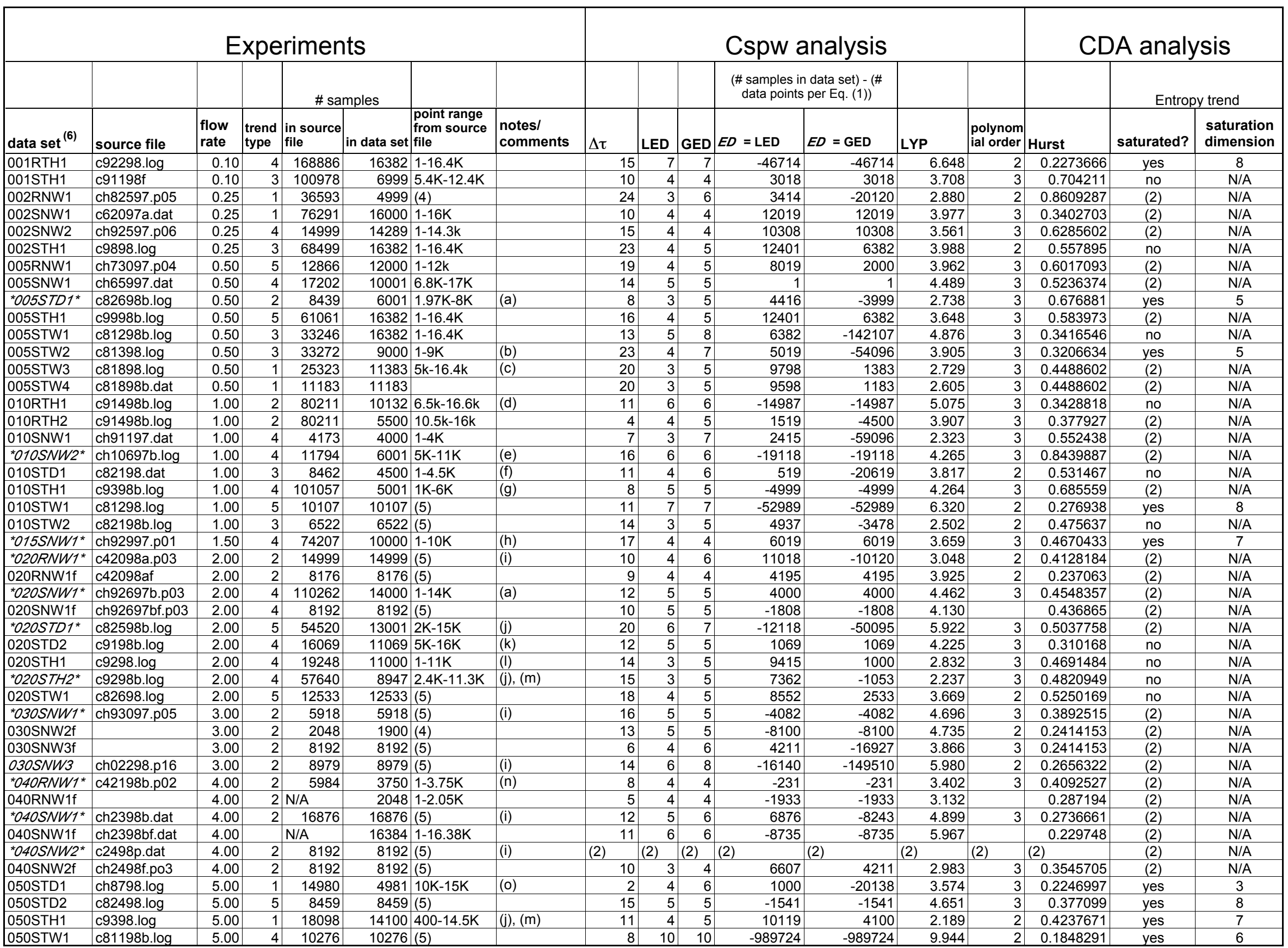




\begin{tabular}{|c|c|c|c|c|c|c|c|c|c|c|c|c|c|c|c|c|c|}
\hline \multicolumn{8}{|c|}{ Experiments } & \multicolumn{7}{|c|}{ Cspw analysis } & \multicolumn{3}{|c|}{ CDA analysis } \\
\hline & & & & \# sar & amples & & & & & & $\begin{array}{l}\text { (\# samples in } \\
\text { data points }\end{array}$ & $\begin{array}{l}\text { data set) - (\# } \\
\text { per Eq. (1)) }\end{array}$ & & & & Entrop & $\mathrm{y}$ trend \\
\hline data set $^{(6)}$ & source file & $\begin{array}{l}\text { flow } \\
\text { rate }\end{array}$ & \begin{tabular}{|l|} 
trend \\
type
\end{tabular} & \begin{tabular}{|l|} 
in source \\
file
\end{tabular} & in data set & $\begin{array}{l}\text { point range } \\
\text { from source } \\
\text { file } \\
\end{array}$ & $\begin{array}{l}\text { notes/ } \\
\text { comments }\end{array}$ & $\Delta \tau$ & LED & GED & $E D=\mathrm{LED}$ & $E D=\mathrm{GED}$ & LYP & \begin{tabular}{|l} 
polynom \\
ial order
\end{tabular} & Hurst & saturated? & $\begin{array}{l}\text { saturation } \\
\text { dimension }\end{array}$ \\
\hline 050STW2 & c82598.log & 5.00 & 5 & 17406 & 16382 & $1-16.4 \mathrm{~K}$ & & 23 & 3 & 5 & 14797 & 6382 & 2.863 & 3 & 0.531467 & $(2)$ & $\mathrm{N} / \mathrm{A}$ \\
\hline 060STD1 & c9198.log & 6.00 & 1 & 8059 & 5059 & 3K-8K & (p) & 12 & 4 & 5 & 1078 & -4941 & 3.889 & 3 & 0.2393166 & yes & 7 \\
\hline 080STD1 & c83198.log & 8.00 & 5 & 8463 & 6000 & $1 \mathrm{~K}-7 \mathrm{~K}$ & (p) & 8 & 3 & 5 & 2019 & -4000 & 2.230 & & 0.5105328 & yes & 6 \\
\hline 100RTH1 & c91798.log & 10.00 & 5 & 15389 & 15000 & $1-15 \mathrm{~K}$ & (q) & 3 & 4 & 7 & 11019 & -48096 & 2.301 & & 0.16 & (2) & $\mathrm{N} / \mathrm{A}$ \\
\hline 100RTH2 & c91798v.log & 10.00 & 5 & 60901 & 16382 & $1-16.38 \mathrm{~K}$ & & 5 & 4 & 5 & 12401 & 6382 & 3.963 & 2 & 0.1528276 & yes & 6 \\
\hline${ }^{*} 100 S T D 1^{*}$ & c82198c.dat & 10.00 & 5 & 8448 & 8448 & (5) & (i), (j), (1) & 9 & 3 & 4 & 6863 & 4467 & 2.755 & 2 & 0.2835984 & no & $\mathrm{N} / \mathrm{A}$ \\
\hline 100STW1 & ch8798b.log & 10.00 & 1 & 220983 & 3667 & $3.25 \mathrm{~K}-7 \mathrm{~K}$ & $(\mathrm{~s}),(\mathrm{t})$ & 3 & 5 & 5 & -6333 & -6333 & 4.682 & 3 & 0.1124402 & $(2)$ & $\mathrm{N} / \mathrm{A}$ \\
\hline $\begin{array}{l}\text { (aka } \\
\text { RGTG1) }\end{array}$ & c031799b.log & 5.00 & 1 & 40499 & 20001 & $20 \mathrm{~K}-40 \mathrm{~K}$ & & 14 & 4 & 8 & 16020 & -138488 & 3.399 & 3 & 0.2425362 & yes & 5 \\
\hline $\begin{array}{l}\text { 100RGTG1 } \\
\text { (aka } \\
\text { RGTG2) }\end{array}$ & c031299a.log & 10.00 & 1 & 13770 & 13770 & (5) & & 9 & 3 & 7 & 12185 & -49326 & 2.963 & 3 & 0.2506334 & yes & 7 \\
\hline $\begin{array}{l}\text { 200RGTG1 } \\
\text { (aka } \\
\text { RGTG3) }\end{array}$ & c031599a.log & 20.00 & 5 & 13675 & 13675 & (5) & & & $>12$ & $>12$ & & & (3) & & 0.1340247 & no & $\mathrm{N} / \mathrm{A}$ \\
\hline $\begin{array}{l}\text { 005RGTG1 } \\
\text { (aka } \\
\text { RGTG4) }\end{array}$ & c031199b.log & 0.50 & 1 & 45563 & 13000 & $1-13 \mathrm{~K}$ & & 11 & 4 & 8 & 9019 & -145489 & 3.084 & 3 & 0.4504181 & $(2)$ & $\mathrm{N} / \mathrm{A}$ \\
\hline $\begin{array}{l}\text { 050RGTG2 } \\
\text { (aka } \\
\text { RGTG5) }\end{array}$ & 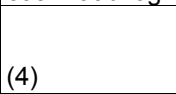 & 5.00 & & (4) & 10000 & (5) & & 8 & 4 & 5 & 6019 & 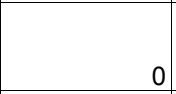 & 3.500 & & 0.3686228 & (2) & $\mathrm{N} / \mathrm{A}$ \\
\hline $\begin{array}{l}\text { 005RGTGN } \\
\text { S1 (aka } \\
\text { RGTGNS1) }\end{array}$ & c032299a.log & 0.50 & 5 & 62653 & 14000 & $1-14 \mathrm{~K}$ & & 6 & 4 & 4 & 10019 & 10019 & 3.819 & 3 & 0.6951705 & (2) & $\mathrm{N} / \mathrm{A}$ \\
\hline $\begin{array}{l}\text { *005RGTG } \\
\text { NS2* (aka } \\
\text { RGTGNS2) }\end{array}$ & c032299a.log & 0.50 & 1 & 62653 & 28000 & $30 \mathrm{~K}-45 \mathrm{~K}$ & (u) & 18 & 4 & 5 & 24019 & 18000 & 3.696 & 3 & 0.6314782 & (2) & $\mathrm{N} / \mathrm{A}$ \\
\hline $\begin{array}{l}\text { 005RGTGN } \\
\text { S3 (aka } \\
\text { RGTGNS3) }\end{array}$ & c032299a.log & 0.50 & 1 & 62653 & 15001 & $45 \mathrm{~K}-60 \mathrm{~K}$ & & 17 & 4 & 5 & 11020 & 5001 & 3.878 & 3 & 0.6141598 & (2) & N/A \\
\hline $\begin{array}{l}\text { 050RGTGN } \\
\text { S1 (aka } \\
\text { RGTGNS4) }\end{array}$ & c031899a.log & 5.00 & 1 & 15235 & 10000 & $4 \mathrm{~K}-14 \mathrm{~K}$ & & 7 & 4 & 6 & 6019 & -15119 & 3.874 & 3 & 0.2938455 & (2) & $\mathrm{N} / \mathrm{A}$ \\
\hline $\begin{array}{l}\text { 050RGTGN } \\
\text { S2 (aka } \\
\text { RGTGNS5) }\end{array}$ & c031999a.log & 5.00 & 4 & 30000 & 25001 & $1-25 \mathrm{~K}$ & & 12 & 4 & 5 & 21020 & 15001 & 3.279 & 2 & 0.4051721 & yes & 8 \\
\hline $\begin{array}{l}\text { 100RGTGN } \\
\text { S1 (aka } \\
\text { RGTGNS6) }\end{array}$ & c031899b.log & 10.00 & 4 & 62193 & 10000 & $2 \mathrm{~K}-12 \mathrm{~K}$ & & 16 & 4 & 4 & 6019 & 6019 & 3.978 & 3 & 0.5075548 & yes & 7 \\
\hline $\begin{array}{l}\text { 005RTGH1 } \\
\text { (aka } \\
\text { RTGH1) }\end{array}$ & c030199b.log & 0.50 & 4 & 32299 & 20000 & $1-20 \mathrm{~K}$ & & 17 & 4 & 5 & 16019 & 10000 & 3.997 & 3 & 0.4500418 & (2) & $\mathrm{N} / \mathrm{A}$ \\
\hline $\begin{array}{l}\text { 050RTGH1 } \\
\text { (aka } \\
\text { RTGH2) }\end{array}$ & c030199a.log & 5.00 & 4 & 23494 & 20000 & $1-20 \mathrm{~K}$ & & 6 & 4 & 6 & 16019 & -5119 & 3.964 & 2 & 0.1896454 & yes & 5 \\
\hline${ }^{*} 0020 N 1 *$ & ch10997.p04 & 0.25 & $\mathrm{~N} / \mathrm{A}$ & 54508 & 8192 & (4) & & 11 & 3 & 5 & 6607 & -1808 & 2.844 & 3 & 0.3532207 & (2) & $\mathrm{N} / \mathrm{A}$ \\
\hline
\end{tabular}




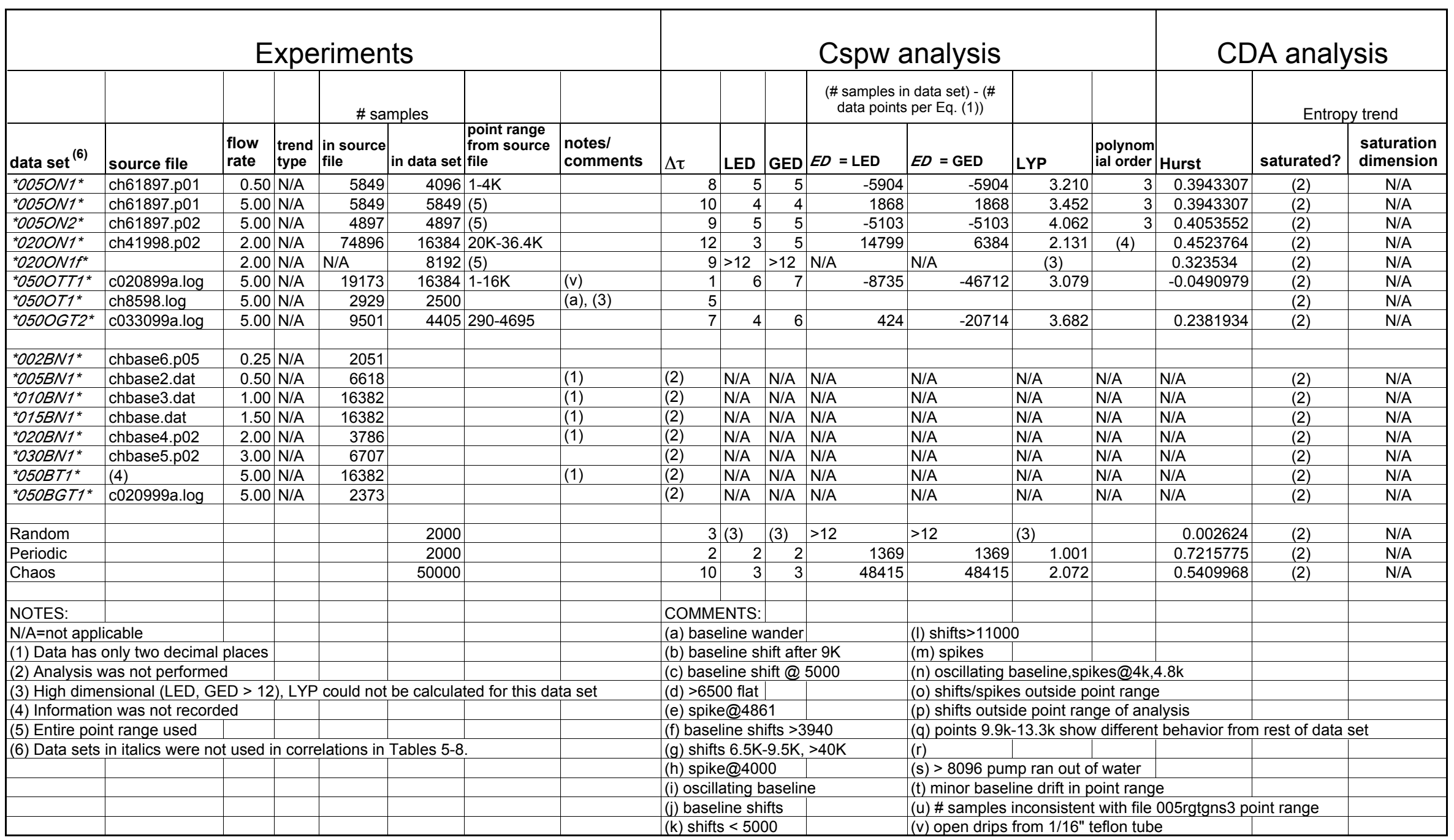




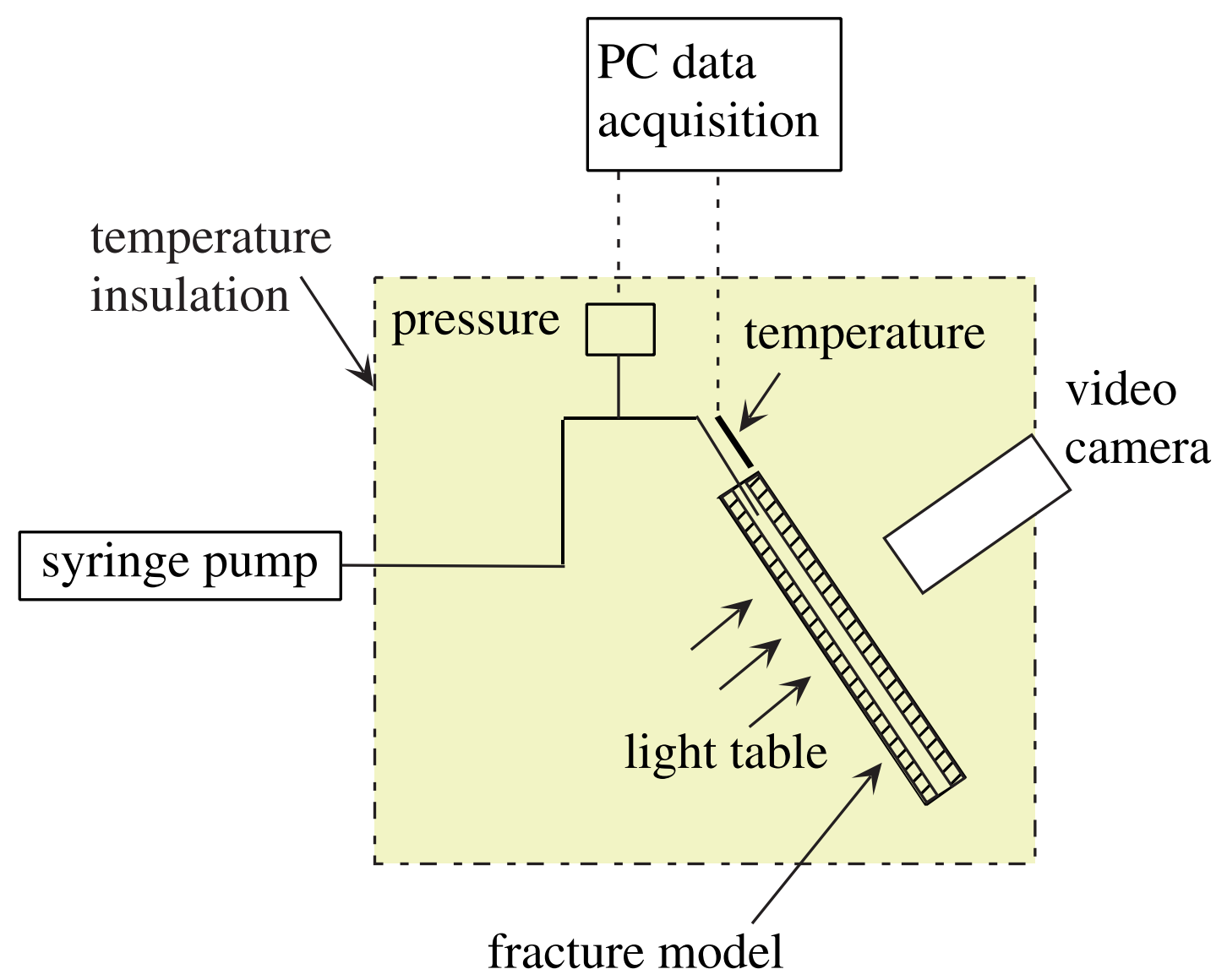

Figure 1. Schematic of experimental apparatus 
$0020 N 1$

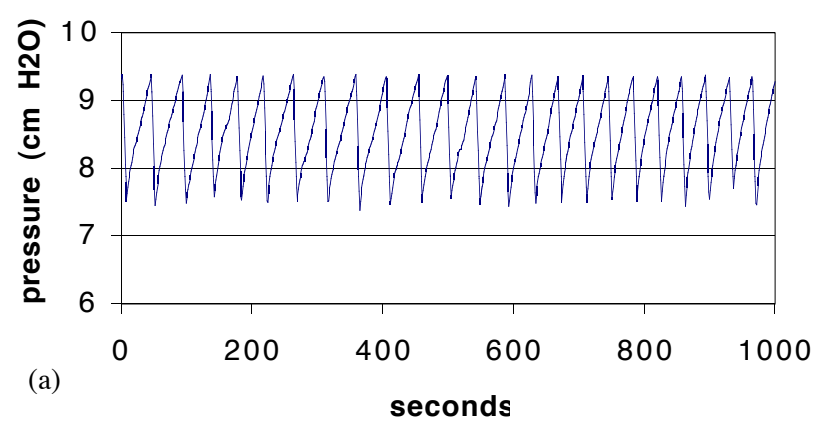

005ON1

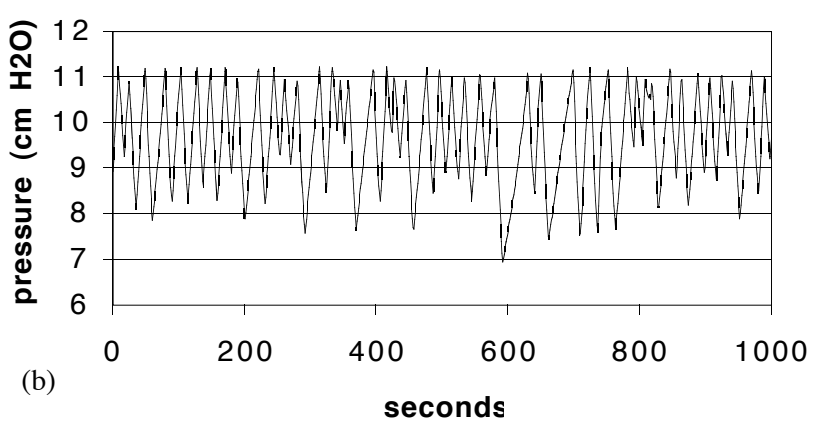

$0500 T 1$

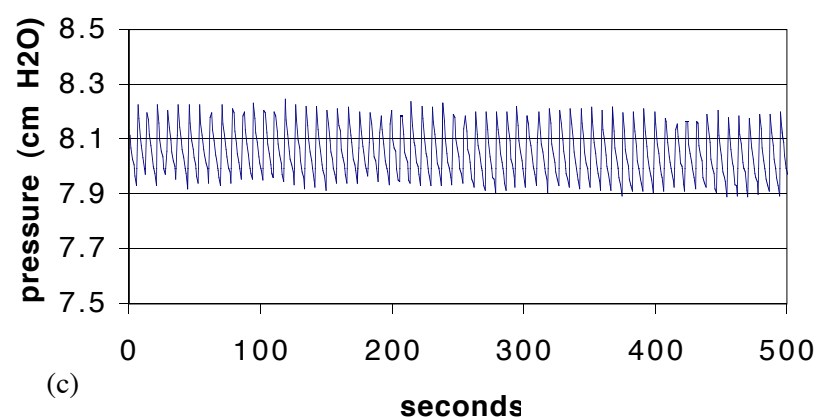

050OGT2

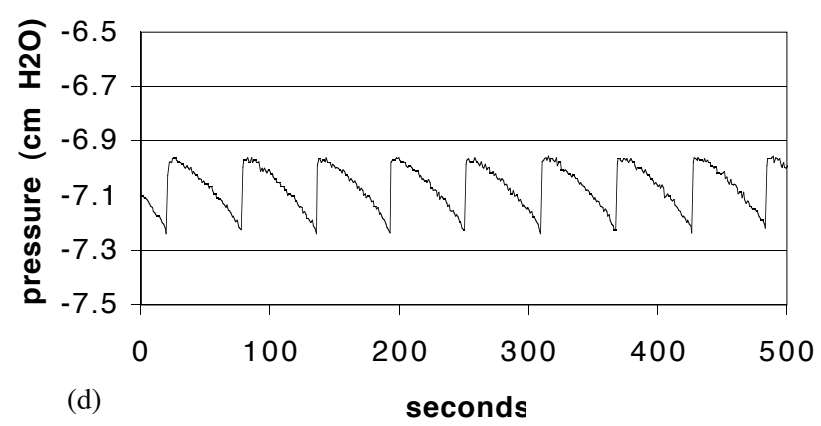

Figure 2. Pressure time-trend for flow through point sources dripping into open air. (a) $0.25 \mathrm{~mL} / \mathrm{hr}$ through needle, (b) $0.5 \mathrm{~mL} / \mathrm{hr}$ through needle, (c) $5 \mathrm{~mL} / \mathrm{hr}$ through plastic tube,

(d) $5 \mathrm{~mL} / \mathrm{hr}$ through glass tube. (Negative pressures result from elevation of pressure transducer relative to elevation of needle, which was different in each experiment.) 
$002 B N 1$
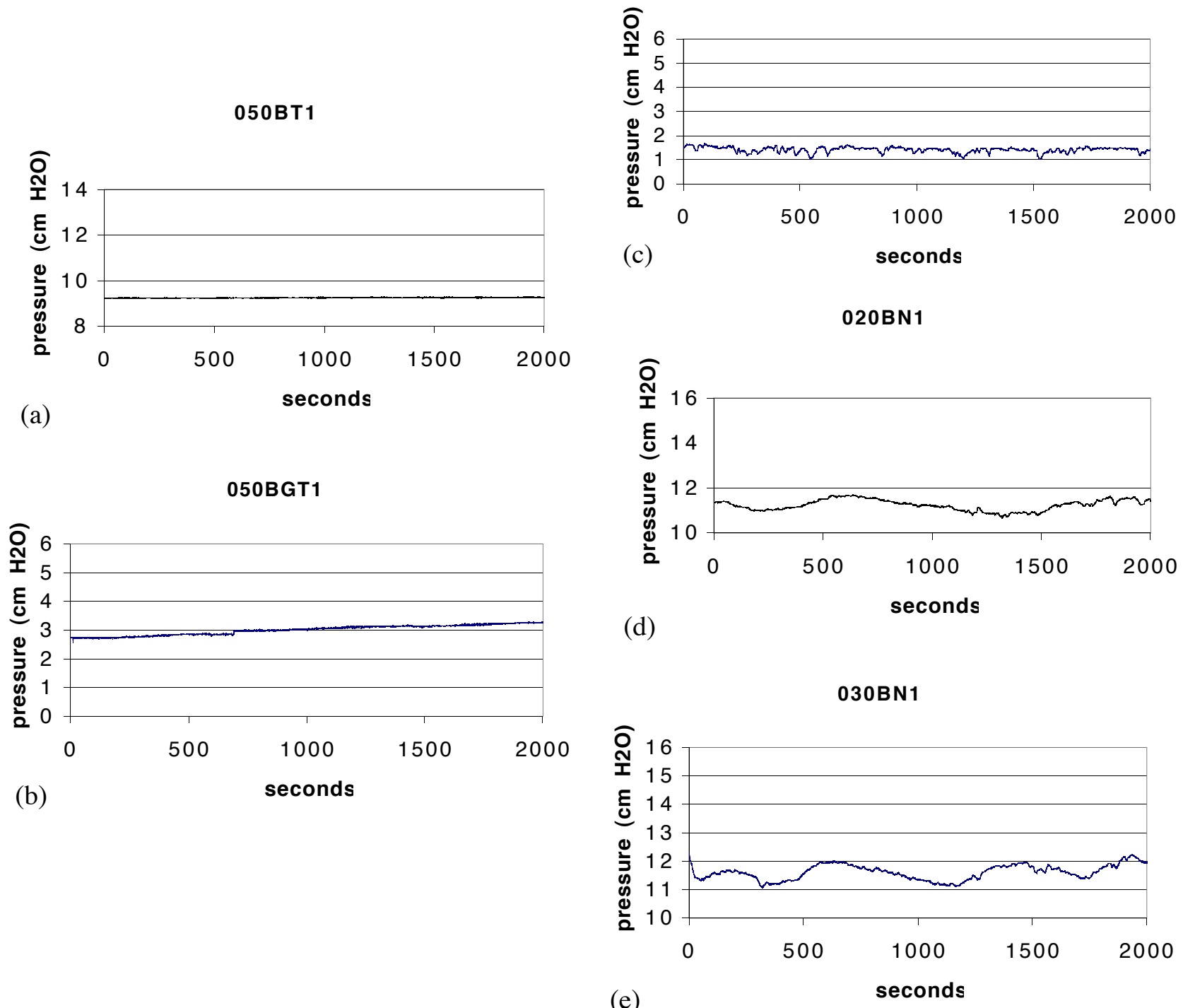

Figure 3. Pressure time-trends for point sources submerged in water. (a) $5 \mathrm{~mL} / \mathrm{hr}$ through plastic tube, (b) $5 \mathrm{~mL} / \mathrm{hr}$ through glass tube, (c) $0.25 \mathrm{~mL} / \mathrm{hr}$ through needle, (d) $2 \mathrm{~mL} / \mathrm{hr}$ through needle, and (e) $3 \mathrm{~mL} / \mathrm{hr}$ through needle. (The pressure increase in (b) reflects water level rise in container with submerged tube.) 


\section{N1 (ch41998.dat)}

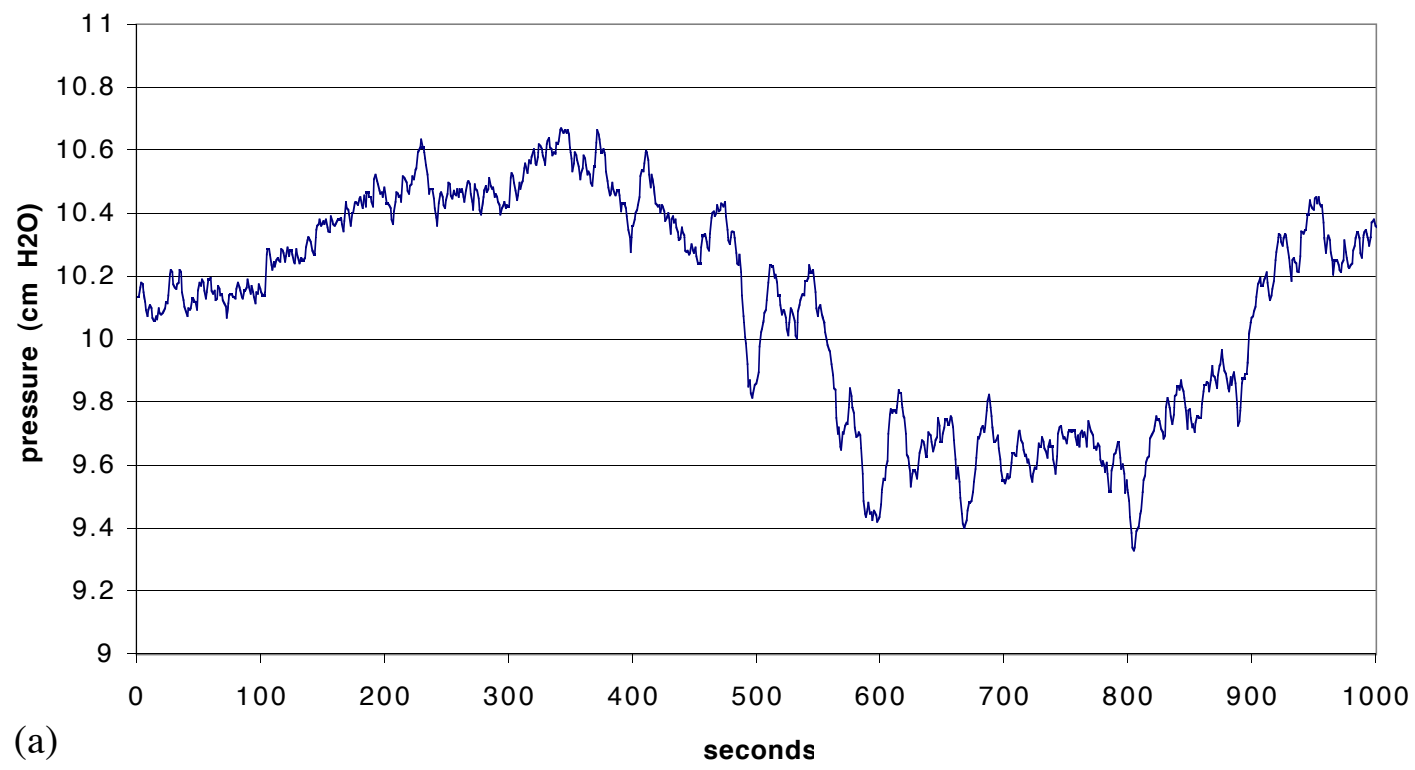

0200N1 (filtered) (ch41998f.dat

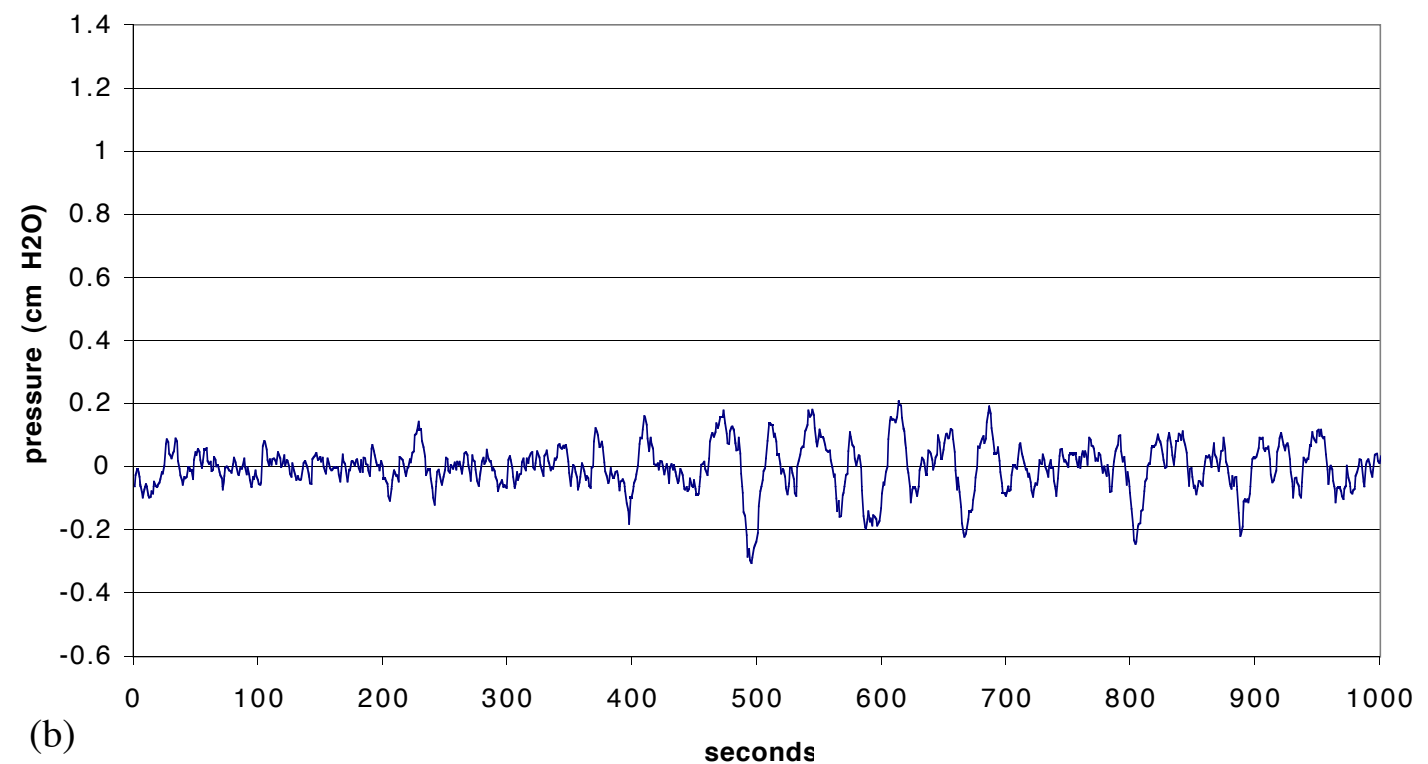

Figure 4. Pressure time-trend for $2 \mathrm{~mL} / \mathrm{hr}$ through needle into open air. (a) Raw data, and (b) Filtered data to remove low frequency oscillation. 


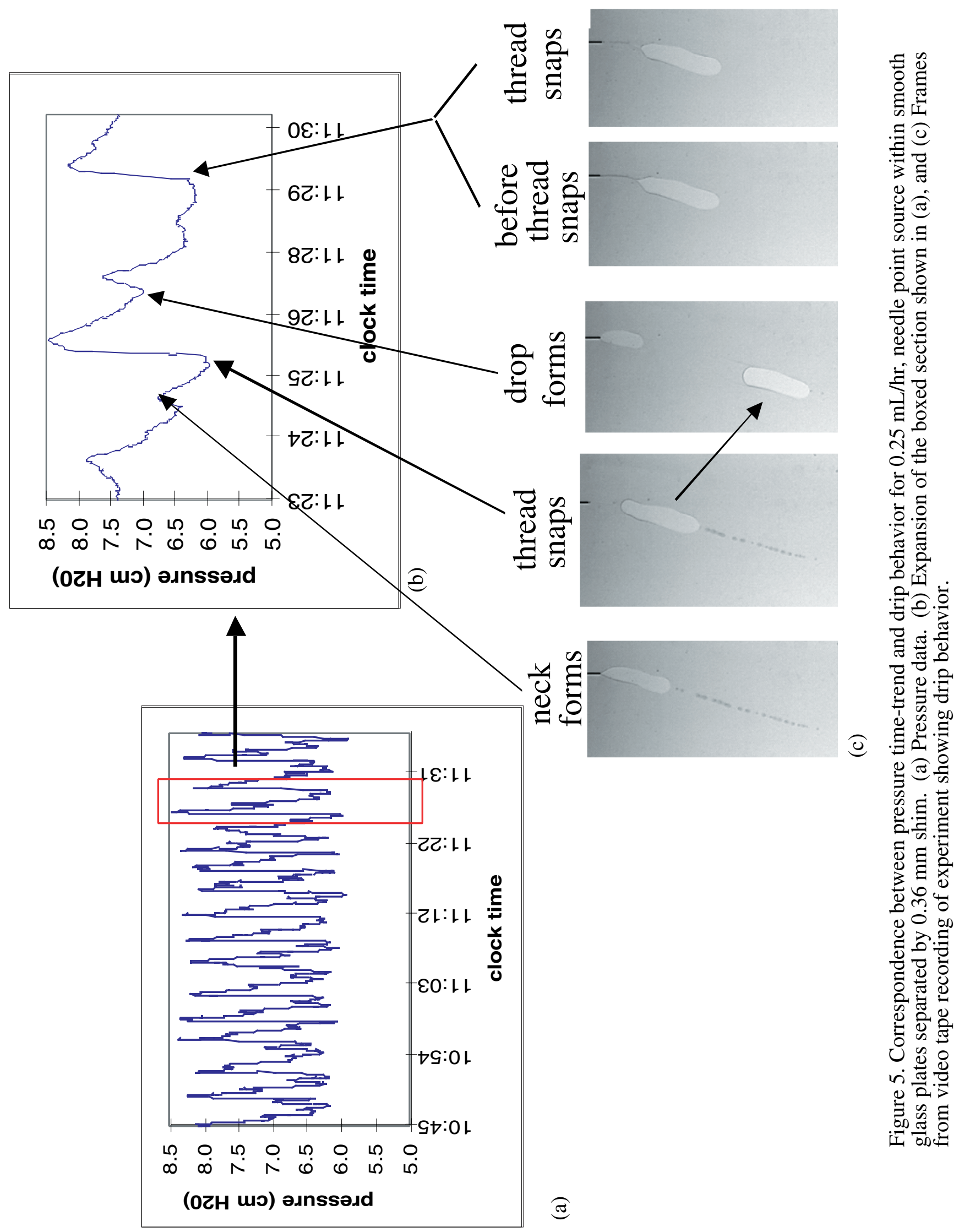




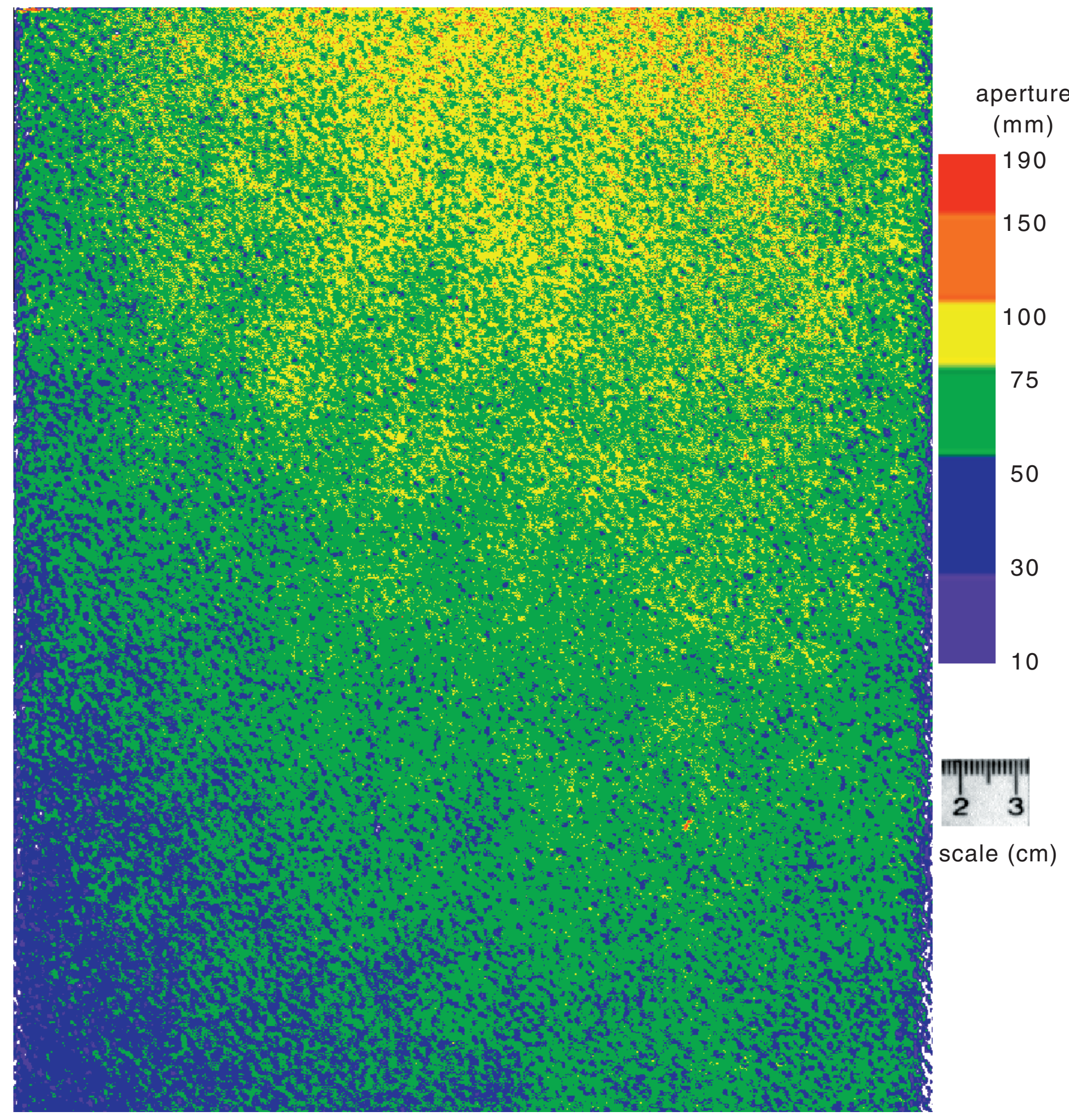

Figure 6. Aperture distribution measured by light attenuation in the variable aperture fracture model (mated plates of rough glass.) 

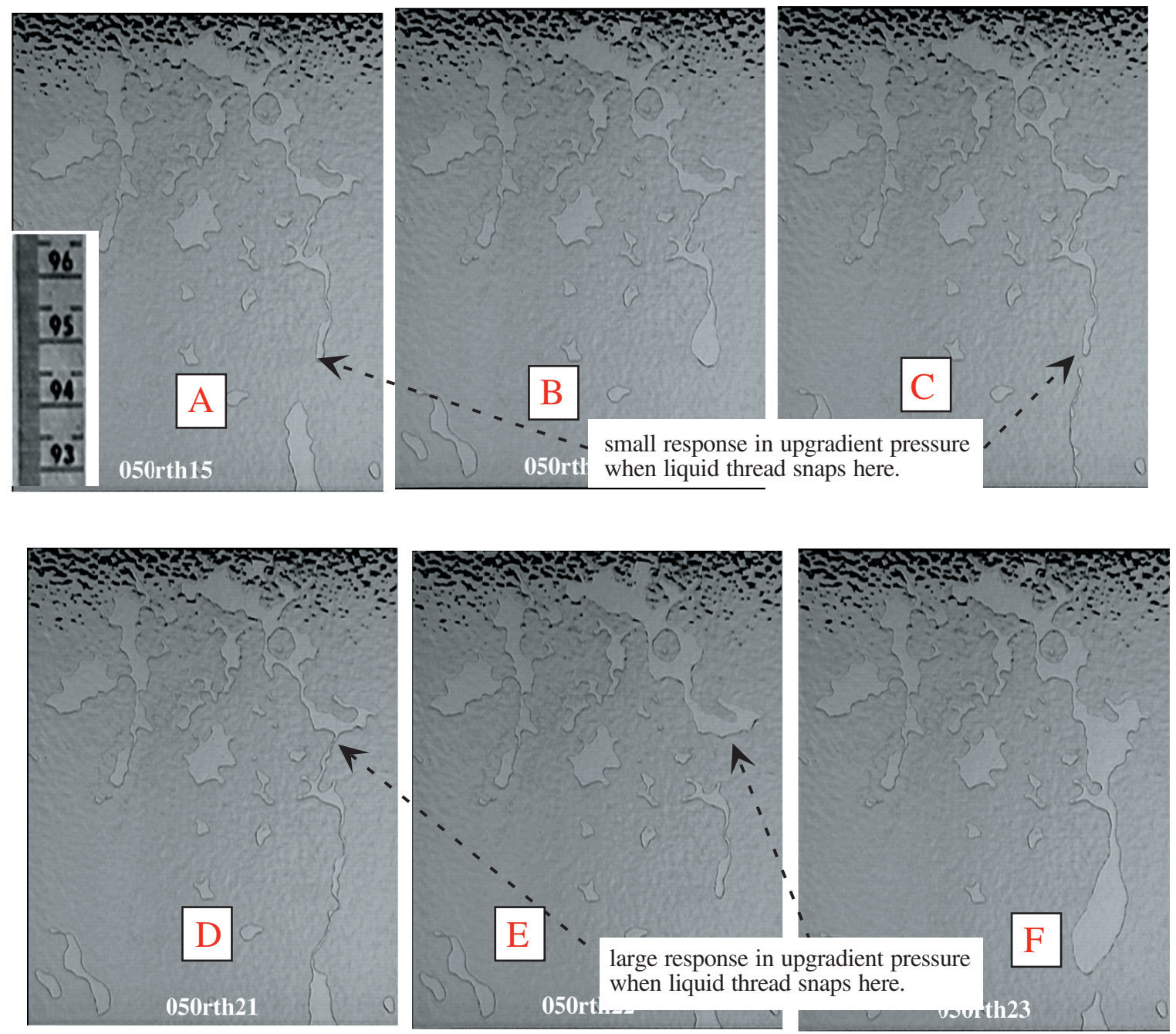

(a)

(b)

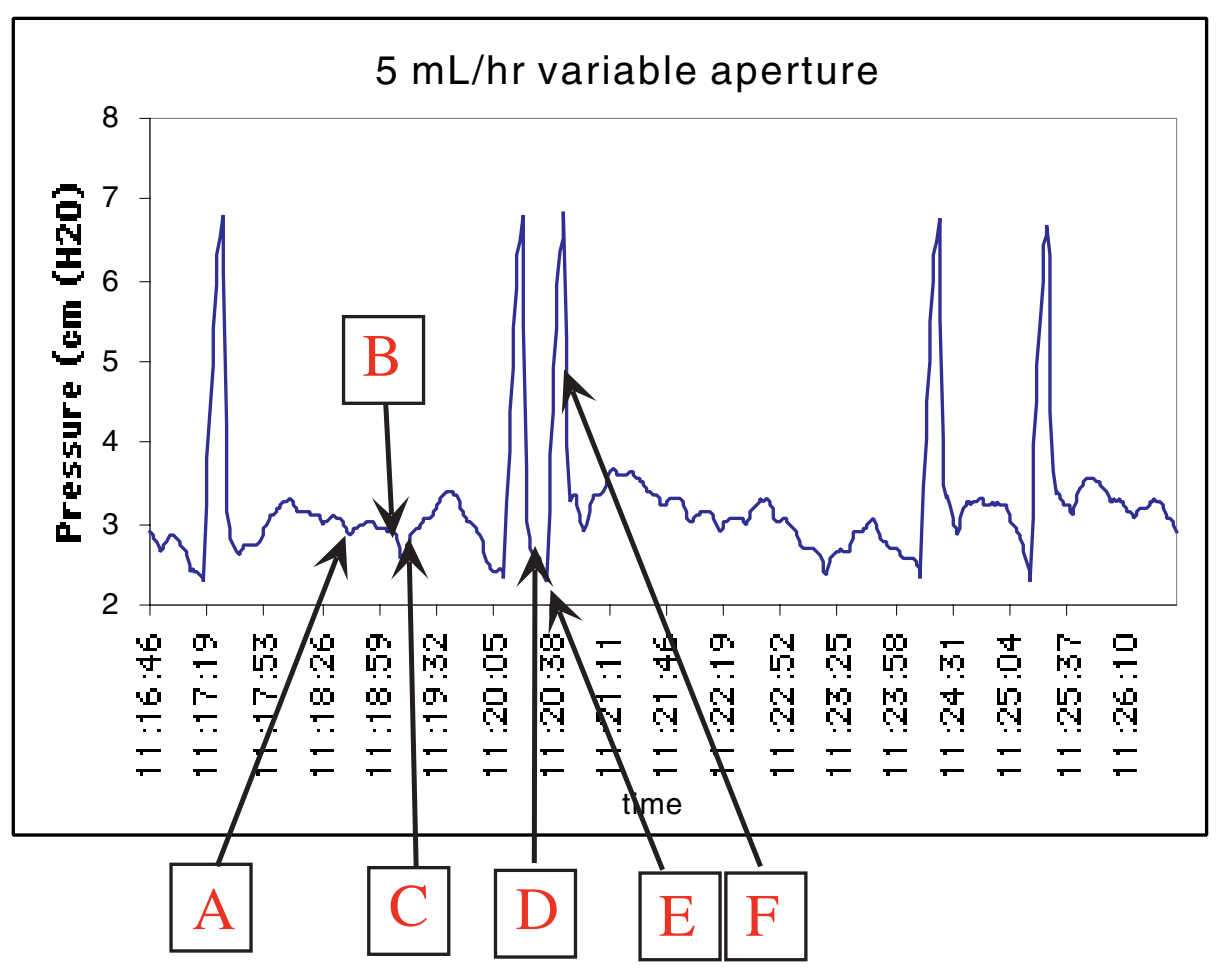

Figure 7. Pressure response to drip behavior for $5 \mathrm{~mL} / \mathrm{hr}$ through a plastic tube point source contacting the variable aperture fracture. (a) Frames from video tape recording of experiment showing drip behavior, and (b) Pressure data. 
Type 1 (002SNW1 3k-3.5k)

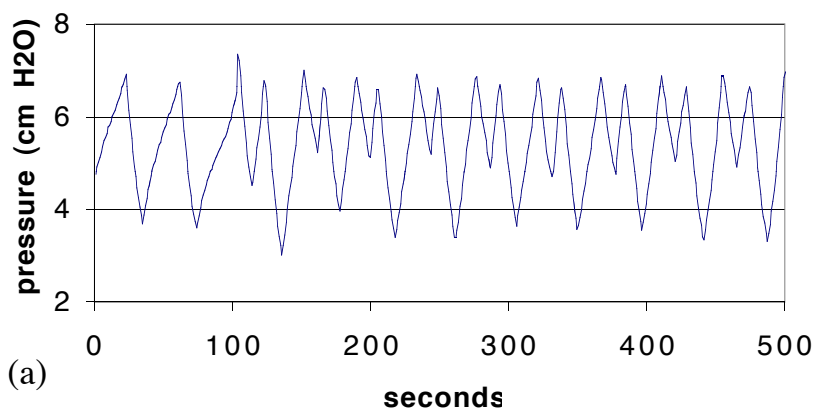

Type 3 (010STW2 1K-2K)

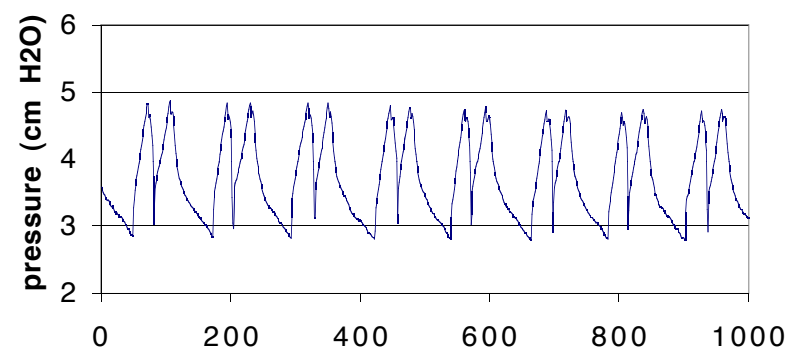

(c)

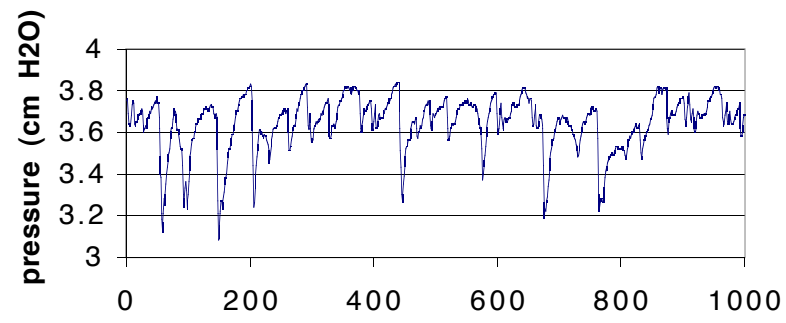

(b)

seconds

Type 4 (002SNW2 1K-4K)

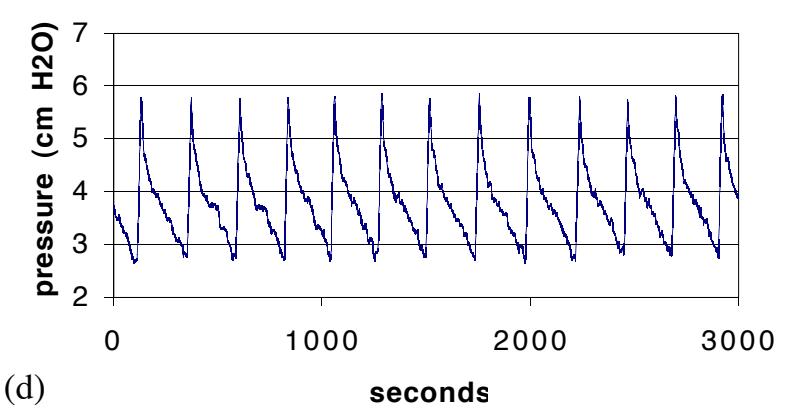

Type 5 (005STH1 4K-8K)

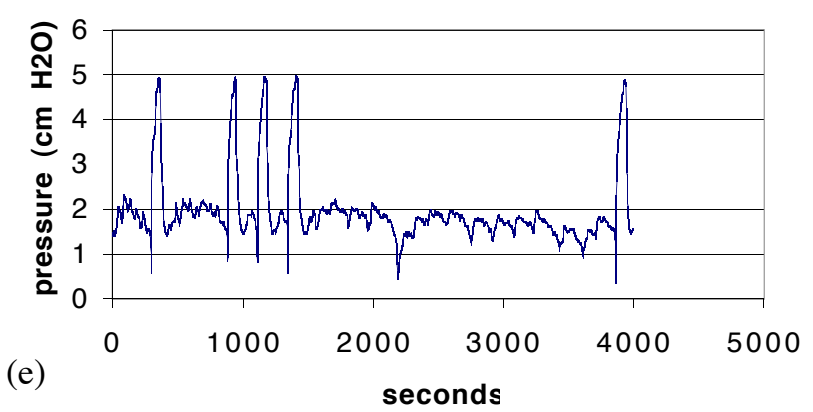

Figure 8. Pressure trend types. (a) Type 1 - "sawtooth" signature (dripping without string formation), (b) Type 2 -irregular occurrence of large and small pressure fluctuations, corresponding to long and short drip formation, respectively, before snap-off, (c) Type 3 combination of Type 1 and Type 4, (d) Type 4 - "sawtooth" with lag due to string formation before drip detachment, and (e) Type 5 - contains sections of Types 1,2 and 4. 
All Experiments

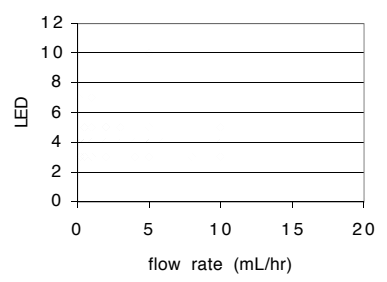

All Experiments

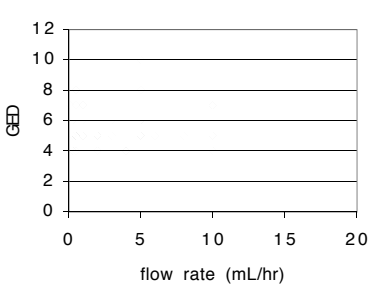

All Experiments

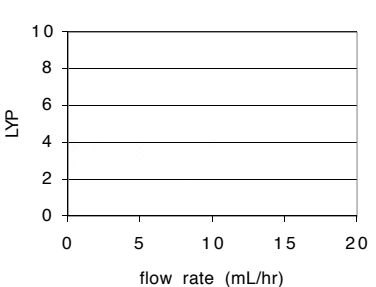

All Experiments

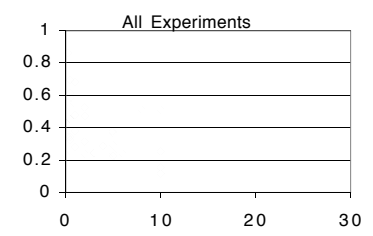

(a)

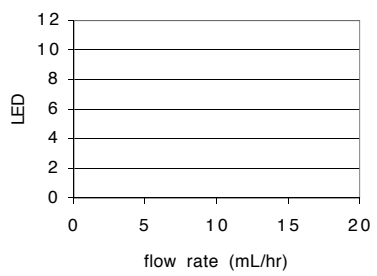

SN

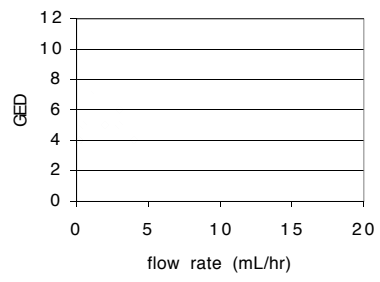

SN
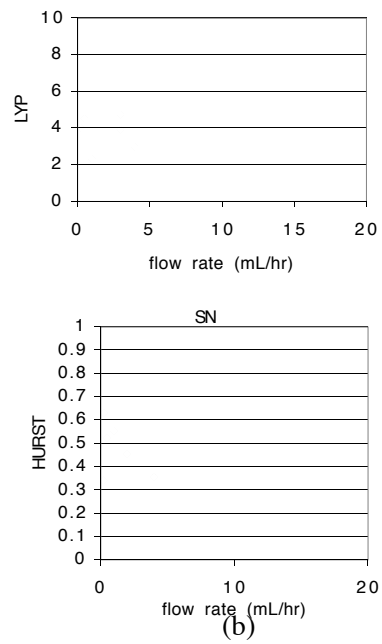

ST

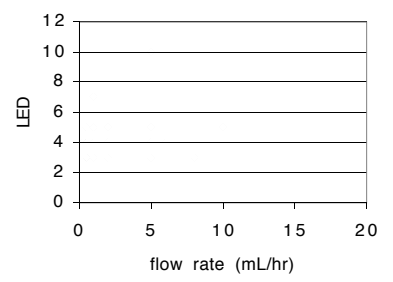

ST

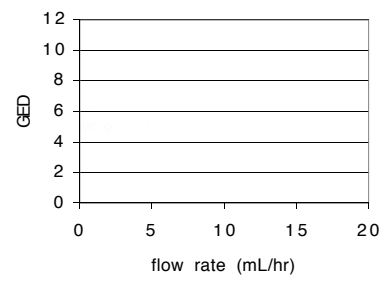

ST
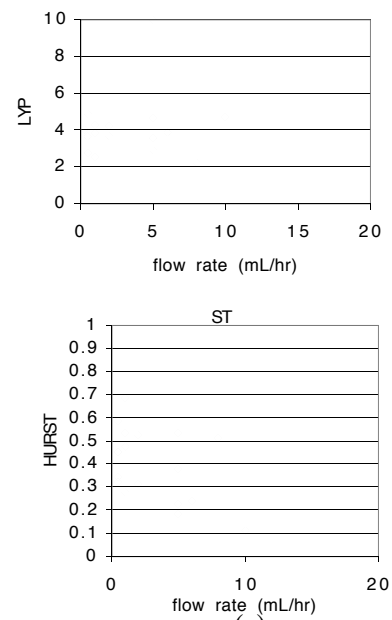

(c)

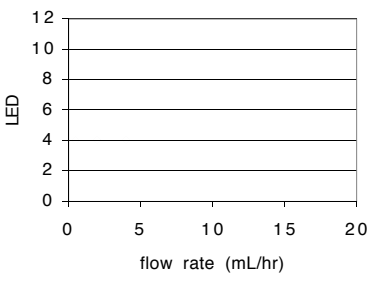

PN

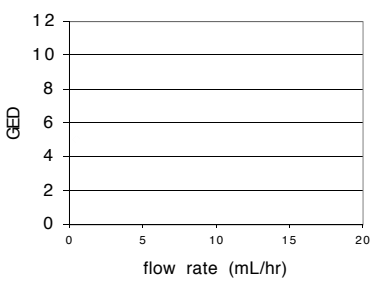

$\mathrm{RN}$
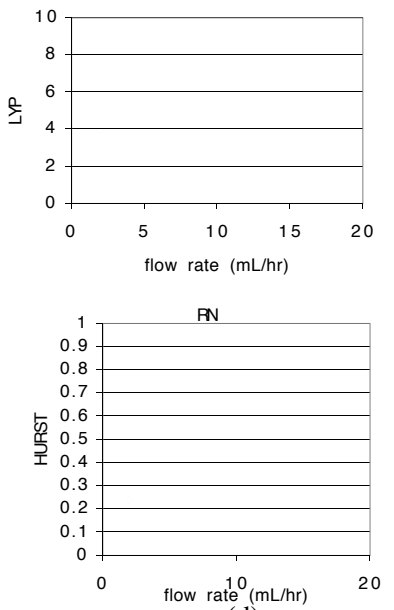

(d)

Figure 9. Embedding dimensions, Lyapunov dimension and Hurst exponent as a function of flow rate. (a) All experiments, (b) SN data sets, (c) ST data sets, and (d) RN data sets. 
RT

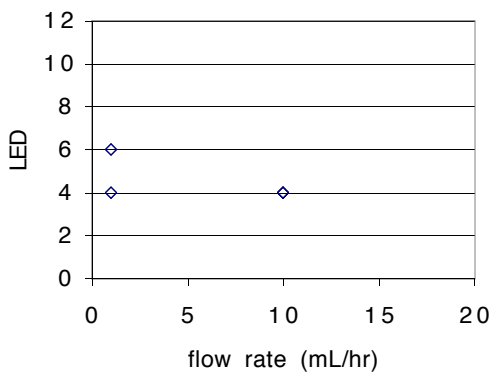

RT

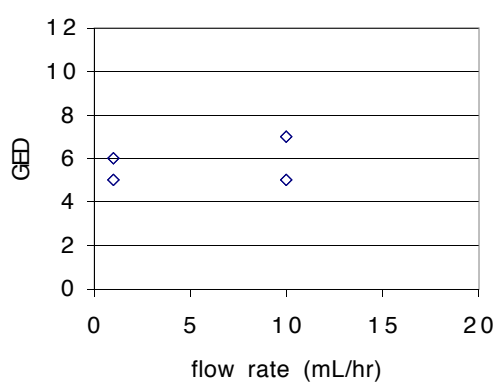

RT

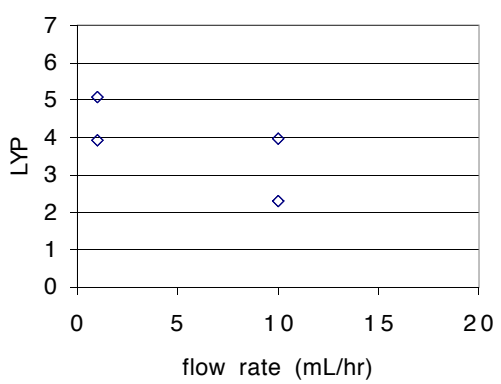

RT

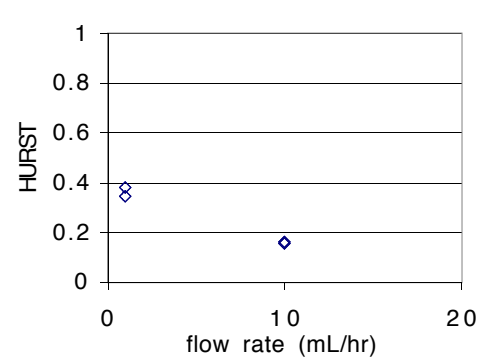

(a)

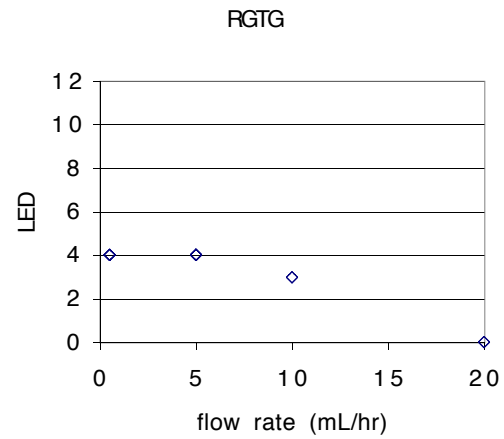

RGTG

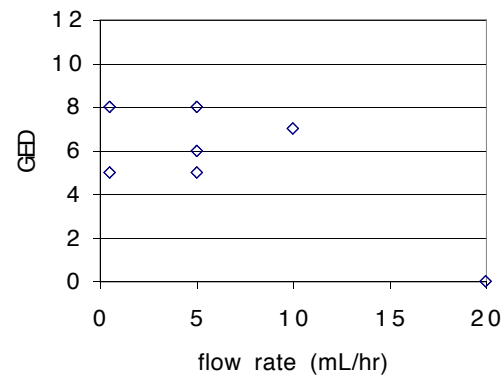

RGTG

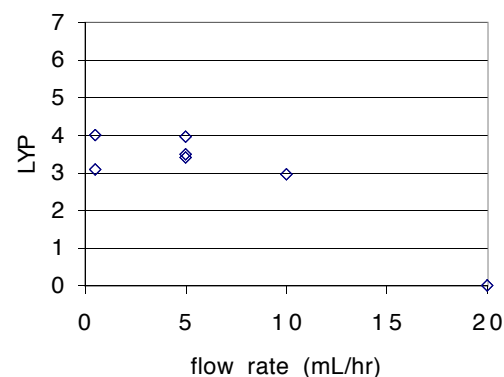

RGTG

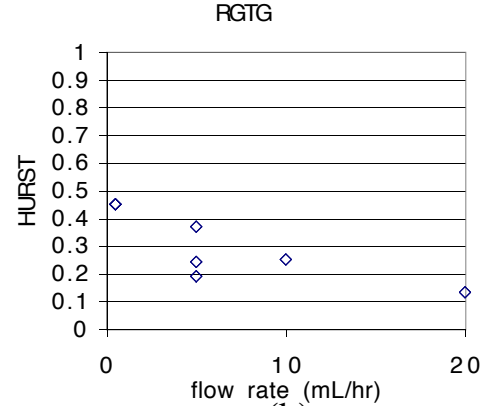

(b)

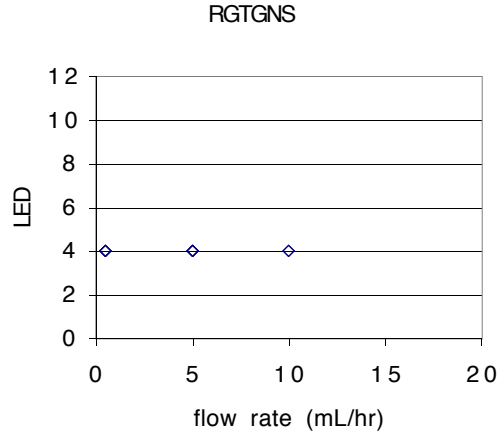

RGTGNS

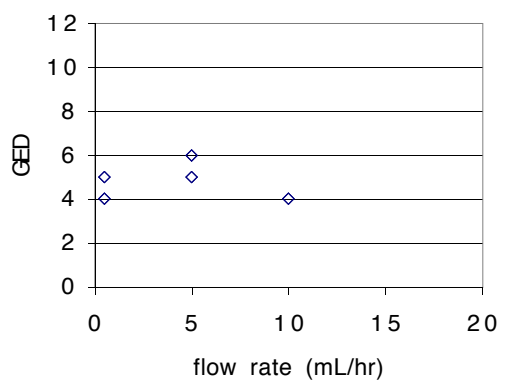

RGTGNS

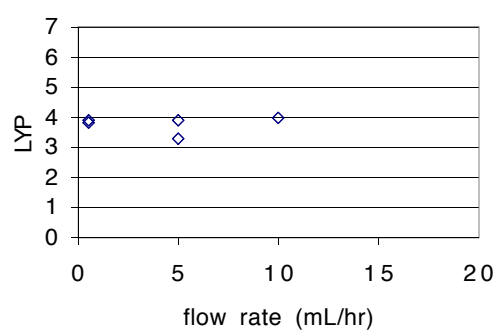

RGTGNS

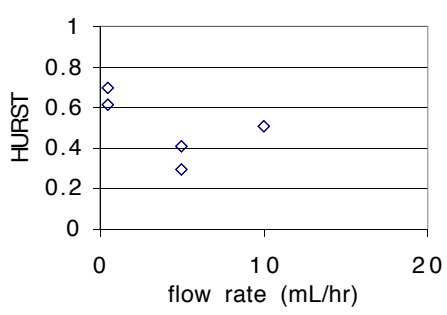

(c)

Figure 10. Embedding dimensions, Lyapunov dimension and Hurst exponent as a function of flow rate. (a) RT data sets, (b) RGTG data sets, and (c) RGTGNS data sets. 
$0.1-0.25 \mathrm{~mL} / \mathrm{hr}$

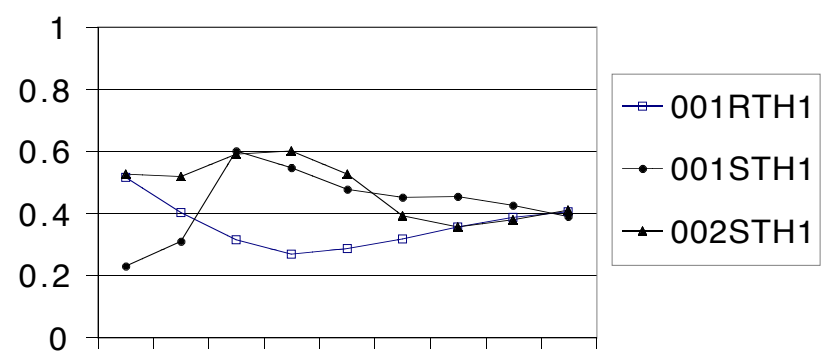

(a) $\begin{array}{lllllllll}1 & 2 & 3 & 4 & 5 & 6 & 7 & 8 & 9\end{array}$

$0.5 \mathrm{~mL} / \mathrm{hr}$
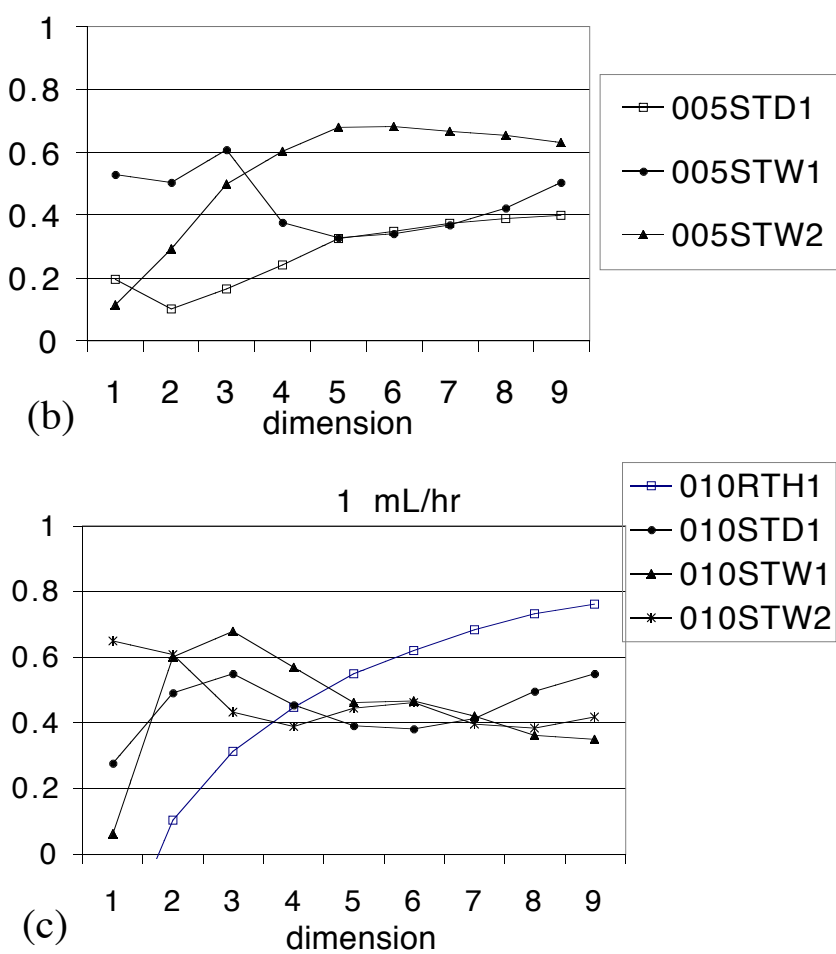

$2 \mathrm{~mL} / \mathrm{hr}$

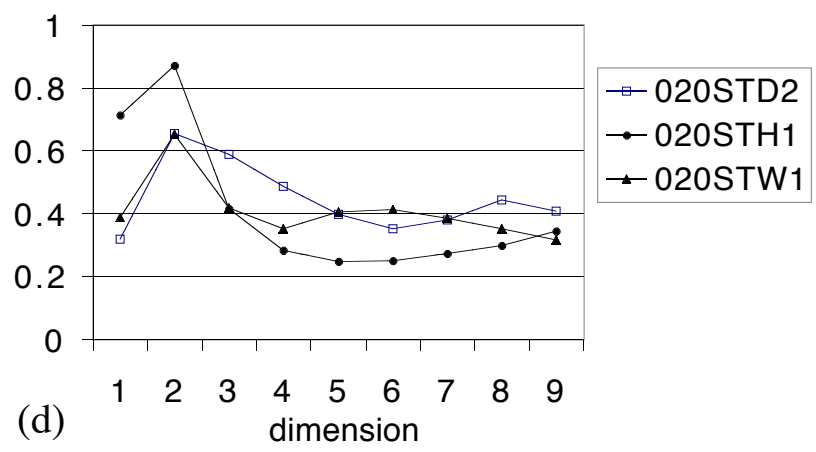

$5 \mathrm{~mL} / \mathrm{hr}$

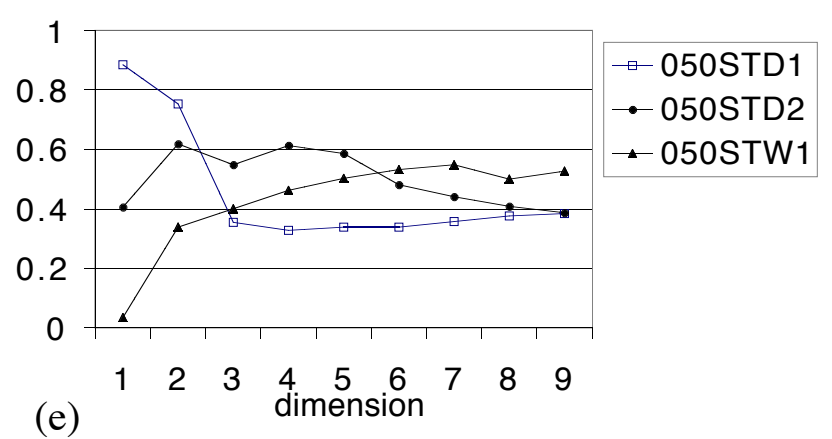

$6,8,10 \mathrm{~mL} / \mathrm{hr}$

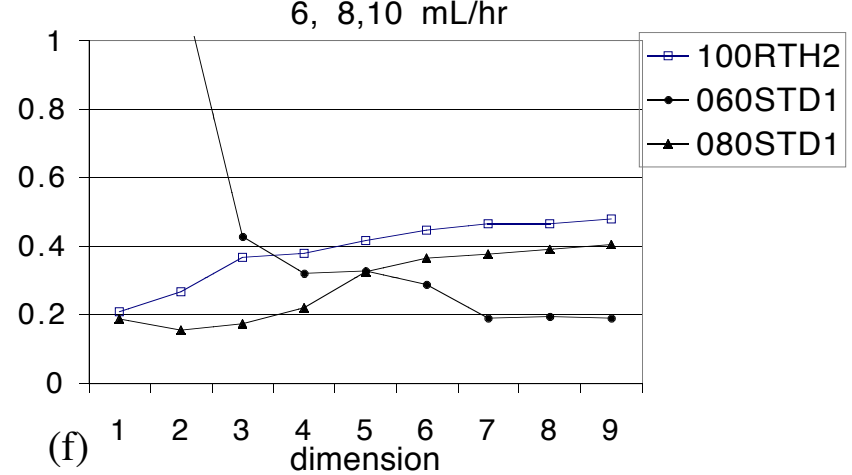

Figure 11. Entropy trend as a function of dimension for plastic tube point source contacting fracture models ( $\mathrm{R}=$ rough glass plates, $\mathrm{S}=$ smooth glass plates). (a) 0.1 and $0.25 \mathrm{~mL} / \mathrm{hr}$, (b) $0.5 \mathrm{~mL} / \mathrm{hr}$, (c) $1 \mathrm{~mL} / \mathrm{hr}$, (d) $2 \mathrm{~mL} / \mathrm{hr}$, (e) $5 \mathrm{~mL} / \mathrm{hr}$, and (f) 6,8 and $10 \mathrm{~mL} / \mathrm{hr}$. 
RGTG 5, 10, $20 \mathrm{~mL} / \mathrm{hr}$
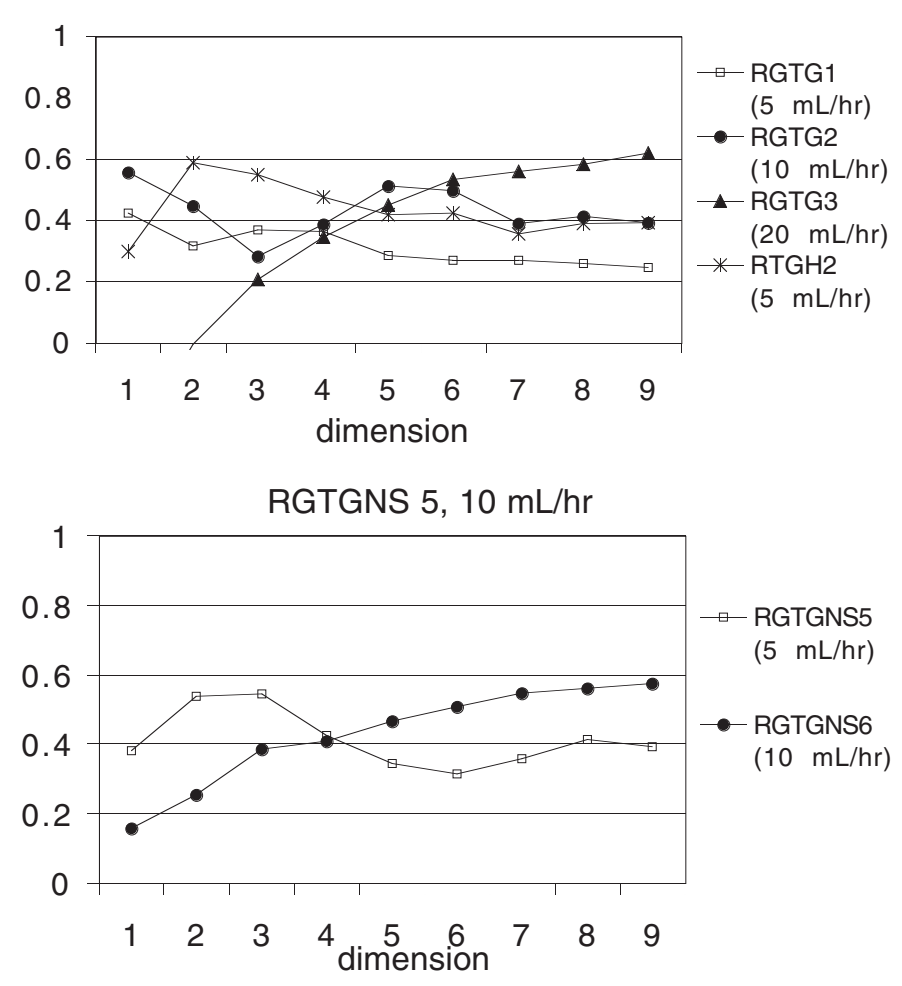

Figure 12. Entropy trend as a function of dimension for glass tube point source contacting rough glass fracture models. (a) RGTG 5, 10 and $20 \mathrm{~mL} / \mathrm{hr}$, and (b) RGTGNS 5, $10 \mathrm{~mL} / \mathrm{hr}$. 


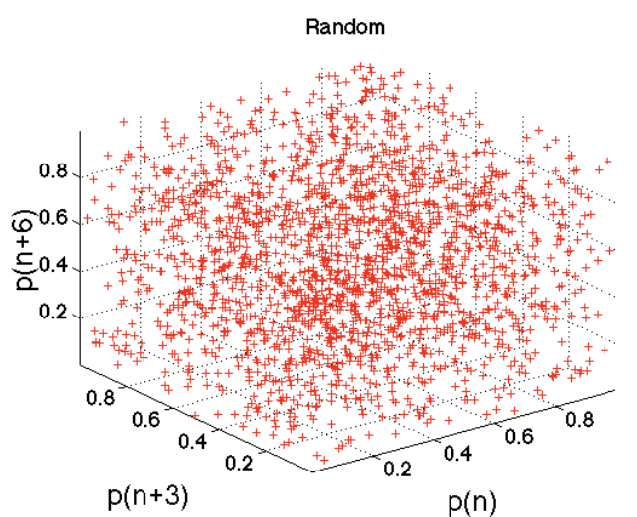

(a)

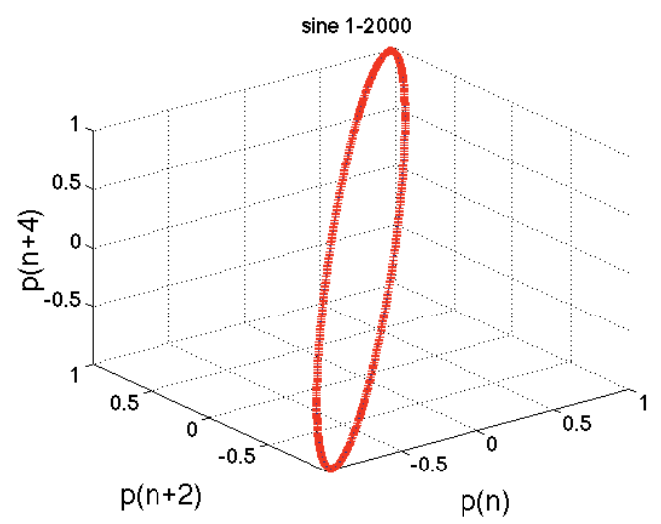

(b)
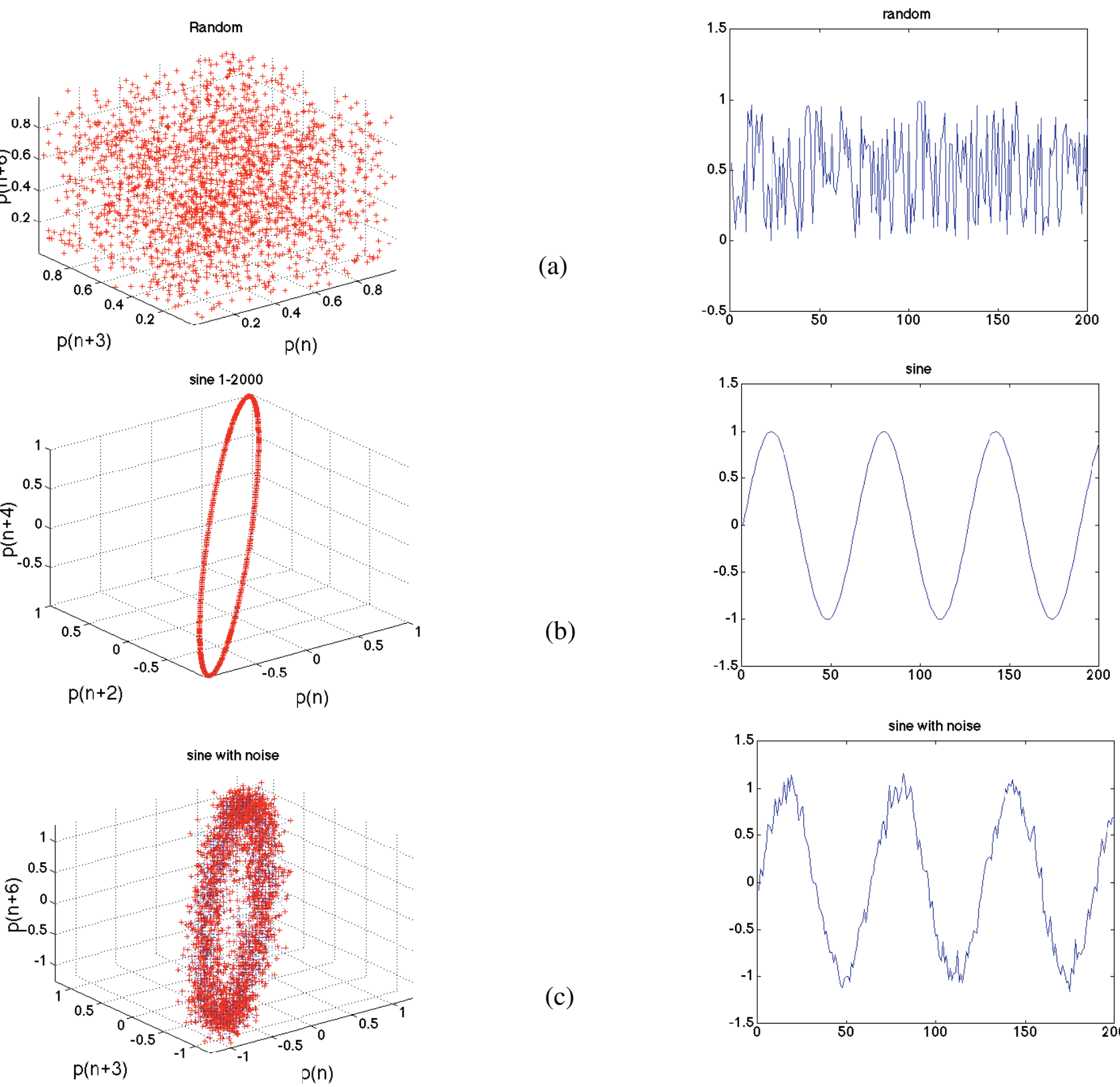

(c)
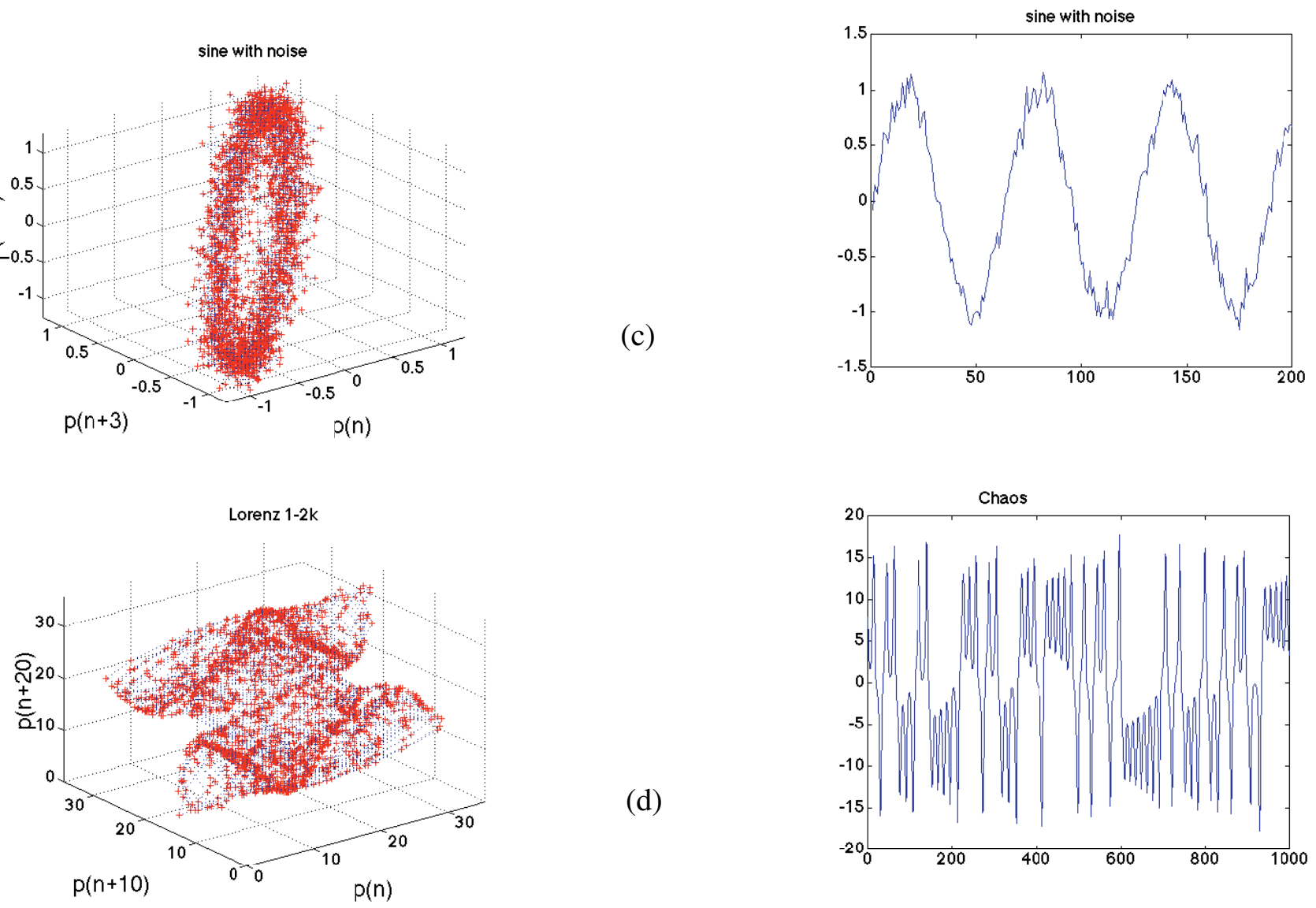

Figure 13. Attractors and pressure time trends for different characteristic data sets. (a) Random, (b) Sine function, (c) Sine function with noise, and (d) Lorenz equations. $\Delta t$ was determined from the minimum of the AMI function. 

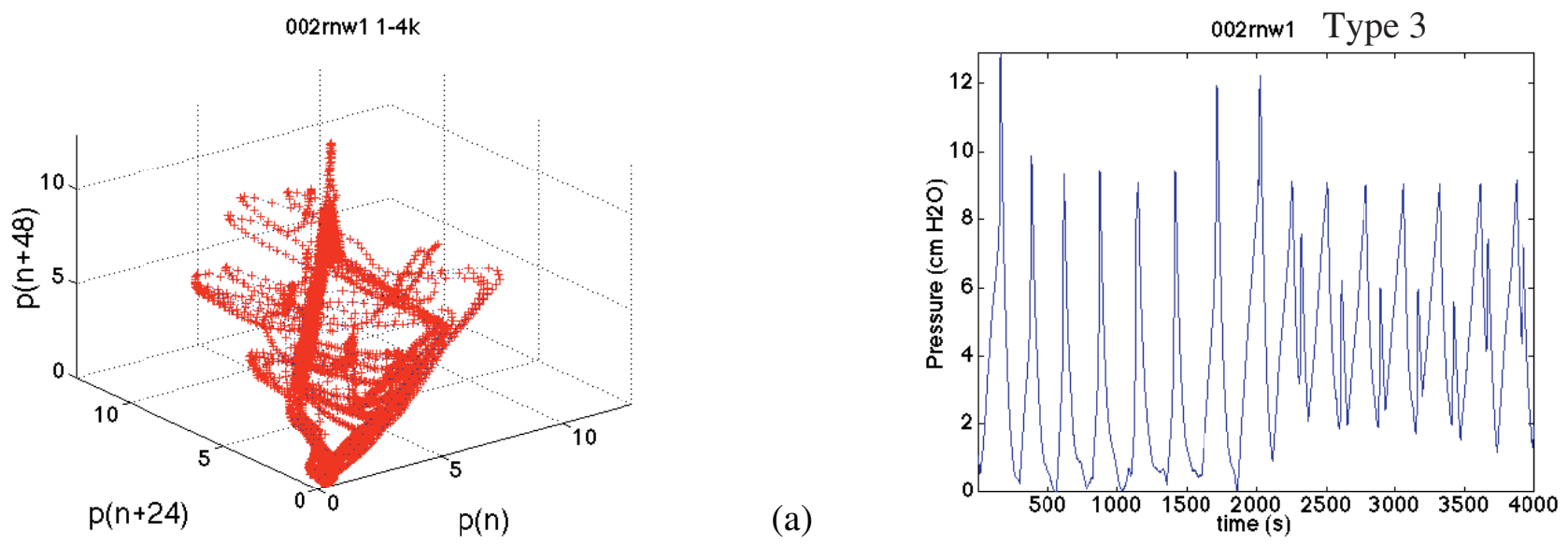

LED=3; GED=6: LYP=2.88; Hurst=0.861
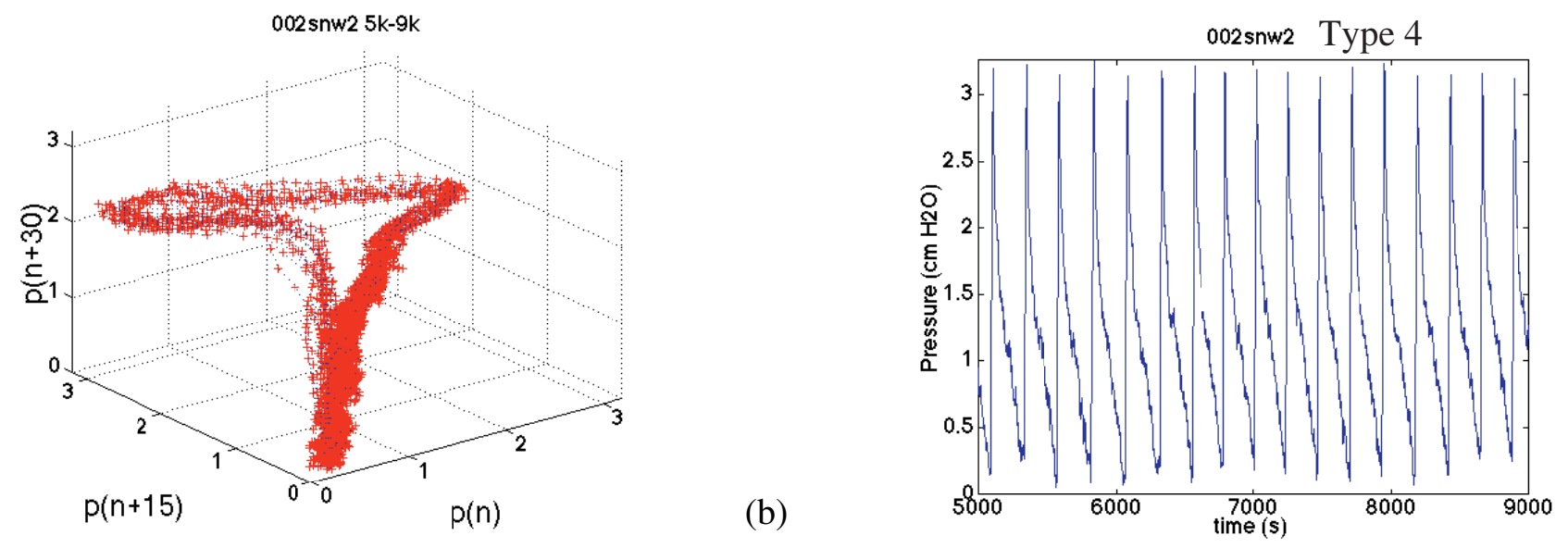

LED=4; GED=4: LYP=3.561; Hurst=0.629

(b)

(a)
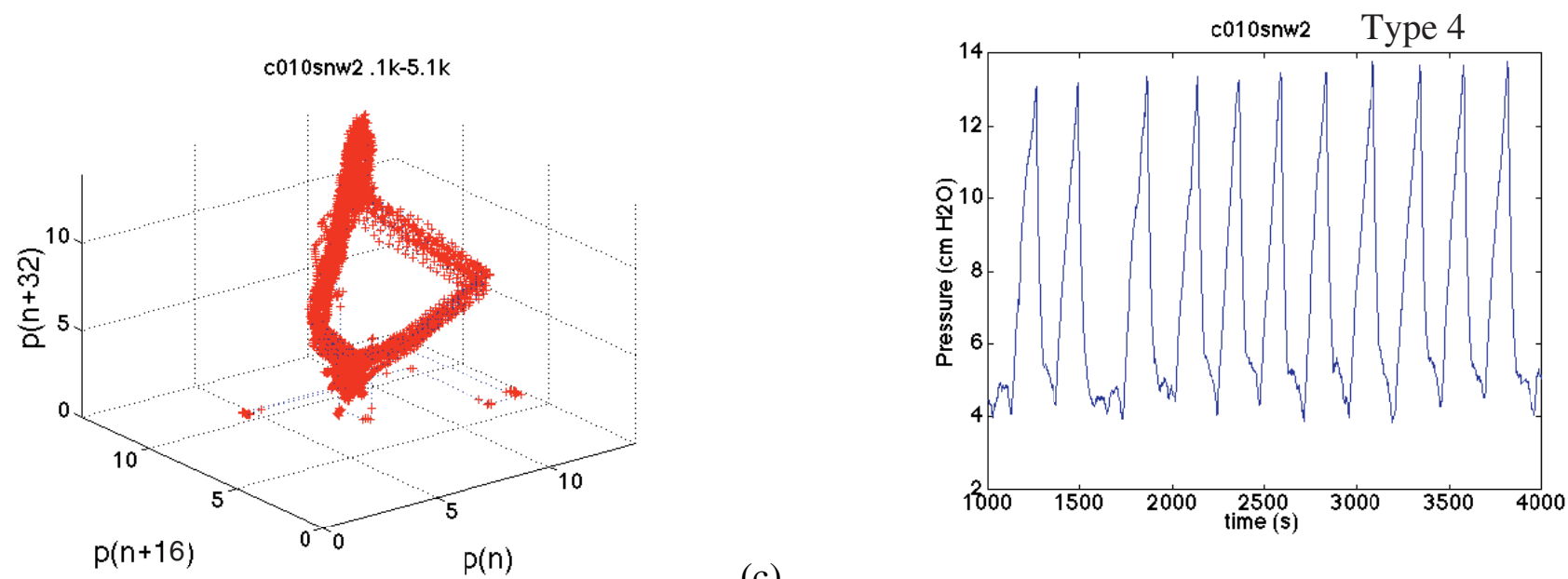

(c)

LED=6; GED=6: LYP=4.265; Hurst 0.844

Figure 14. Attractors and pressure time trends of data obtained in this study. Values are pressure in $\mathrm{cm}$ $\mathrm{H}_{2} \mathrm{O}$. (a) $0.25 \mathrm{~mL} / \mathrm{hr}$, needle, rough glass plates, (b) $0.25 \mathrm{~mL} / \mathrm{hr}$ needle, smooth glass plates, (c) $1 \mathrm{~mL} / \mathrm{hr}$ needle, smooth glass plates. 


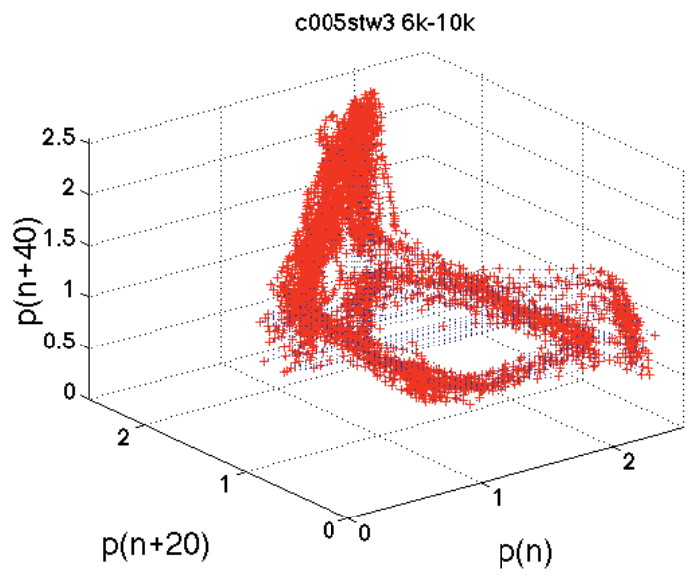

(a)

$\mathrm{LED}=3 ; \mathrm{GED}=5 ; \mathrm{LYP}=2.729 ;$ Hurst $=0.449$

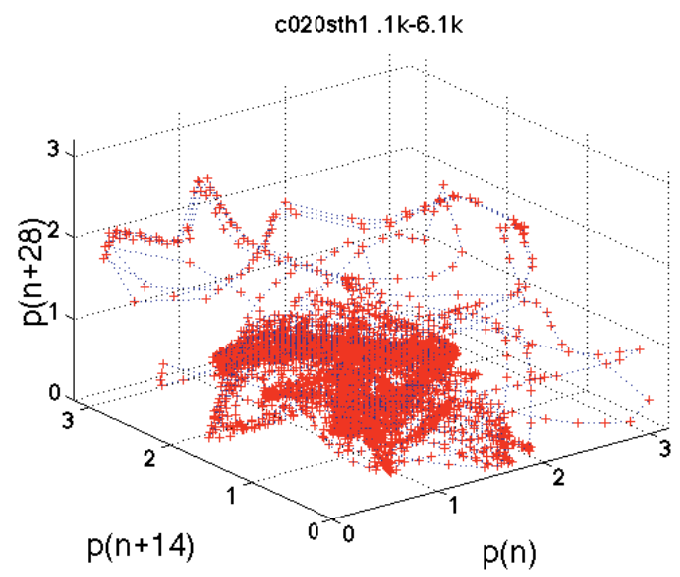

(b)

$\mathrm{LED}=3 ; \mathrm{GED}=5 ; \mathrm{LYP}=2.832 ;$ Hurst $=0.469$
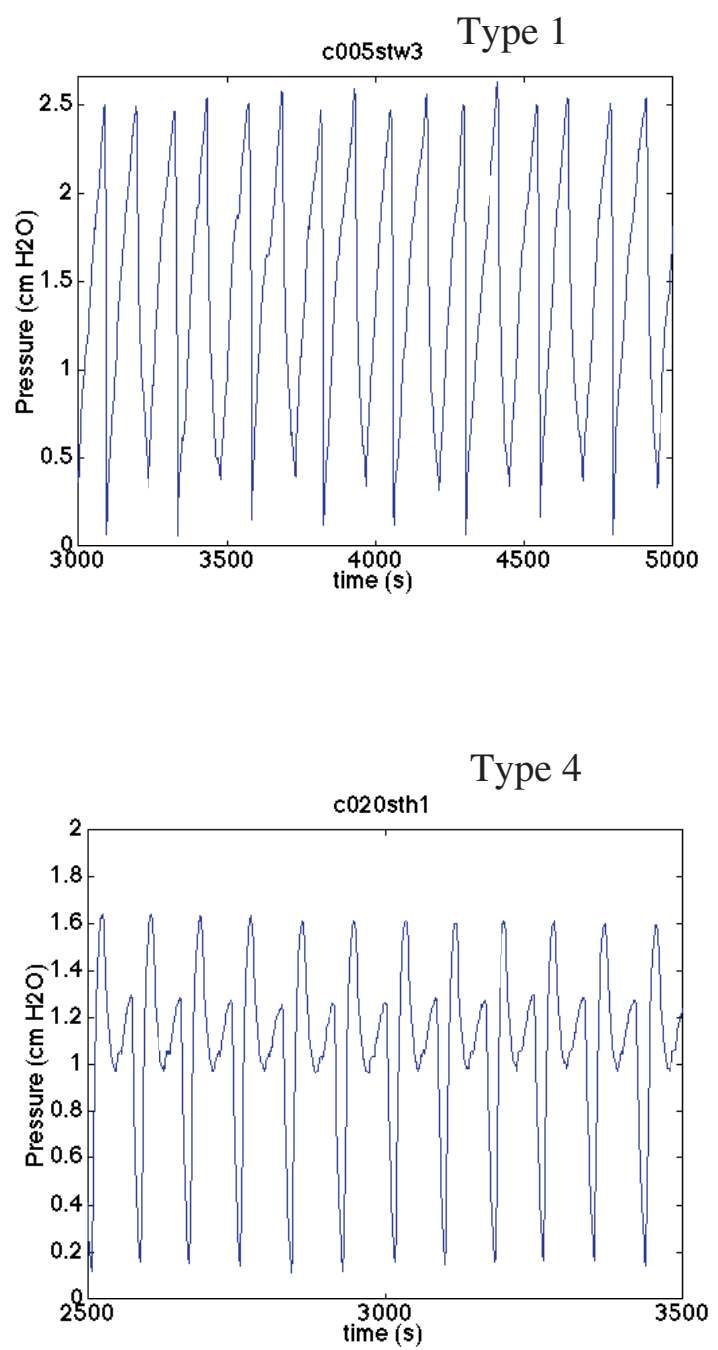
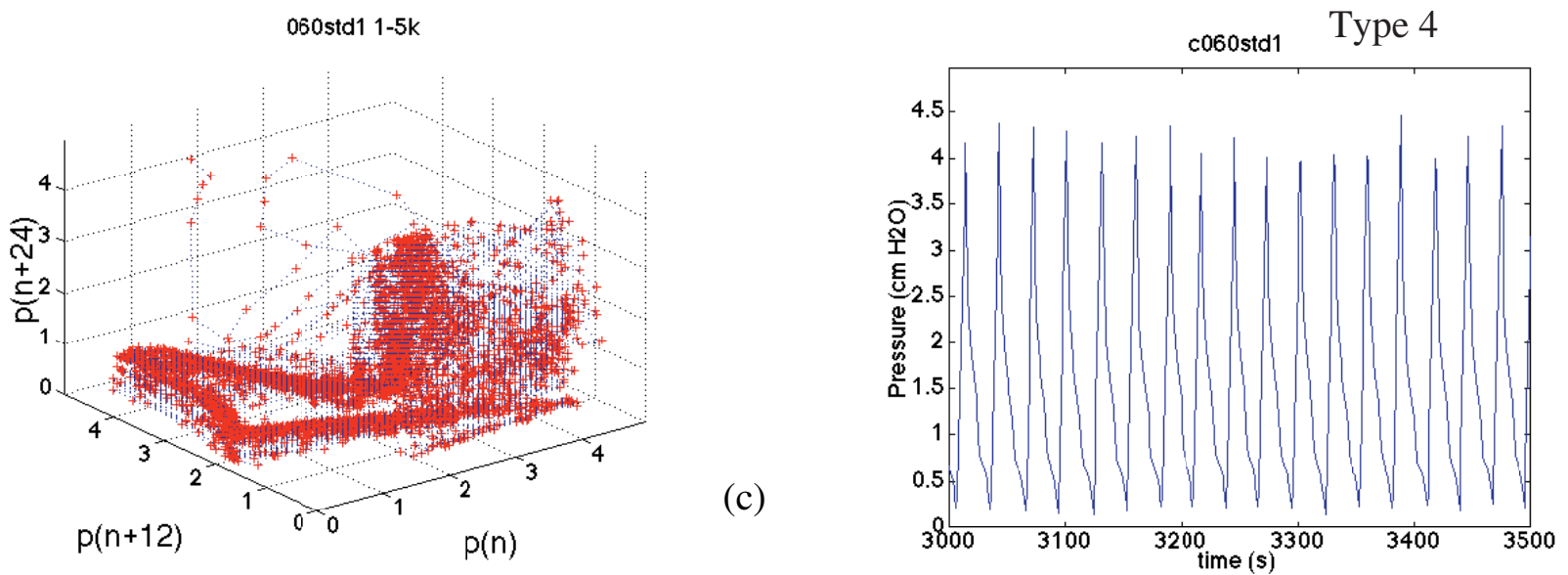

$\mathrm{LED}=4 ; \mathrm{GED}=5 ; \mathrm{LYP}=3.889 ;$ Hurst=0.239

Figure 15. Attractors and pressure time trends of data obtained in this study for plastic tube point source contacting constant aperture fracture model (smooth glass plates.) Values are pressure in $\mathrm{cm} \mathrm{H} \mathrm{H}_{2} \mathrm{O}$. (a) $0.5 \mathrm{~mL} / \mathrm{hr}$, (b) $2 \mathrm{~mL} / \mathrm{hr}$, and (c) $6 \mathrm{~mL} / \mathrm{hr}$. 

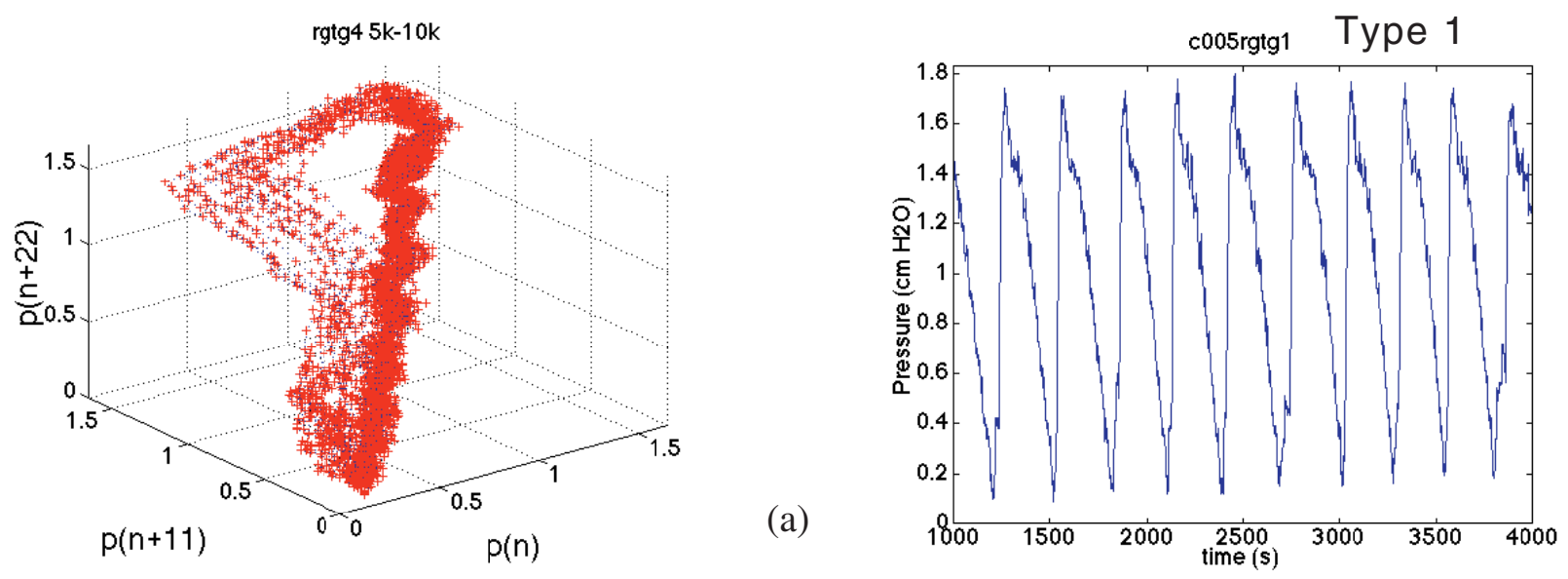

LED=4; GED=8: LYP=3.084; Hurst $=0.450$
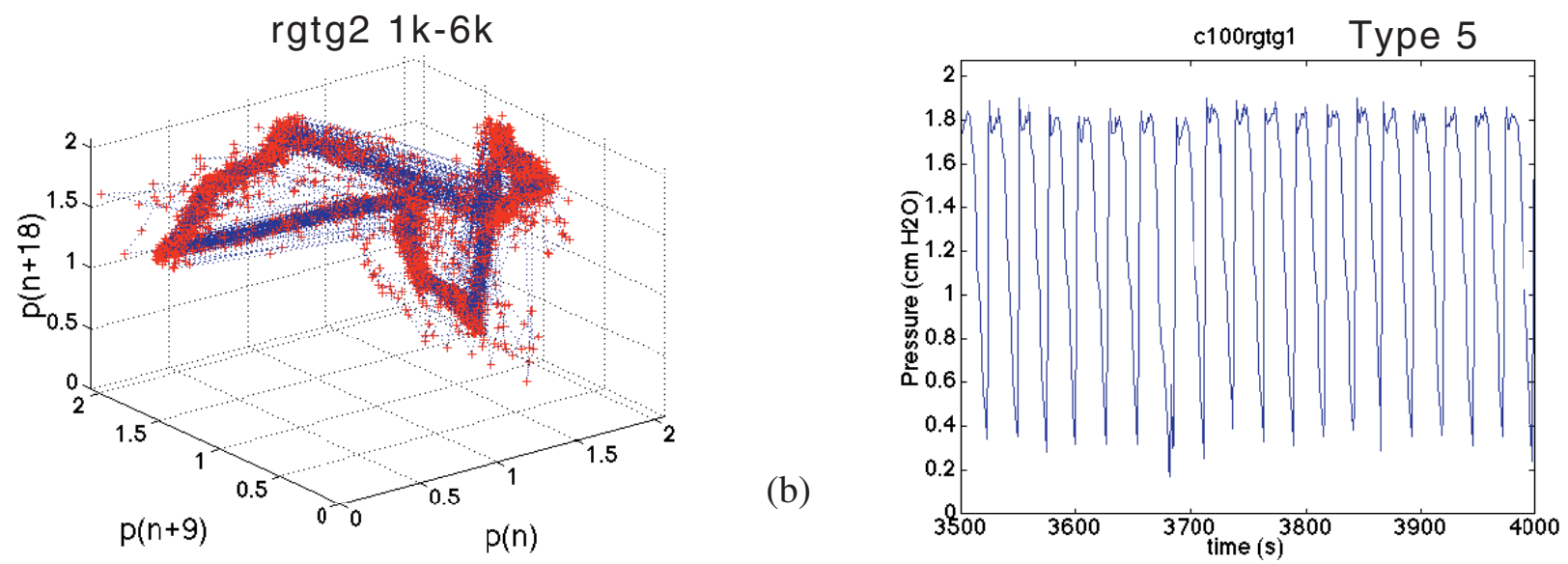

LED=3; GED=7; LYP=2.963; Hurst 0.251

Figure 16. Attractors and pressure time trends of data obtained in this study for glass tube point source contacting variable aperture fracture model (rough glass plates separated by $0.36 \mathrm{~mm}$ shim.) Values are pressure in $\mathrm{cm} \mathrm{H}_{2} \mathrm{O}$. (a) $0.5 \mathrm{~mL} / \mathrm{hr}$, (b) $5 \mathrm{~mL} / \mathrm{hr}$. 


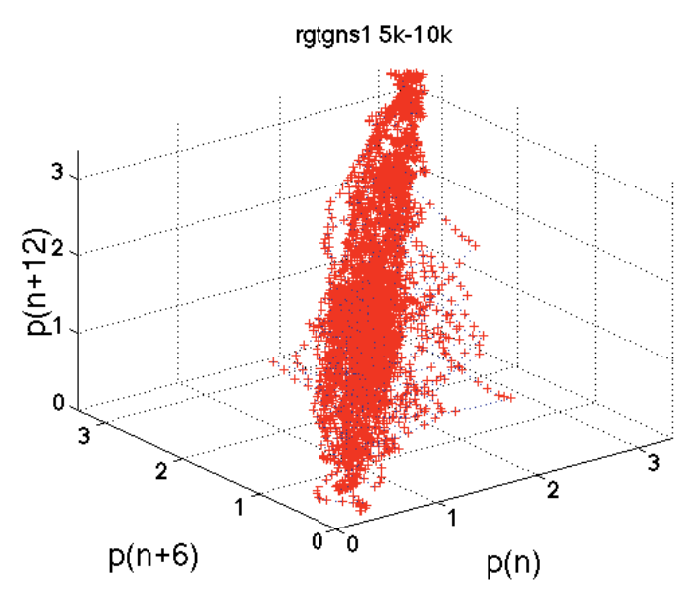

LED=4; GED=4; LYP=3.819; Hurst=0.695

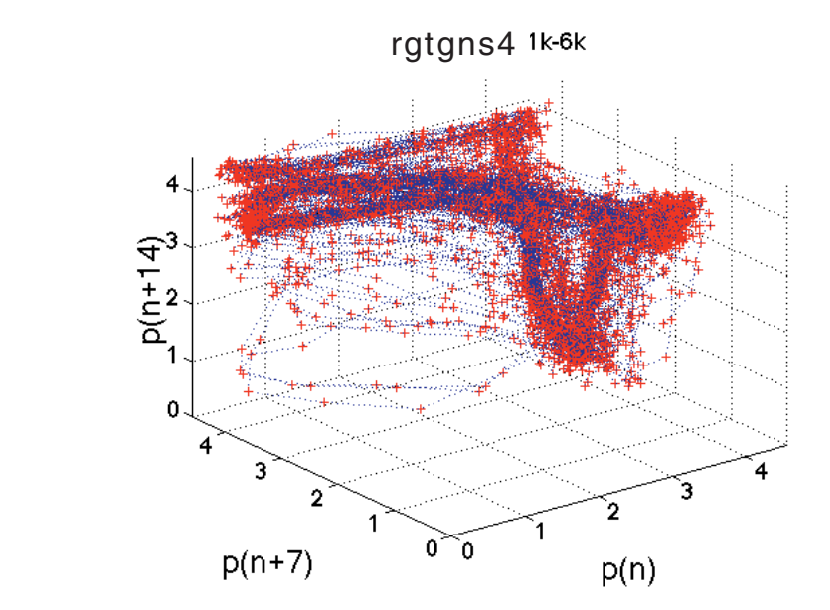

(b)
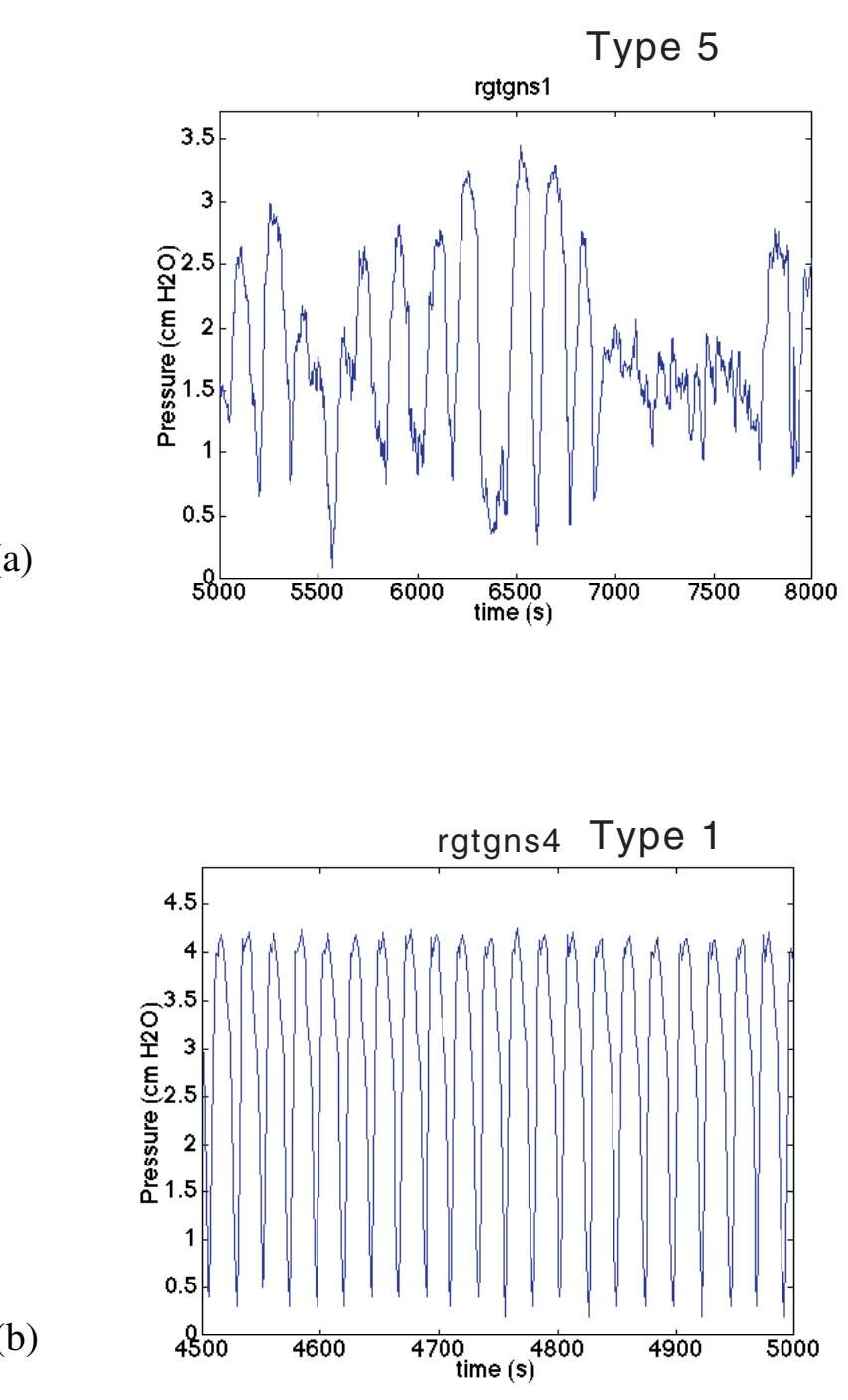

(a)

LED=4; GED=6; LYP=3.874; Hurst 0.294

Figure 17. Attractors and pressure time trends of data obtained in this study for glass tube point source contacting variable aperture fracture model (rough glass plates.) Values are pressure in $\mathrm{cm}$ $\mathrm{H}_{2} \mathrm{O}$. (a) $0.5 \mathrm{~mL} / \mathrm{hr}$, (b) $5 \mathrm{~mL} / \mathrm{hr}$. 

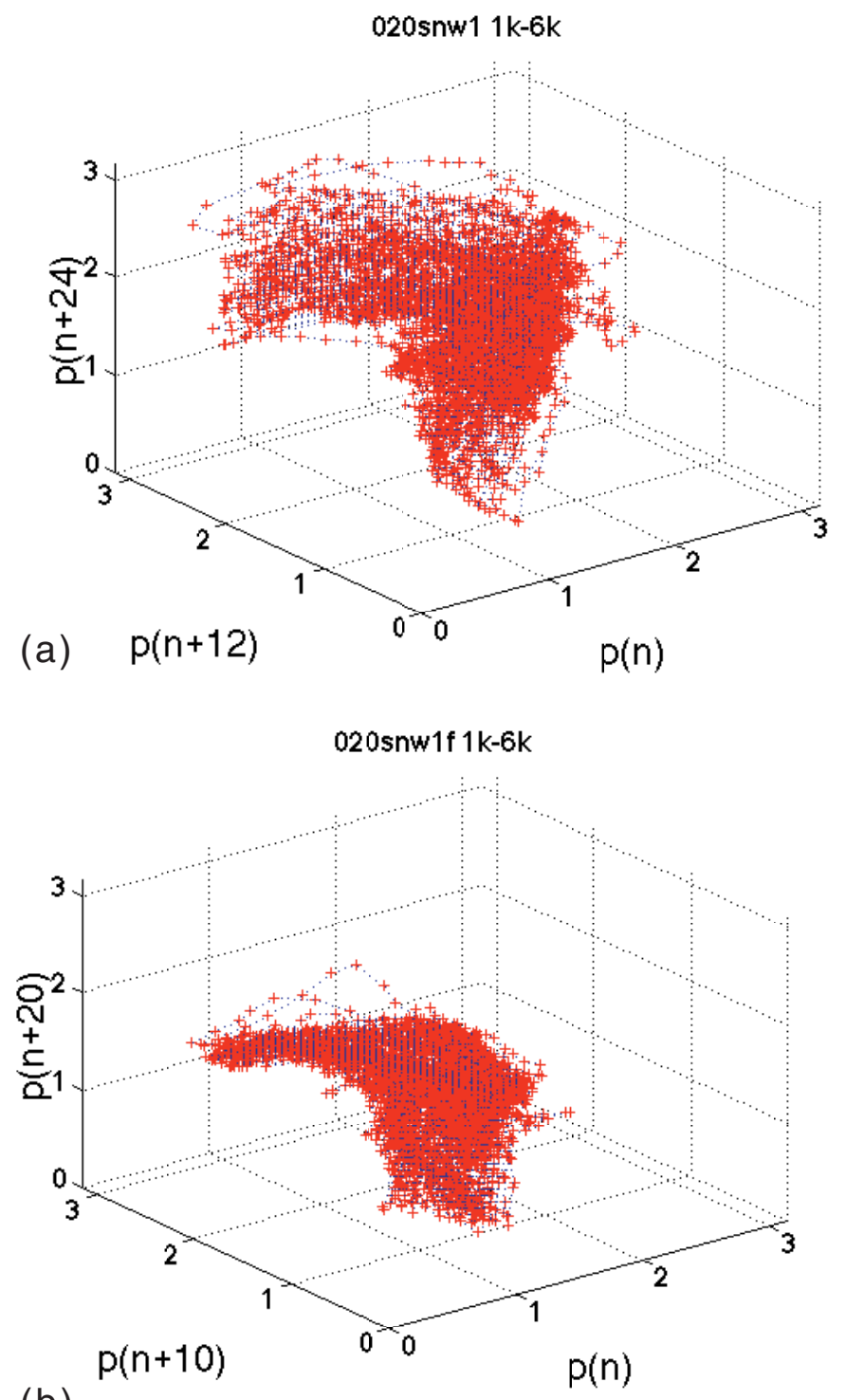

(b)

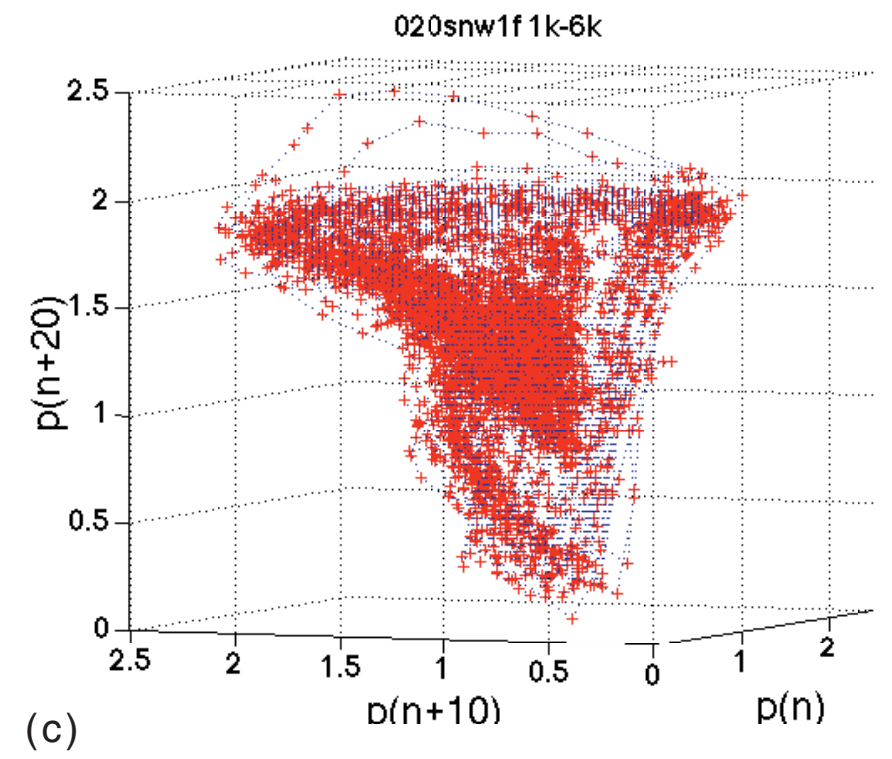

Figure 18. Effect of filtering low frequency oscillations on attractors for $2 \mathrm{~mL} / \mathrm{hr}$, needle, smooth plates. Values are pressure in $\mathrm{cm} \mathrm{H}_{2} \mathrm{O}$. (a) unfiltered. (b) filtered. (c) filtered and rotated with expanded scale. 


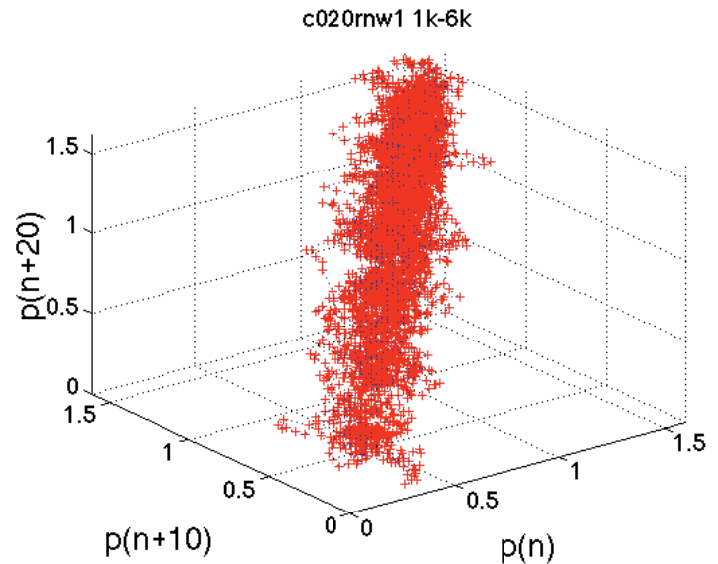

(a)

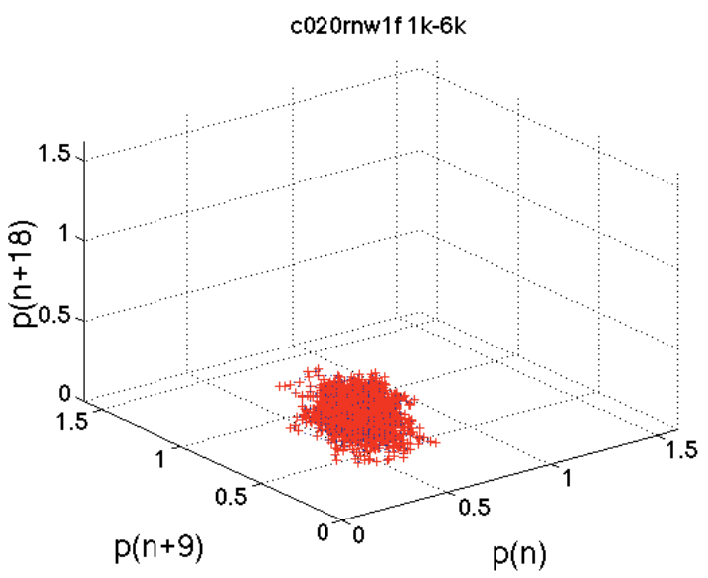

(b)

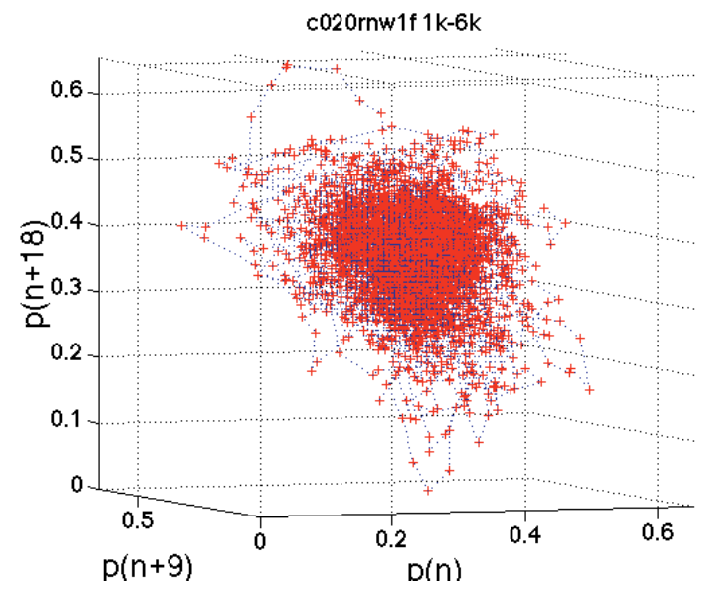

(c)

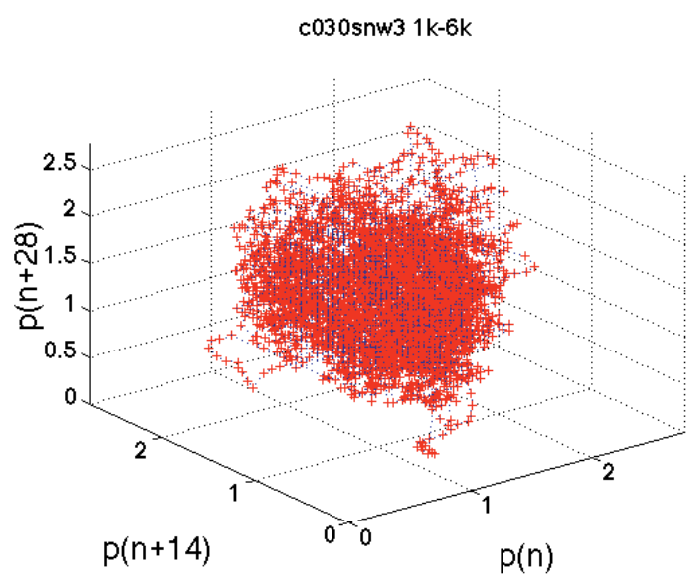

(d)

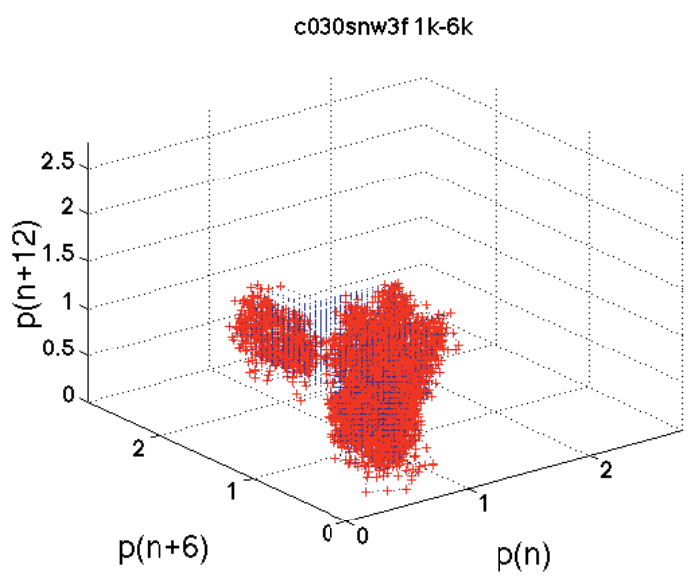

(e)

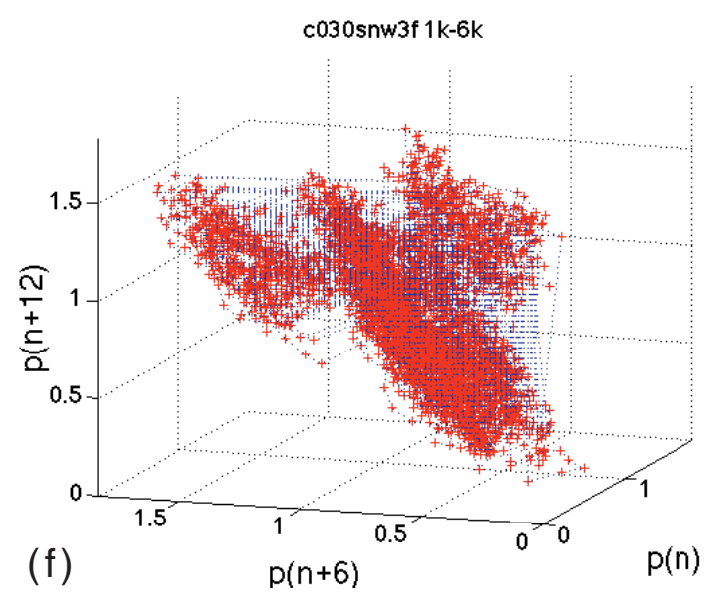

Figure 19. Effect of filtering low frequency oscillations on attractors for (a)-(c) $2 \mathrm{~mL} / \mathrm{hr}$, needle, rough plates, and (d)-(f) $3 \mathrm{~mL} / \mathrm{hr}$, needle, smooth plates. Values are pressure in $\mathrm{cm}$ $\mathrm{H}_{2} \mathrm{O}$. (a), (d) unfiltered. (b), (e) filtered. (c), (f) filtered and rotated with expanded scale. 


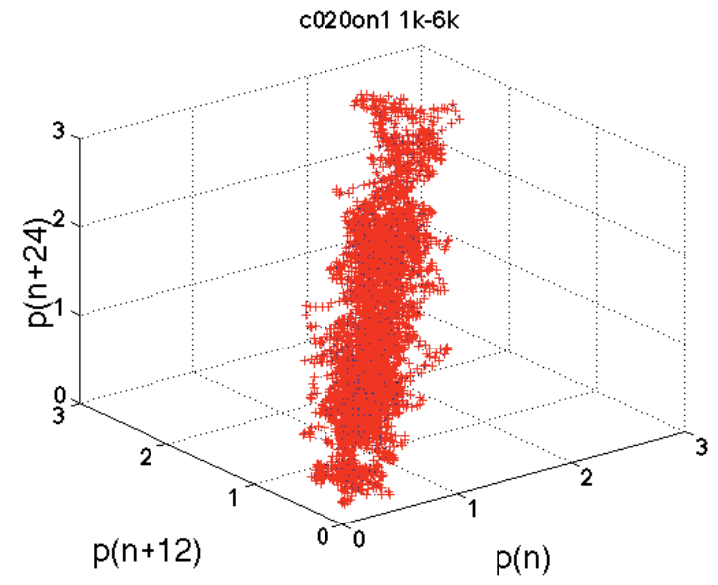

(a)

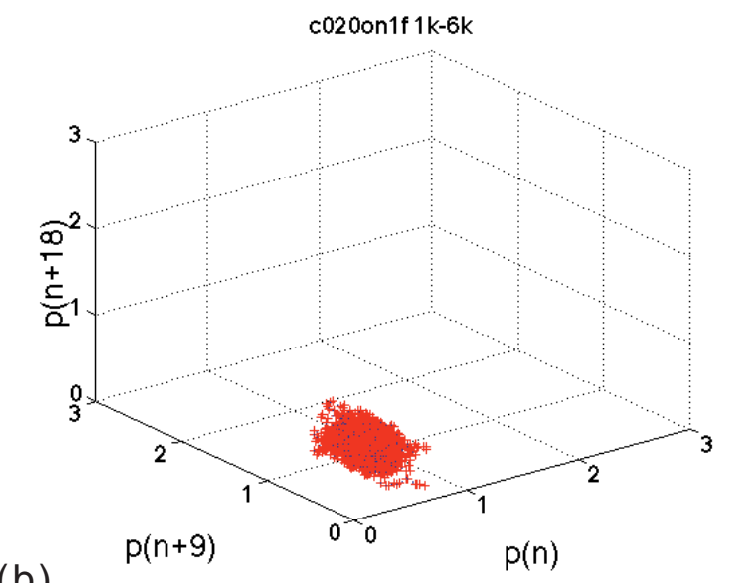

(b)

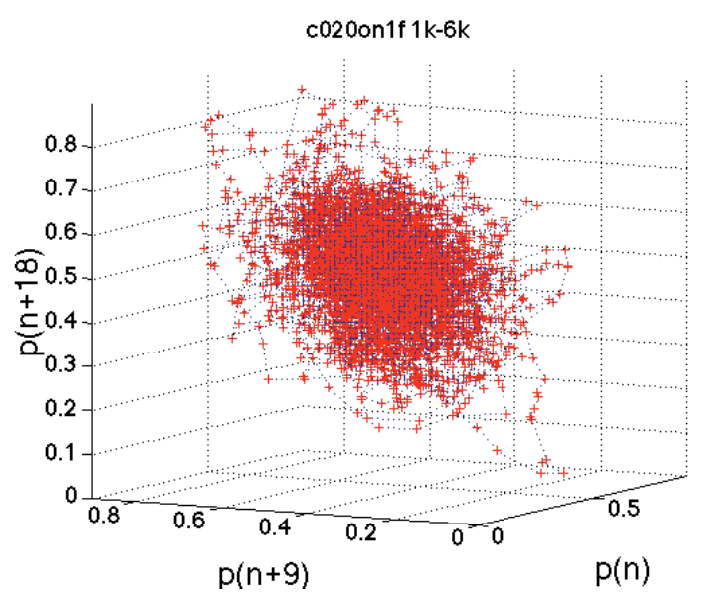

(c)

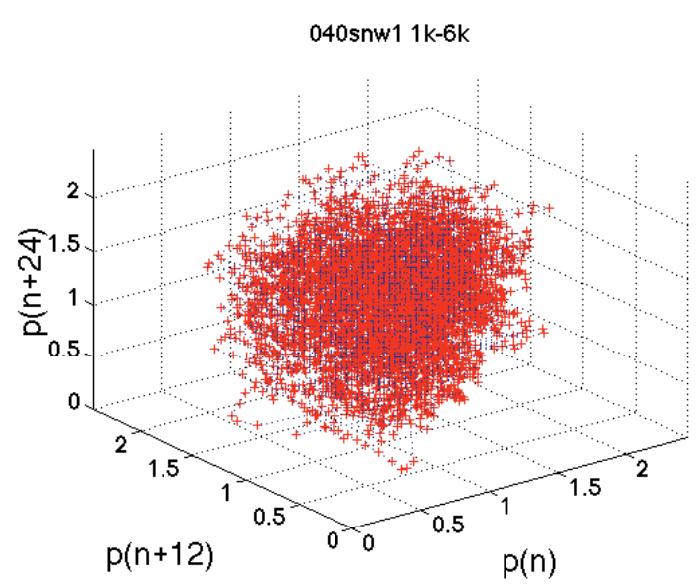

(d)
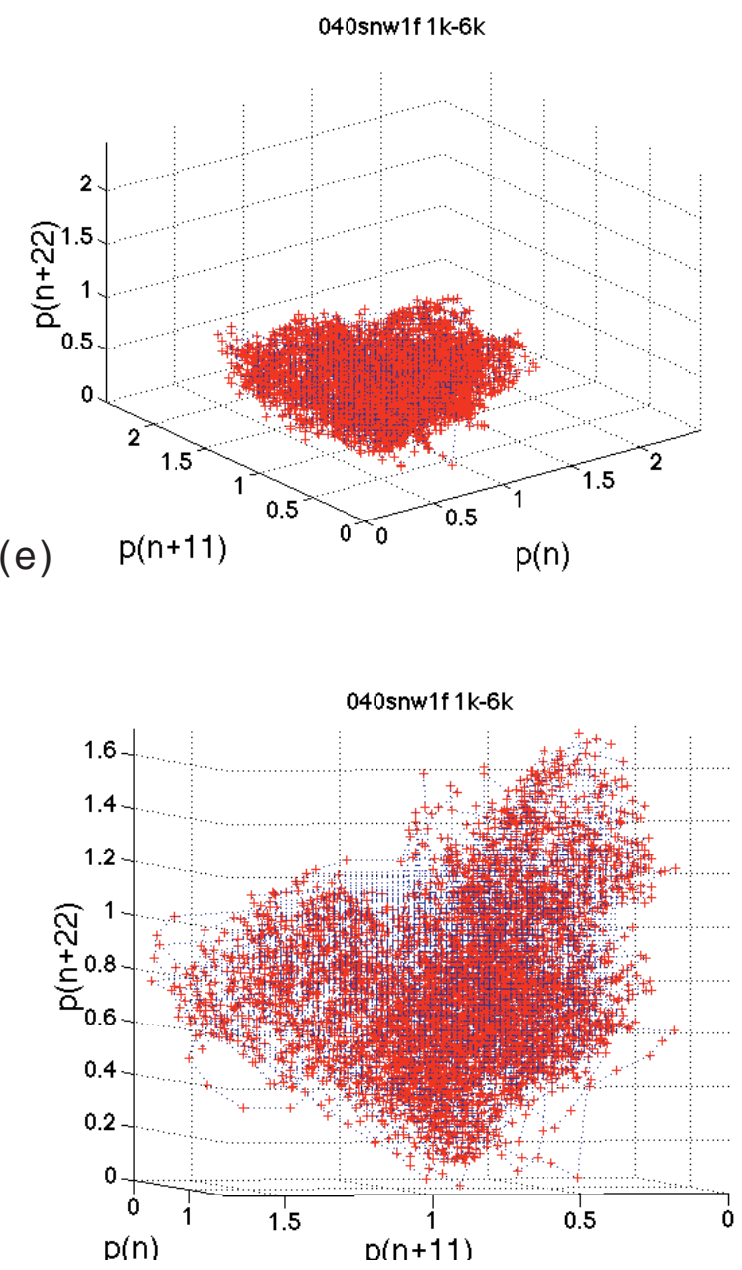

(f)

Figure 20. Effect of filtering low frequency oscillations on attractors for (a)-(c) $2 \mathrm{~mL} / \mathrm{hr}$, needle in open air, and (d)-(f) $4 \mathrm{~mL} / \mathrm{hr}$, needle, smooth plates. Values are pressure in $\mathrm{cm}_{2} \mathrm{O}$. (a), (d) unfiltered. (b), (e) filtered. (c), (f) filtered and rotated with expanded scale. 
002ON1

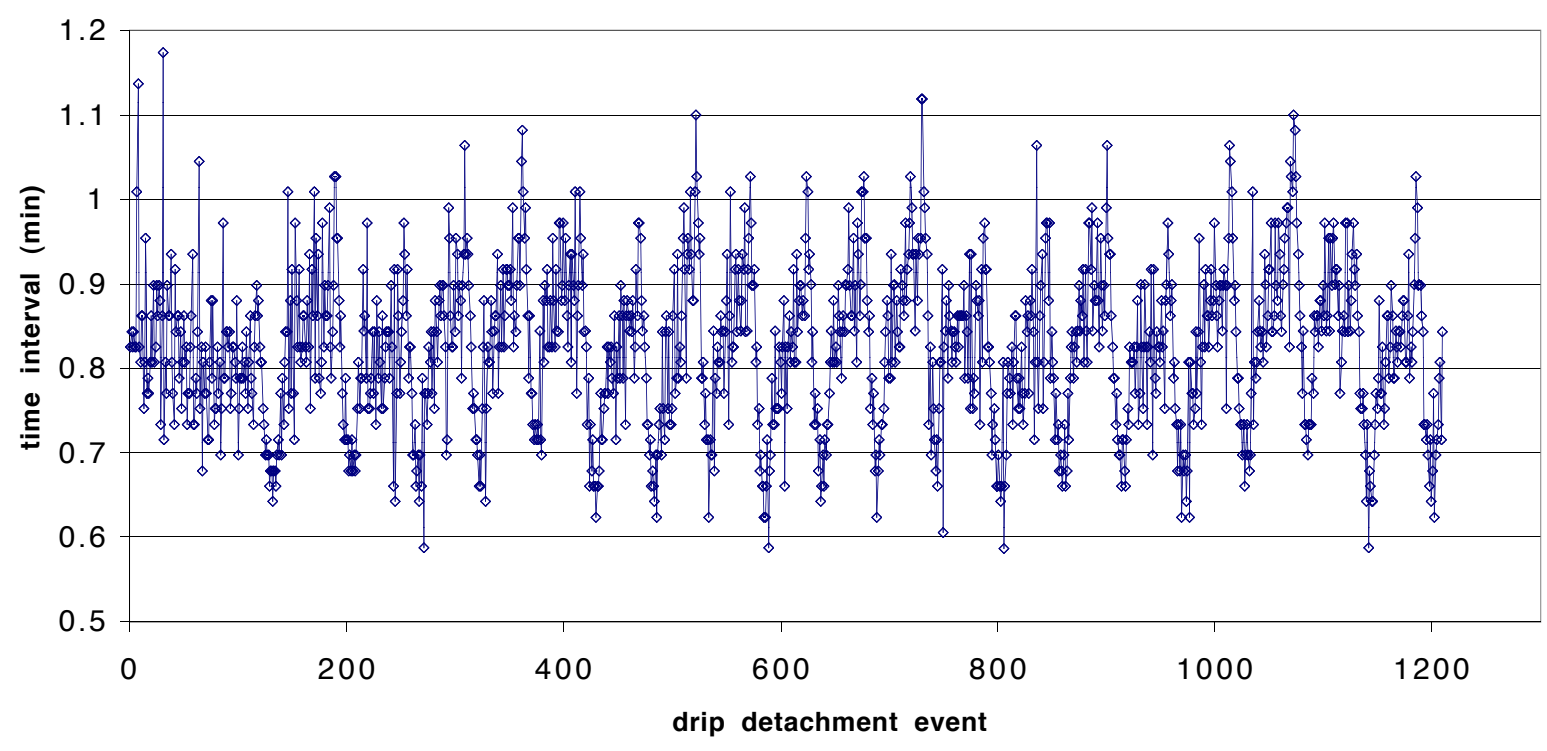

020RNW1

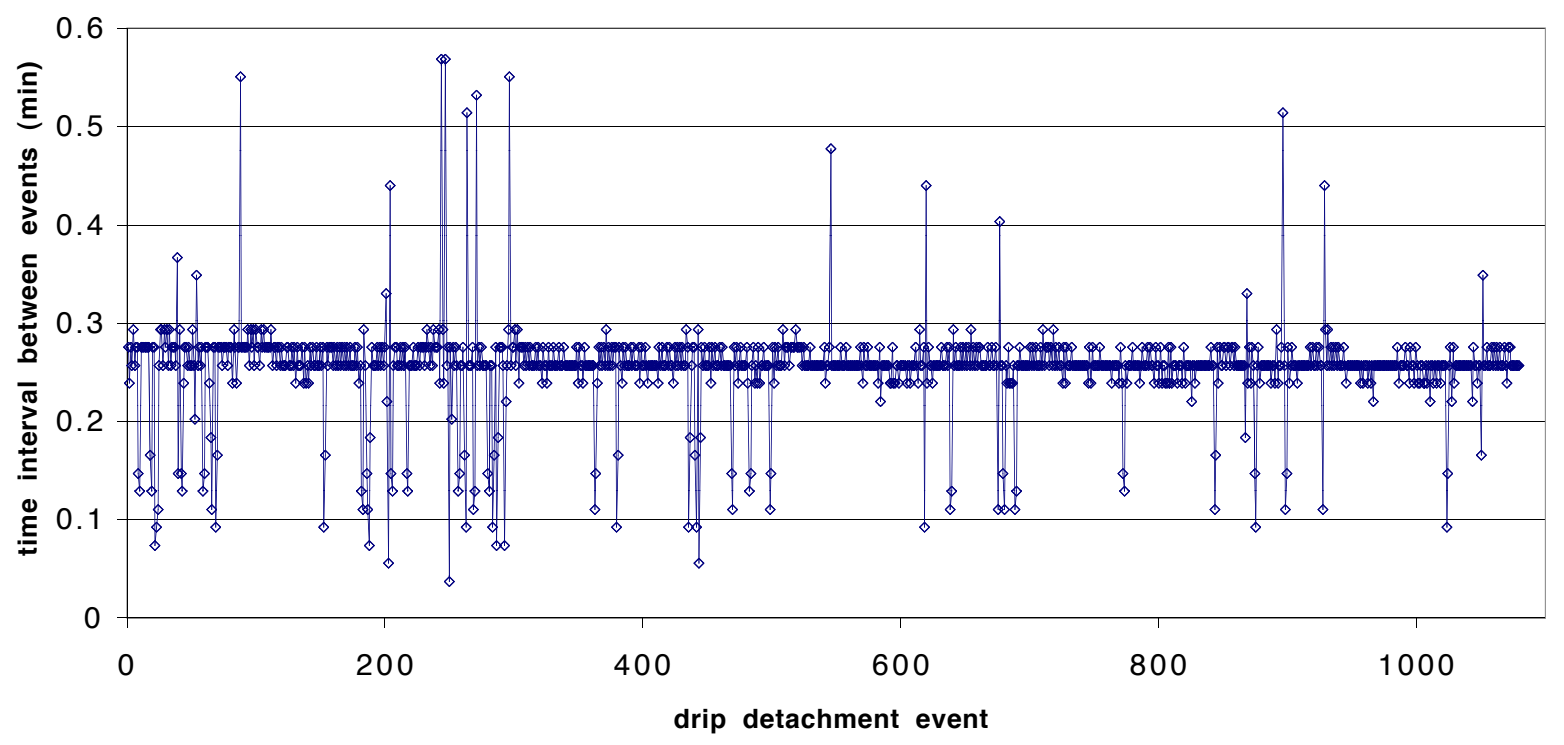

Figure 21. Time interval between dripping events for open drips through needle, 0.25 $\mathrm{mL} / \mathrm{hr}(002 \mathrm{ON} 1)$, and (b) dripping through needle in rough glass plates at $2 \mathrm{~mL} / \mathrm{hr}$ (020RNW1). 


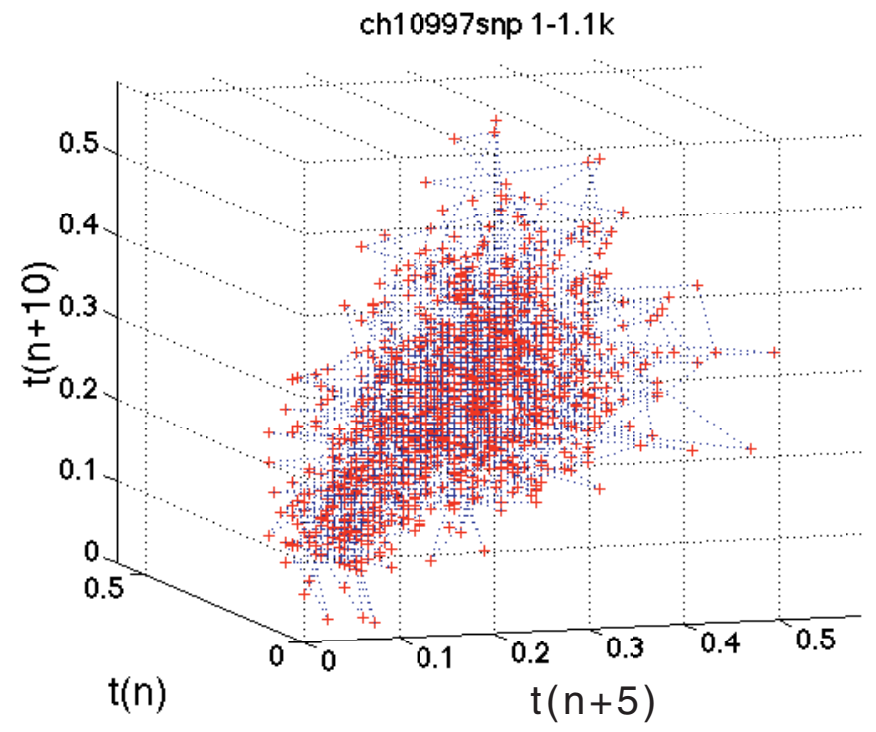

Hurst exponent $=0.164$

(a)

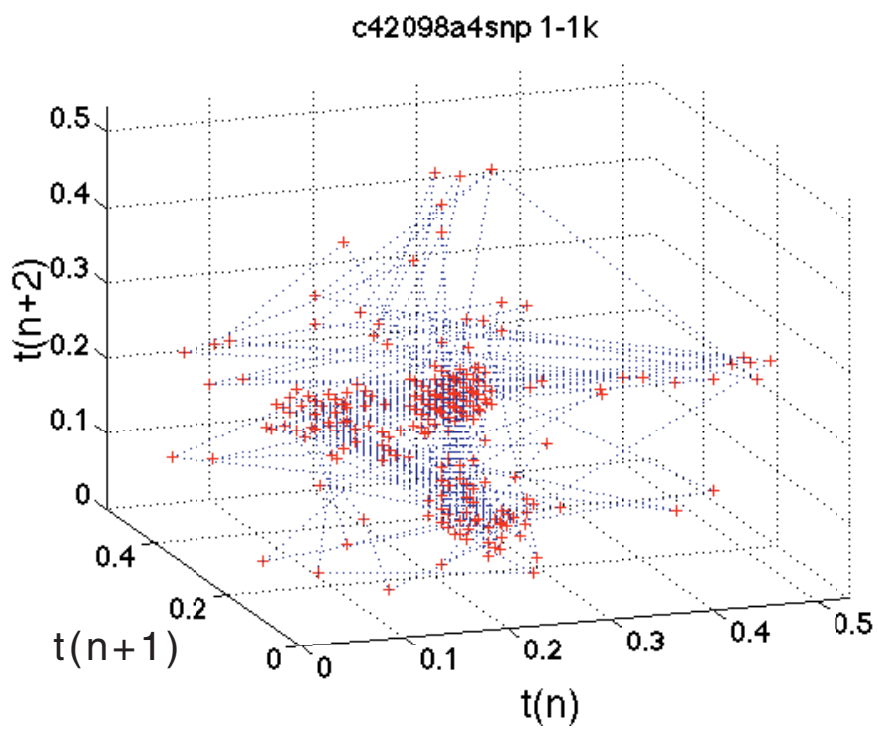

Hurst exponent $=0.0132$

(b)

Figure 22. Attractors for drip-time intervals. Values are time, in minutes. (a) open drips through needle, $0.25 \mathrm{~mL} / \mathrm{hr}(002 \mathrm{ON} 1)$. (b) dripping through needle in rough glass plates at $2 \mathrm{~mL} / \mathrm{hr}$ (020RNW1). 